\title{
A SECONDARY OPTION MARKET DESIGN FOR RESERVE PROCUREMENT \\ BY RENEWABLE ENERGY SOURCES
}

\author{
By
}

Reza Ghaffari

Bachelor of Science in Electrical Engineering, K.N.T. University of Technology, Iran, 1997

Master of Engineering in Electrical Engineering, University of Idaho, USA, 2008

\author{
A dissertation \\ presented to Ryerson University \\ in partial fulfillment of the \\ requirements for the degree of \\ Doctor of Philosophy \\ in the Program of
}

Electrical and Computer Engineering

Toronto, Ontario, Canada, 2014

CReza Ghaffari 2014 


\section{AUTHOR'S DECLARATION}

I hereby declare that I am the sole author of this dissertation. This is a true copy of the dissertation, including any required final revisions, as accepted by my examiners.

I authorize Ryerson University to lend this dissertation to other institutions or individuals for the purpose of scholarly research.

I further authorize Ryerson University to reproduce this dissertation by photocopying or by other means, in total or in part, at the request of other institutions or individuals for the purpose of scholarly research.

I understand that my dissertation may be made electronically available to the public. 


\section{ABSTRACT}

Dissertation Title:

\section{A SECONDARY OPTION MARKET DESIGN FOR RESERVE PROCUREMENT BY RENEWABLE ENERGY SOURCES}

Degree: Doctor of Philosophy

Year: 2014

Student Name: $\quad$ Reza Ghaffari

Program: $\quad$ Electrical Engineering

University: $\quad$ Ryerson University

Wind power generation is uncertain and intermittent accentuating variability. Currently in many power systems worldwide, the total generation-load unbalance caused by mismatch between forecast and actual wind power output is handled by automatic governor control and real-time 5-minute balancing markets, which are operated by the independent system operators for maintaining reliable operation of power systems. Mechanisms such as automatic governor control and real-time 5-minute balancing markets are in place to correct the mismatch between the load forecast and the actual load. They are not designed to address increased uncertainty and variability introduced by large-scale wind power or solar power generation expected in the future. Thus, large-scale wind power generation with increased uncertainty and intermittency causing variability poses a techno-economic challenge of sourcing least cost load balancing services (reserve). 
This dissertation offers a secondary intra-day option market via a techno-economic approach whereby wind power producers purchases reserved energy from other generators to cover for any deficit of wind energy or sells any excess of wind energy to other generators using Option Pricing concept in an optimization framework. The latest ISO price forecasts are used in the proposed secondary market. In such a market, wind power producers are not subsidized and they must compete with other power suppliers in the system.

The proposed secondary intra-day reserve market uses a model for describing uncertainty in wind power forecast a few hours from contract time and a model for options contract to price reserves for overcoming underproduction or overproduction. Several versions of the secondary intra-day reserve market are proposed and analysed in this dissertation. Wind power generation uncertainty is modeled using several methods such as Gaussian, Cauchy and Binomial Tree. Two widely used Option pricing methods - Binomial model and the Black-Scholes model - are used in this research to model options contract. The network limitations of the power system are also considered in the optimization to ensure the feasibility of the contracts. The IEEE 118-bus test system with real Ontario wind farms data highlights the applicability of the proposed secondary market. 


\section{ACKNOWLEDGEMENTS}

I would like to express my sincere gratitude to Dr. Bala Venkatesh for his invaluable advices throughout the period of this study. I would also like to thank him for providing financial assistance in this period. I would also like to thank Dr. Daniel Cheng for giving his important thoughts and reviews. I also recognize the moral support given by Dr. Andu Dukpa, Dr. Peng Yu, Dr. Bhanu Opathella and all present and past colleagues in the Power \& Energy Analysis Research (PEAR) laboratory and the Centre for Urban Energy (CUE) at Ryerson University during the last four years. Also I would like to thank my wife Visda for all of her patience and moral supports and finally I thank my family members especially my parents who taught me the value of education. 


\section{DEDICATION}

To my wife Visda 


\section{TABLE OF CONTENTS}

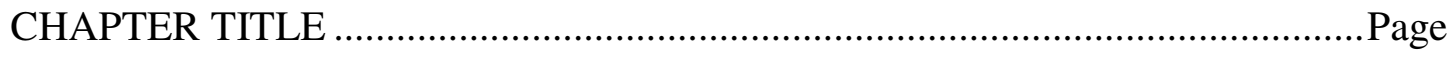

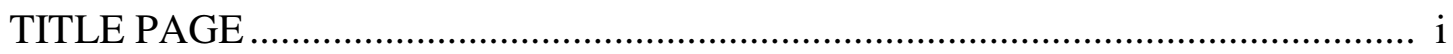

AUTHOR'S DECLARATION ....................................................................... ii

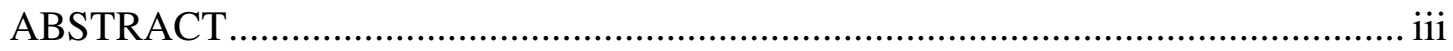

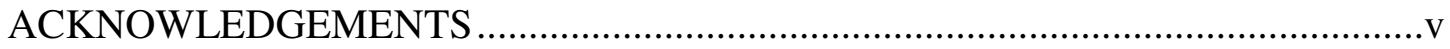

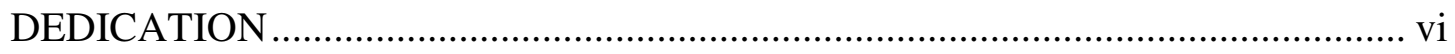

TABLE OF CONTENTS ........................................................................... vii

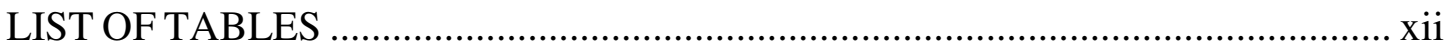

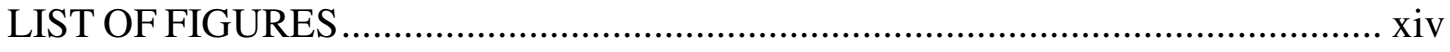

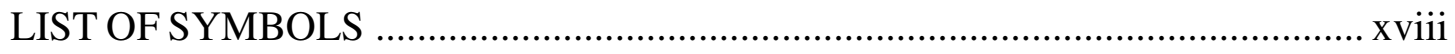

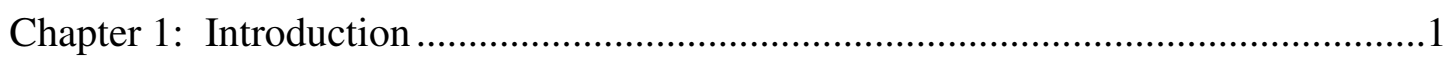

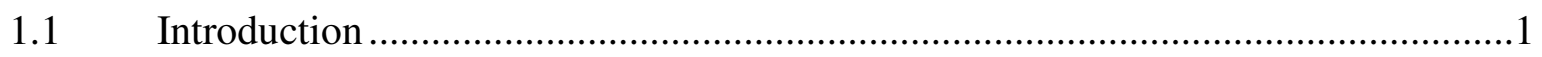

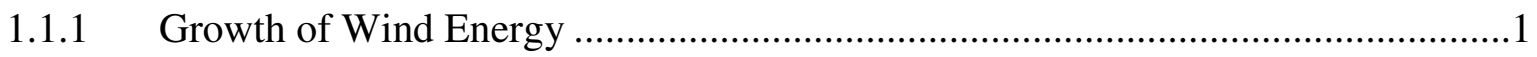

1.1.2 Challenges of Wind Energy Uncertainty …..............................................

1.2 Market Structures of Power Systems ........................................................4

1.2.1 Operating Reserve and Reserve Markets ....................................................

1.2.2 A survey in previous publications of Reserve Markets ...................................10

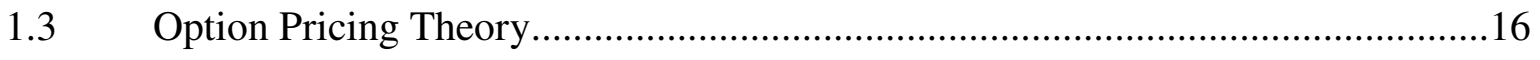

vii 
1.3.1 Binomial Tree and Option Pricing …………….........................................18

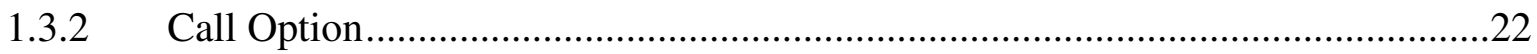

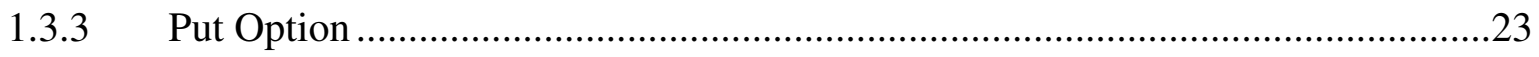

1.3.4 Black-Scholes Model and Option Pricing............................................................24

$1.4 \quad$ Energy Forecast Error Expectation ................................................................26

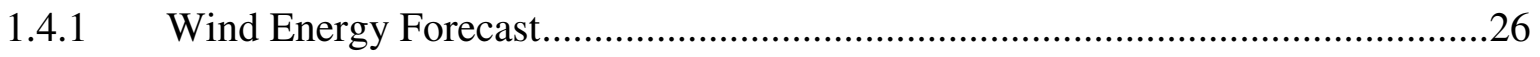

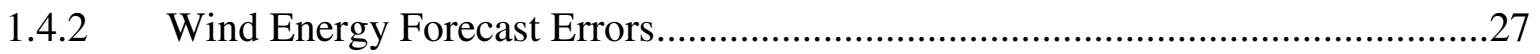

1.5 Objectives of Dissertation and Chapter-wise Summary........................................30

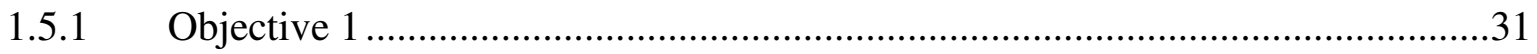

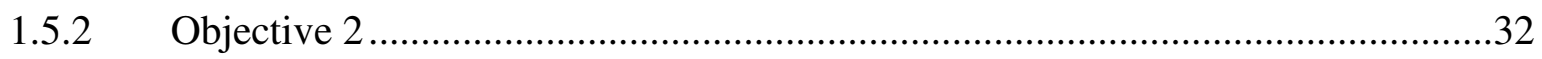

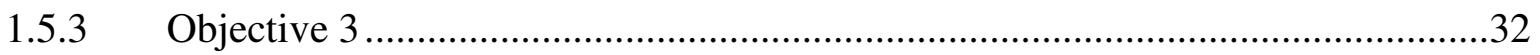

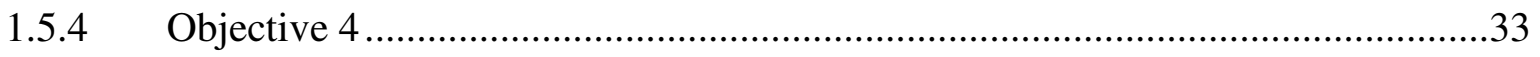

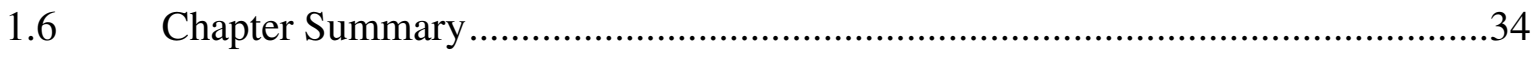

Chapter 2: Options Based Reserve Procurement Strategy for Wind Generators Using

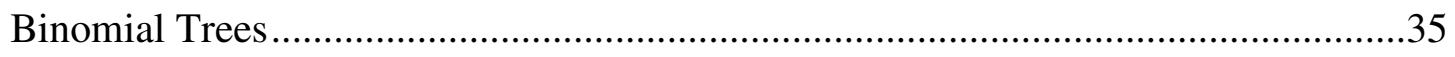

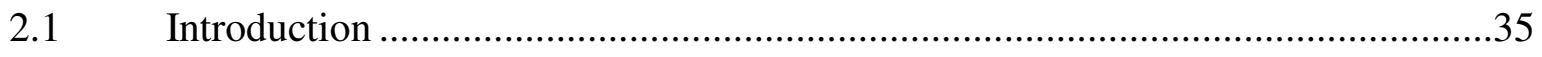

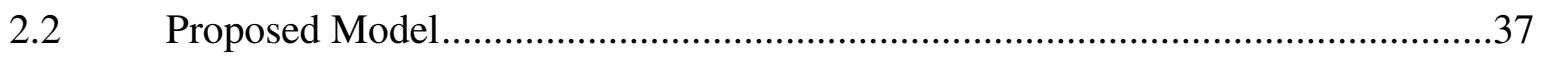

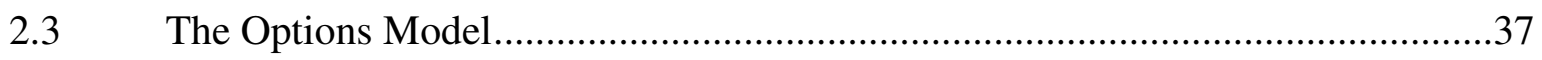

2.4 Binomial Tree Model of Energy Forecast Error ………........................................38

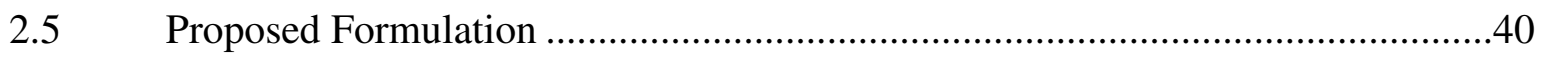

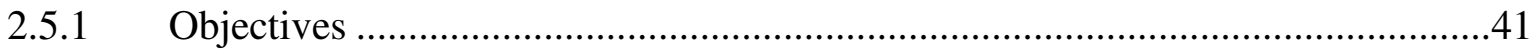

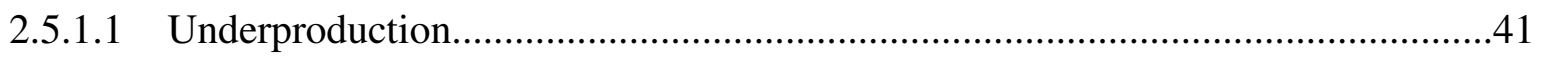

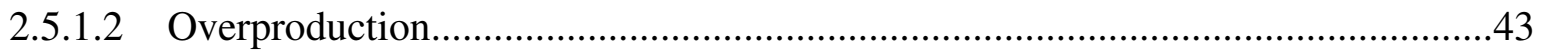

viii 
2.6 Results and Analysis.

2.6.1 Simple Case ......................................................................................45

2.6.2 Ontario Wind Farm Example ................................................................

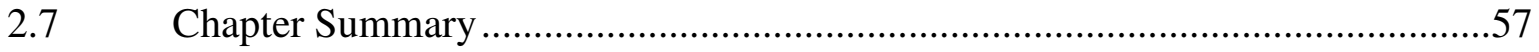

Chapter 3: Network Constrained Model for Options Based Reserve Procurement by

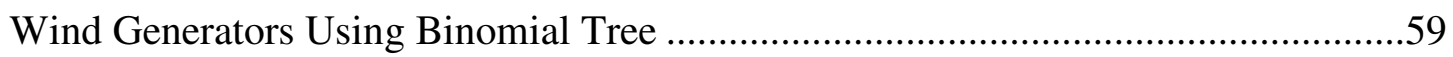

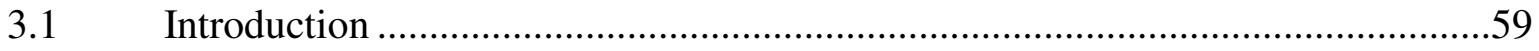

Proposed Secondary Market Model ................................................................60

Options Model for Prices ..........................................................................60

Cauchy-Lorentz distribution model Wind Energy Forecast Error .......................61

Probabilistic Model and Optimization .........................................................63

Problem Formulation and Objectives ......................................................66

3.6.1 Underproduction objective and constraints ..........................................66

3.6.2 Locational marginal prices for underproduction........................................69

3.6.3 Overproduction objective and constraints ...............................................69

3.6.4 Locational marginal prices for overproduction ..........................................72

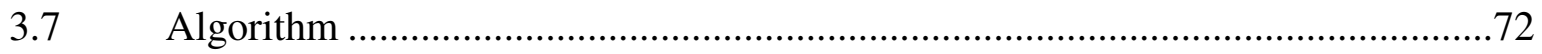

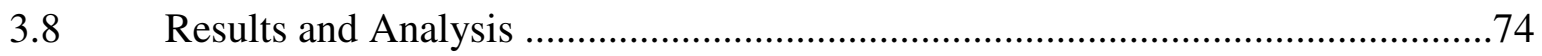

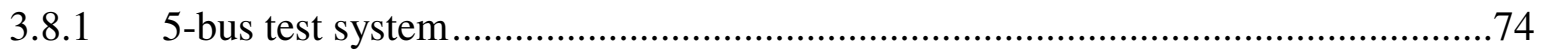

3.8.2 IEEE 118-bus test system with realistic wind farms data...............................80

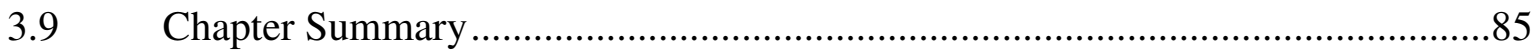

Chapter 4: Energy Reserve Trade Optimization for Wind Generators Using Black-

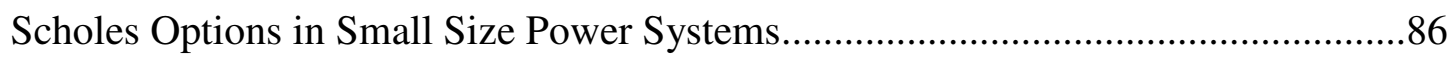




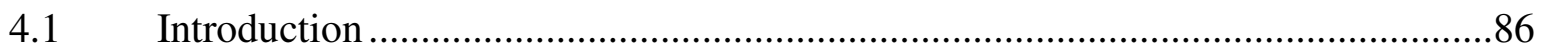

4.2 Proposed Secondary Market Model ...................................................................

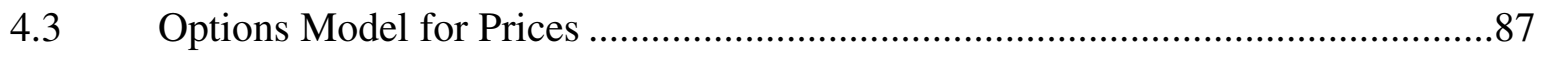

4.4 Distribution model for Wind Energy Forecast Error ...............................................89

4.5 Problem Formulation and Objectives..............................................................92

4.5.1 Underproduction objective and constraints …….............................................92

4.5.2 Locational marginal prices for underproduction................................................92

4.5.3 Overproduction objective and constraints ………..............................................93

4.5.4 Locational marginal prices for overproduction .................................................94

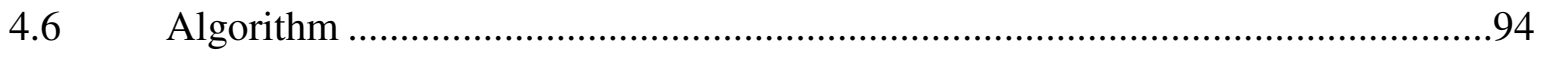

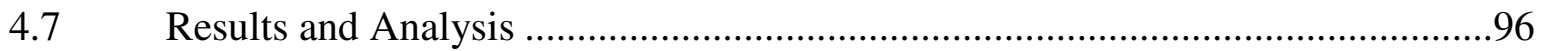

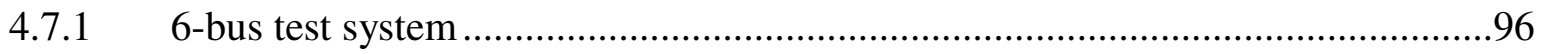

4.7.2 118-bus test system ...................................................................................105

4.8 Comparison of the results of Binomial and Gaussian Forecast Error ..................111

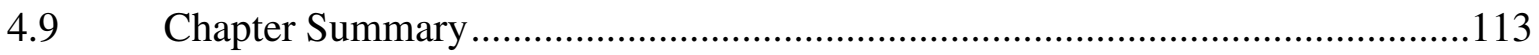

Chapter 5: Wind Energy Forecast Error Estimation Using Black-Scholes

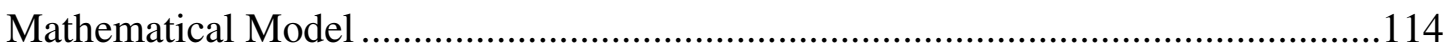

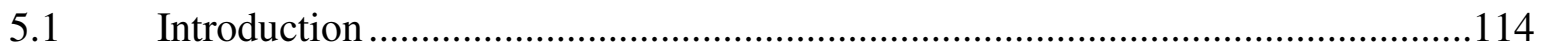

5.2 Proposed Secondary Market Model …………………......................................114

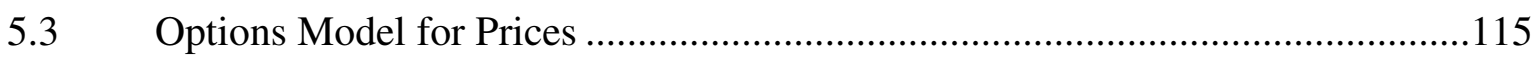

5.4 Distribution Model for Error in Wind Energy Forecast.......................................116

5.5 Problem Formulation and Objectives..........................................................119

5.5.1 Underproduction objective and constraints ...................................................120 
5.5.2 Locational marginal prices for underproduction........................................120

5.5.3 Overproduction objective and constraints ................................................121

5.5.4 Locational marginal prices for overproduction.........................................122

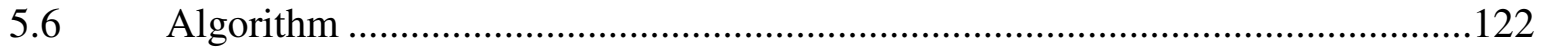

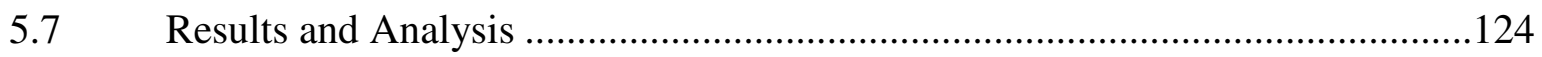

$5.8 \quad$ Comparison of the Results of Gaussian and Black \& Scholes ..........................132

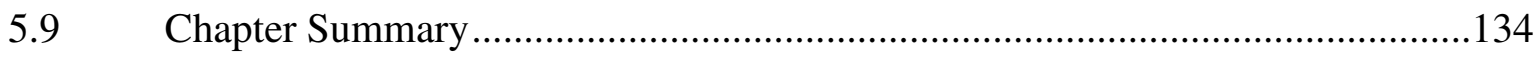

Chapter 6: Conclusion and Future Work ........................................................135

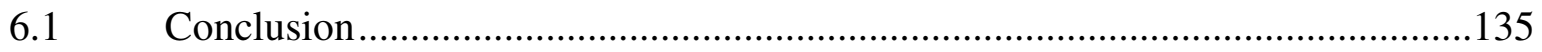

Recommendations for Future Work ........................................................... 139

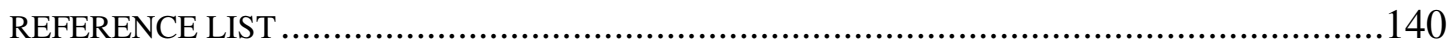




\section{LIST OF TABLES}

Table 1.1 Unit Costs of Electricity Generation of Renewable Energy Sources.................2

Table 2.1 Data for example 1 ..............................................................................46

Table 2.2 Revenue of Wind Generator in different scenarios .......................................53

Table 2.3 Port Alma energy and price volatility values ...........................................54

Table 2.4 Port Alma actual and forecasted data.........................................................56

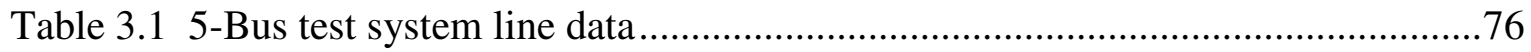

Table 3.2 Results of Study on 5-bus System by aggregation of 36 scenarios for each

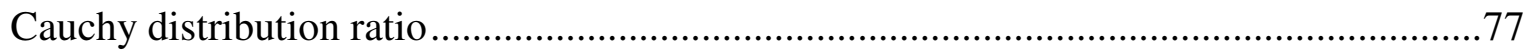

Table 3.3 Nodal market prices at wind farms (\$/MWh)/ Forecast wind energy (MWh).. 82

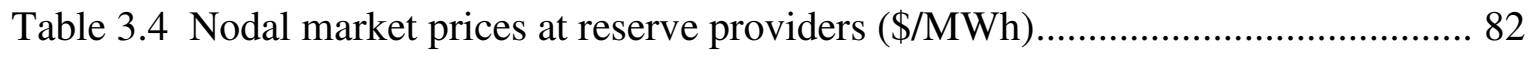

Table 3.5 Actual Revenue of Wind Generators .................................................. 83

Table 3.6 Case number / Wind forecast data (MWh) (Refer to table 3.5) ..................... 83

Table 4.1 Nodal prices in the Example 1 estimated using day-ahead unit commitment

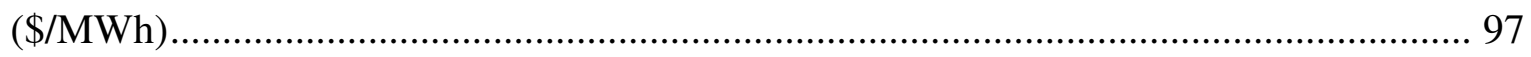

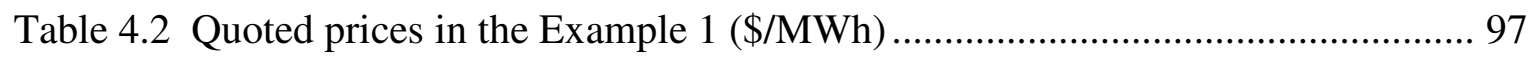

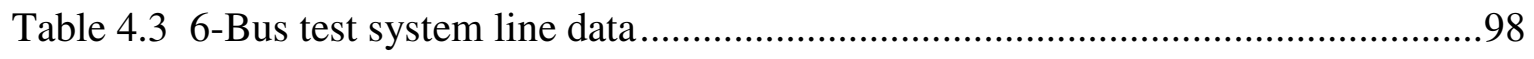

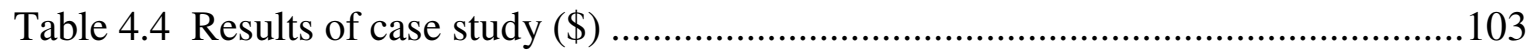

Table 4.5 Load flow (MVA) of the 6-bus test system ............................................ 104 
Table 4.6 ISO estimated nodal prices using day-ahead unit commitment in Example-2 $(\$ / \mathrm{MWh})$ 106

Table 4.7 Quoted market prices for underproduction (\$/MWh) 106

Table 4.8 Actual Revenue of Wind Generators 108

Table 4.9 Case number / Wind forecast data $(\mathrm{MWh}) / \sigma_{\mathrm{w}}$ (refer to Table 4.7) ..............108

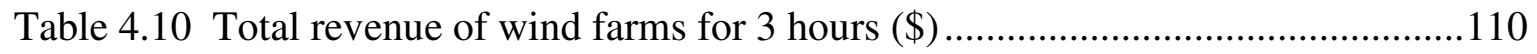

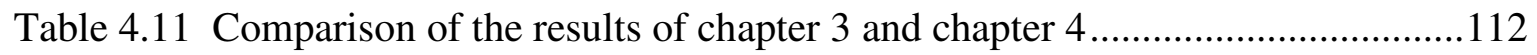

Table 5.1 ISO estimated nodal prices in the Example (\$/MWh) ...............................127

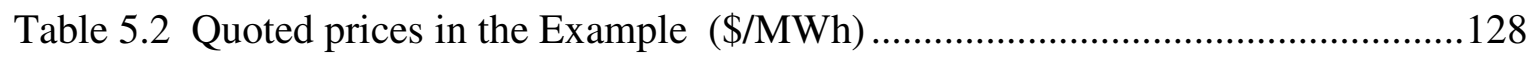

Table 5.3 6-Bus test system line data.............................................................. 128

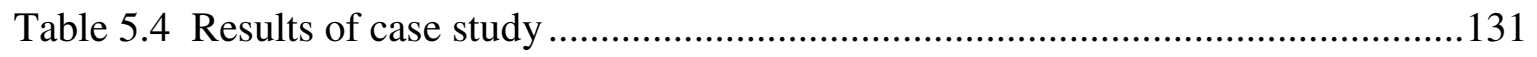

Table 5.5 Comparison of the results of chapter 4 and chapter 5 ................................133

Table 6.1 Summary of Option Models Adopted in this Research ...............................138 


\section{LIST OF FIGURES}

Fig. 1.1 Historical Trend of World Wind Electricity Generation ..................................2

Fig. 1.2 A conventional electricity market .........................................................

Fig. 1.3 A conventional electricity market with separation of WindCos .........................6

Fig. 1.4 Binomial tree for stock price ( $\mathrm{T}=2$ time steps) ...................................... 21

Fig. 1.5 Hourly wind power output and forecast wind power values for one week in the

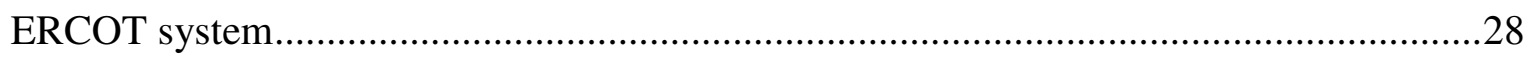

Fig. 1.6 The histogram of the distribution of day-ahead wind power forecasting errors for

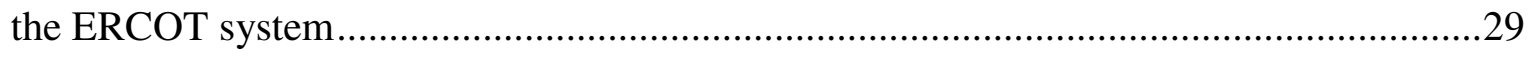

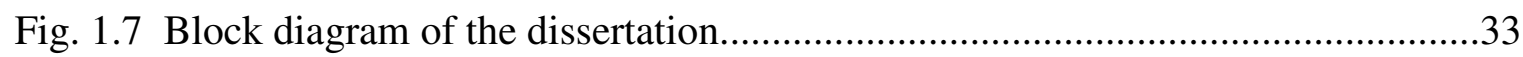

Fig. 2.1 Proposed secondary market ....................................................................36

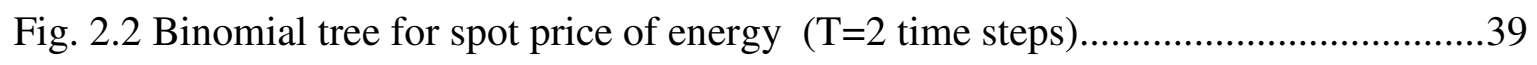

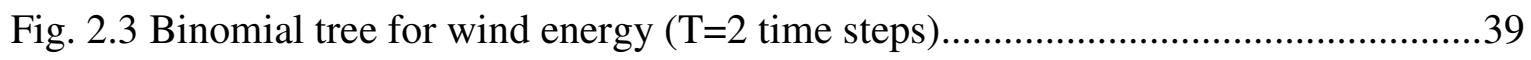

Fig. 2.4 Wind and Market Volatility versus call Strike Prices.....................................47

Fig. 2.5 Wind and Market volatility versus put option strike prices...........................47

Fig. 2.6 Optimal values of avoidable costs of wind generator for various wind and market

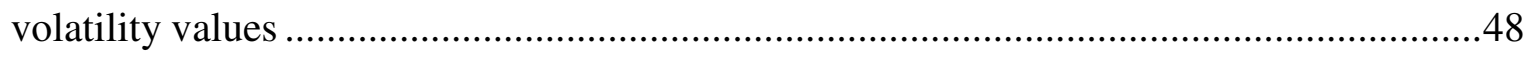

Fig. 2.7 Optimal values of call option premiums ................................................48

Fig. 2.8 Optimal values of put option premiums ....................................................49

Fig. 2.9 Recorded data of wind energy injected to the grid at Port Alma for 12 hours prior

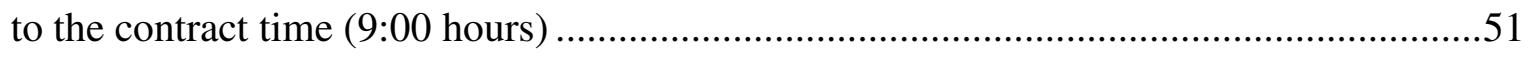


Fig. 2.10 Recorded data of market nodal prices at Port Alma for 12 hours prior to the contract time (9:00 hours)

Fig. 2.11 Daily Variation of strike prices and market price at 13:00 hours during March 1, 2012 to March 5, 2012 .54

Fig. 2.12 Daily Variation of Call and put option forecasted profits of both entities at 13:00 hours during March 1, 2012 to March 5, 2012 .55

Fig. 2.13 Actual revenues for wind generator with and without option contract.

Fig. 3.1 Illustration of the fitted probability distributions on the $x$-interval $[0,1]$ for wind plant \#8 of ERCOT using hour average data for the winter time period. Blue is the beta distribution with shape parameters $\alpha=25.2414$ and $\beta=25.2692$. The Weibull distribution is shown in green with $k=7.1940$ and $\lambda=0.5285$. The Cauchy distribution is in red with xo $=0.4996$ and $\gamma=0.0215$

Fig. 3.2 Illustration of the probable scenarios of under/over production at each wind connected bus

Fig. 3.3 Proposed model's flow chart

Fig. 3.45 -Bus test system.

Fig. 3.5 Aggregated strike prices for call option at all buses for increasing $\gamma / \mathrm{EF}_{\mathrm{w}}$ in Example 1. Each strike price with a certain $\gamma / \mathrm{EF}_{\mathrm{w}}$ and at a certain bus is calculated by aggregation of 36 different prices and their probabilities

Fig. 3.6 Aggregated option (premium) prices for call option at all buses for increasing $\gamma / \mathrm{EF}_{\mathrm{w}}$ in Example 1. Each option price with a certain $\gamma / \mathrm{EF}_{\mathrm{w}}$ and at a certain bus is calculated by aggregation of 36 different prices and their probabilities. 
Fig. 3.7 Variation of aggregated contracted energy for reserve providers and aggregated TAWC, TERC with respect to $\gamma / \mathrm{EF}_{\mathrm{w}}$

Fig. 3.8 Variation of aggregated contracted energy for reserve providers and aggregated call strike and premium prices at bus- 4 with respect to security constraint $\left(\gamma / \mathrm{EF}_{\mathrm{w}}=10 \%\right)$

Fig.3.9 Ontario South-West Generators .81

Fig. 3.10 Actual recorded wind energy production at different wind farms in March 1, 2012 (24 hours)

Fig. 3.11 Total revenue of wind farms with (w) and without (w/o) contract by aggregation of 216 scenarios for each hour .84

Fig. 4.1 PDF of the wind energy absorbed by a wind farm in near future time span .91

Fig. 4.2 Proposed model's algorithm .95

Fig. 4.3 The schematic diagram of the 6-Bus test system..... .97 Fig. 4.4 Variation of locational marginal prices for underproduction with respect to Wind energy standard deviation $(\$ / \mathrm{MWh})$ 98

Fig. 4.5 Wind Energy under or overproduction 100

Fig. 4.6 Optimal amounts of positive reserve (call option) for wind underproduction ...100 Fig. 4.7 Optimal amounts of negative reserve (put option) for wind overproduction (G1 at Bus 2 is not scheduled) 100

Fig. 4.8 Variation of purchased reserve by Wind Generators (W1 and W2 and optimal reserve purchased from reserve providers G1 and G2 with respect to security constraint variation of line 2-5) for underproduction (call option) 
Fig. 4.9 Variation of locational marginal prices with respect to security constraint variation of line 2-5

Fig. 4.10 Actual recorded wind energy production at different wind farms in March 1, 2012 109

Fig. 5.1 Variation of forecast error percentage with respect to time for constant forecast of $100 \mathrm{MWh}$ and volatility $=0.15$ 118

Fig. 5.2 Variation of $d 1 E_{w}, d 2 E_{w}, N\left(d 1 E_{w}\right)$ and $N\left(d 2 E_{w}\right)$ with respect to time for constant forecast of $100 \mathrm{MWh}$ and volatility $=0.15$ 118

Fig. 5.3 Proposed model's algorithm

Fig. 5.4 Single-Line diagram of the 6-Bus test system .

Fig. 5.5 Call option strike prices and premiums at all buses for underproduction with respect to Wind Volatility $(\$ / \mathrm{MWh})$ 128

Fig. 5.6 Wind Energy under or overproduction

Fig. 5.7 Optimal amounts of positive reserve (call option) for wind underproduction ...129

Fig. 5.8 Optimal amounts of negative reserve (put option) for wind overproduction

Fig.5.9 Purchased reserve by Wind Generators (W1 and W2) and optimal reserve purchased from reserve providers (G1 and G2) with respect to security constraints of line 2-5 for underproduction (call option) .130

Fig. 5.10 Optimal call strike prices with respect to security constraint of line 2-5 .130 


\section{LIST OF SYMBOLS}

\section{Definition of Convention:}

\section{Stock market}

T Number of time steps between contract and maturity time

S Current price of stock In binomial tree

ps $\quad$ Probability of jumping up in Binomial Tree

$\lambda s \quad$ Current value of stock price in B\&S method

os $\quad$ Volatility of stock price

rs Interest rate plus one

r Interest rate

us,ds Coefficients of moving upward and downward at each node of binomial tree

SC, SP Call and put option premiums for stock in binomial tree

$\mathrm{KSc}, \mathrm{KSp} \quad$ Strike price of stock option for call and put in binomial tree

fps $(\mathrm{j}, \mathrm{T}) \quad$ The probability of the price outcome that turns out to be at the $\mathrm{j}^{\text {th }}$ node in the $\mathrm{T}^{\text {th }}$ time step

$\mathrm{N}(\mathrm{x} 0) \quad$ Cumulative distribution function of the standard normal distribution at point $\mathrm{x} 0$.

$\mathrm{d} 1 \mathrm{~s}, \mathrm{~d} 2 \mathrm{~s} \quad$ Interim parameters of Black and Scholes formula for stock market

\section{Call option ( Underproduction)}

$\lambda \mathrm{m}_{\mathrm{i}}^{\mathrm{OC}} \quad$ Locational marginal price of energy at $\mathrm{i}^{\text {th }}$ bus result of optimization for call option

$\gamma \mathrm{W}_{\mathrm{w}}^{\mathrm{C}} \quad$ Quote factor of energy by $\mathrm{w}^{\text {th }}$ wind generator for call option 


\begin{tabular}{|c|c|}
\hline$\gamma \mathrm{r}_{\mathrm{k}}^{\mathrm{C}}$ & Quote factor of energy by $\mathrm{k}^{\text {th }}$ reserve provider for call option \\
\hline$\lambda \mathrm{E}_{\mathrm{k}}^{\mathrm{QC}}$ & Quote price of energy by $\mathrm{k}^{\text {th }}$ reserve provider for call option \\
\hline$\lambda \mathrm{E}_{\mathrm{w}}^{\mathrm{QC}}$ & Quote price of energy by $\mathrm{w}^{\text {th }}$ wind generator for call option \\
\hline $\mathrm{Kmc}_{\mathrm{i}}$ & Optimal call option strike price of energy at $i^{\text {th }}$ bus \\
\hline omc $_{\mathrm{i}}$ & Optimal call option premium at $\mathrm{i}^{\text {th }}$ bus \\
\hline $\mathrm{Kc}_{\mathrm{i}}$ & $\begin{array}{l}\text { Optimal call option strike price of energy at } i^{\text {th }} \text { bus in } B \& S \\
\text { model }\end{array}$ \\
\hline $\mathrm{Cm}_{\mathrm{i}}$ & Optimal call premium of energy at $\mathrm{i}^{\text {th }}$ bus in $\mathrm{B} \& S$ model \\
\hline$\overline{E U_{w, m}}$ & $\begin{array}{l}\text { Expected energy underproduction for } \mathrm{w}^{\text {th }} \text { wind generator in } \\
\text { the } \mathrm{m}^{\text {th }} \text { segment }\end{array}$ \\
\hline$\overline{\mathrm{EU}_{\mathrm{w}}}$ & Expected energy underproduction for $\mathrm{w}^{\text {th }}$ wind generator \\
\hline $\mathrm{EU}_{\mathrm{w}}$ & Optimal energy to be purchased for $\mathrm{w}^{\text {th }}$ wind generator \\
\hline $\mathrm{EC}_{\mathrm{K}}$ & $\begin{array}{l}\text { Optimal energy to be provided by the reserve provider for } \mathrm{k}^{\text {th }} \\
\text { reserve provider }\end{array}$ \\
\hline$\overline{\mathrm{EC}_{\mathrm{K}}}$ & Max. capacity of $\mathrm{k}^{\text {th }}$ reserve provider \\
\hline TAWC & Total avoidable loss for wind generators in call option \\
\hline TERC & Total extra revenue for reserve providers in call option \\
\hline & Put option (Overproduction) \\
\hline$\lambda \mathrm{m}_{\mathrm{i}}^{\mathrm{OP}}$ & $\begin{array}{l}\text { Locational marginal price of energy at } \mathrm{i}^{\text {th }} \text { bus result of } \\
\text { optimization for put option }\end{array}$ \\
\hline$\gamma \mathrm{W}_{\mathrm{w}}^{\mathrm{P}}$ & Quote factor of energy by $w^{\text {th }}$ wind generator for put option \\
\hline$\gamma \mathrm{r}_{\mathrm{k}}^{\mathrm{P}}$ & Quote factor of energy by $\mathrm{k}^{\text {th }}$ reserve provider for put option \\
\hline$\lambda \mathrm{E}_{\mathrm{k}}^{\mathrm{QP}}$ & Quote price of energy by $\mathrm{k}^{\text {th }}$ reserve provider for put option \\
\hline$\lambda \mathrm{E}_{\mathrm{w}}^{\mathrm{QP}}$ & Quote price of energy by $\mathrm{w}^{\text {th }}$ wind generator for put option \\
\hline $\mathrm{Kmp}_{\mathrm{i}}$ & Optimal put option strike price of energy at $i^{\text {th }}$ bus \\
\hline $\mathrm{omp}_{\mathrm{i}}$ & Optimal put option premium at $i^{\text {th }}$ bus \\
\hline
\end{tabular}


$\mathrm{Kp}_{\mathrm{i}} \quad$ Optimal put strike price of energy at $\mathrm{i}^{\text {th }}$ bus in B\&S model

$\mathrm{Pm}_{\mathrm{i}} \quad$ Optimal put premium of energy at $\mathrm{i}^{\text {th }}$ bus in $\mathrm{B} \& \mathrm{~S}$ model

$\overline{\mathrm{EO}_{\mathrm{w}, \mathrm{m}}}$ Expected energy overproduction for $\mathrm{w}^{\text {th }}$ wind generator in the $\mathrm{m}^{\text {th }}$ segment

$\overline{\mathrm{EO}}$ Expected energy overproduction for $\mathrm{w}^{\text {th }}$ wind generator

$\mathrm{EO}_{\mathrm{w}} \quad$ Optimal energy to be sold by $\mathrm{w}^{\text {th }}$ wind generator

$\mathrm{EP}_{\mathrm{K}} \quad$ Optimal extra energy to be purchased by the reserve provider for $\mathrm{k}^{\text {th }}$ reserve provider

$\overline{\mathrm{EP}_{\mathrm{K}}} \quad$ Max. negative capacity of $\mathrm{k}^{\text {th }}$ reserve provider

TAWP Total avoidable loss for wind generators in put option

TERP Total extra revenue for reserve providers in put option

\section{General terms}

i Index for system bus

$\mathrm{EF}_{\mathrm{w}} \quad$ Forecasted energy at $\mathrm{w}^{\text {th }}$ wind generator

$\overline{\overline{\mathrm{EF}_{\mathrm{w}}}} \quad$ Forecasted energy at $\mathrm{w}^{\text {th }}$ wind generator in probabilistic

model

$\lambda \mathrm{A}_{\mathrm{i}} \quad$ Actual energy price at $\mathrm{i}^{\text {th }}$ bus

$\lambda \mathrm{m}_{\mathrm{i}} \quad$ Estimated price of energy by ISO at $\mathrm{i}^{\text {th }}$ bus

$\lambda \mathrm{E}_{\mathrm{i}} \quad$ Estimated price of energy by ISO at $\mathrm{i}^{\text {th }}$ bus in chapters 4 and 5

$\sigma \mathrm{E}_{\mathrm{w}} \quad$ Standard deviation of wind energy forecast errors for $\mathrm{w}^{\text {th }}$ wind generator

$\sigma \mathrm{m}_{\mathrm{i}} \quad$ Volatility of energy price at $\mathrm{i}^{\text {th }}$ bus

NB Total bus number

NW Total number of wind plants

NK Total number of reserve connected buses

yo Penalty or discount factor imposed to wind generator by ISO

$\mathrm{P}_{\mathrm{i}}(\mathrm{V}, \delta) \quad$ Total power injected to $\mathrm{i}^{\text {th }}$ bus 


$\begin{array}{cl}\mathrm{Q}_{\mathrm{i}}(\mathrm{V}, \delta) & \text { Total reactive power injected to } \mathrm{i}^{\text {th }} \text { bus } \\ \mathrm{PG}_{\mathrm{i}}, \mathrm{QG}_{\mathrm{i}} & \text { Active \& reactive power of the generator connected to } \mathrm{i}^{\text {th }} \text { bus } \\ \mathrm{PD}_{\mathrm{i}}, \mathrm{QD}_{\mathrm{i}} & \text { Active \& reactive power of the load connected to } \mathrm{i}^{\text {th }} \text { bus } \\ \mathrm{S}_{1}(\mathrm{~V}, \delta) & \text { Flow of the } \mathrm{l}^{\text {th }} \text { line } \\ \mathrm{OBJ}_{\mathrm{C}} & \text { Objective functions for call options } \\ \mathrm{OBJ}_{\mathrm{P}} & \text { Objective functions for put options } \\ \mathrm{GenCo}_{\text {DisCo }} & \begin{array}{l}\text { Generation Company } \\ \text { TransCo }\end{array} \\ \text { WindCo } & \text { Transmission Company } \\ \mathrm{x} & \text { Wind Company } \\ & \text { A random variable which represents the amount of wind }\end{array}$




\section{Chapter 1: INTRODUCTION}

\subsection{Introduction}

Modern power system researchers focus on a wide range of challenges related to technology, as well as economics, environment and policy. New topics such as electricity markets, smart grids, renewable energy, micro grids, etc., have been the focus of recent studies. Wind is one of the most important sources of renewable energy. A significant amount of research outcomes have been reported in literature. Techno-economic solutions to wind energy integration challenges caused by uncertainty in availability are proposed in this dissertation.

\subsubsection{Growth of Wind Energy}

Wind is a source of clean, cheap and accessible energy. The overall decreasing trend in the cost of wind power is expected to continue during the next two decades [1].

Table 1.1 shows unit costs of electricity generation of renewable energy Sources and the decreasing wind energy cost in the future [2]. Rapid technological advancements such as variable speed wind generators, larger turbine sizes, lower wind speed operation capability, developments in offshore turbines, etc., have propelled the significant growth of wind electricity generation recorded in the past decade (Fig. 1.1). Further, this noticeable growth in wind energy was achieved due to various economic incentives made available for wind power generation throughout the world. 
Table 1.1 Unit Costs of Electricity Generation of Renewable Energy Sources [2]

\begin{tabular}{lcc}
\hline Generation Technology & $\begin{array}{c}2010-2020 \\
(\$ / \mathrm{MWh})\end{array}$ & $\begin{array}{c}2021-2035 \\
(\$ / \mathrm{MWh})\end{array}$ \\
\hline Hydro - large & 94 & 95 \\
Hydro - small & 143 & 143 \\
\hline Biomass & 131 & 126 \\
\hline Wind - onshore & 85 & 65 \\
\hline Wind - offshore & 101 & 74 \\
\hline Geothermal & 52 & 46 \\
\hline Solar PV - large scale & 280 & 157 \\
\hline Solar PV - buildings & 406 & 217 \\
\hline Centralised solar power & 207 & 156 \\
\hline Marine & 281 & 187 \\
\hline
\end{tabular}

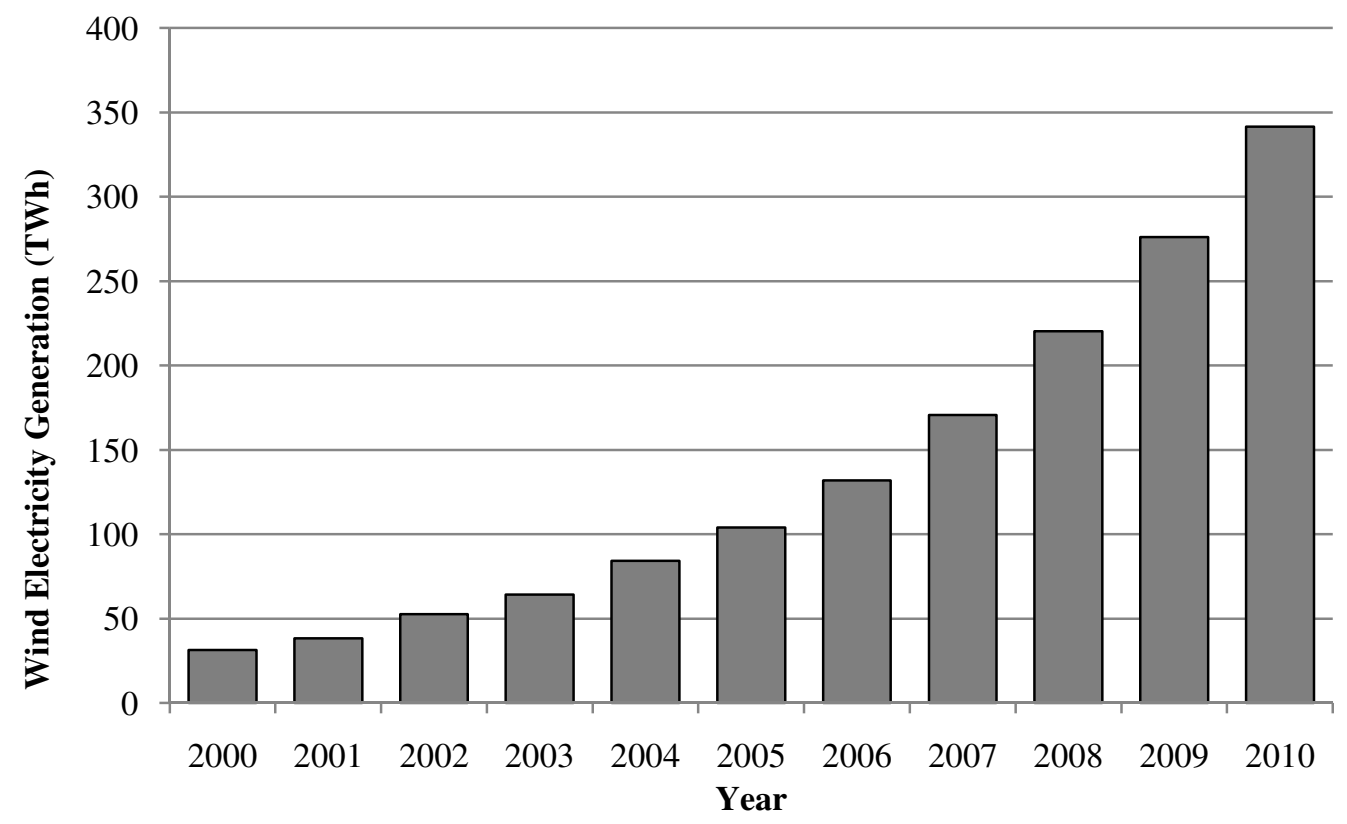

Fig. 1.1 Historical Trend of World Wind Electricity Generation [2]. 


\subsubsection{Challenges of Wind Energy Uncertainty}

Renewable Energy sources such as wind and solar are promising sources of clean and economic energy of the future. When it comes to power system engineering and grid operations, uncertainties in the availability of renewable energy supply can pose serious problems. The demand and supply in a power system must always be balanced at any instant to maintain system frequency. Every power system always maintains a certain amount of AGC (automatic governor control) capacity to ensure demand-supply balance in real-time to maintain system frequency and a certain amount of spinning reserve to deal with contingencies such as sudden loss of a generator. However wind generators aggravate the challenge of balancing demand with supply by always injecting fluctuating amounts of power into the system which cannot be accurately forecasted. Some researchers have been trying to reduce the uncertainty effect of wind energy sources by inventing new storage facilities, while others have been trying to investigate a reserve procurement methodology using financial instruments such as options and derivatives. Trying to find a market model for this investigative purpose, three different approaches have been adopted by utilities [3]:

1) Entirely Regulated-Wind generation is managed in the electricity market as a negative demand, and is paid a fixed regulated tariff for their actual energy production (e.g. Ontario).

2) Partially Regulated - For every MWh of energy produced, wind generators are paid the price resulting from the market-clearing process plus a subsidy intended to attract wind producers to participate in the electricity market.

3) Full Competition-According to the economic principles of a pure competitive market, wind producers must fully bear the burden of the market as do any other market participants. 
This situation is achieved by eliminating the subsidies in approaches 1 and 2 mentioned above.

\subsection{Market Structures of Power Systems}

In the segmentation of the power industry one must distinguish those elements that could conform to the competitive model and operate in a private market from those elements that are likely to require some form of price and service regulation. The usual segmentation of the industry distinguishes among generation companies (GenCos), transmission companies (TransCos) and distribution companies (DisCos). Fig. 1.2 outlines a competitive wholesale market structure that follows this traditional three-part segmentation and emphasizes competition in the generation market. The assumption here is that generation is a market with sufficient participants (GenCos) to enforce reasonable competition. Either there are enough separate generating companies to dilute any market power, or the individual generating units operate under long-term contracts with many customers such that the economic interest in the plants is dispersed and there is competition in the short run [4]. The competing generators must have access to the essential facilities that stand between them and their potential customers in the wholesale market. The thrust of the EPAct of 1992 in United States is that transmission is one such essential facility and open access to the transmission system is a mandatory requirement for operation of a competitive market.

If some participants in the market have more access to these services, then it is impossible to maintain the desired "level playing field" of competition. This reality led eventually to the thrust of the EPAct of 1992. Fig. 1.2 goes beyond the usual GenCo, TransCo, and DisCo trilogy. The obvious feature is the separation of "TransCo" into PoolCo and GridCo. This choice is made based on the institutional structure of regulation in the 
United States, where the $\operatorname{GridCo}(\mathrm{s})$ construction and maintenance of transmission wires might be subject to state regulation and PoolCo control of dispatch to regional or national supervision [4]. The free-flowing grid requires coordination of short-term operations to maintain system stability and achieve least-cost dispatch. This coordination function operates most efficiently through a power pool which provides many services implicit in the economic dispatch. "The dispatch provides an automatic source of backup supplies, short term excess sales, reactive power support, spinning reserve, and the many other services that are bundled in transmission. Without equal access to these functions, some participants in the market will discover that they are at a competitive disadvantage relative to those who have access to the full benefits of a power pool" [4].

For the sake of the present discussion, an independent system operator (ISO) is treated as the function of the dispatcher and it is easiest to describe PoolCo as a single entity.

Implicit in Fig. 1.2 is a separation of the wholesale and retail markets, with regulated distribution companies purchasing in a competitive wholesale market but selling to customers in a retail market. In this case, "the wires component of the distribution business would be recognized as a natural monopoly and an essential facility just as for the high voltage transmission grid" [4].

It would be less likely to find a similar dispatch function at the distribution level. Assuming that PoolCo is governed by ISO we can simplify our model as per Fig. 1.3. 


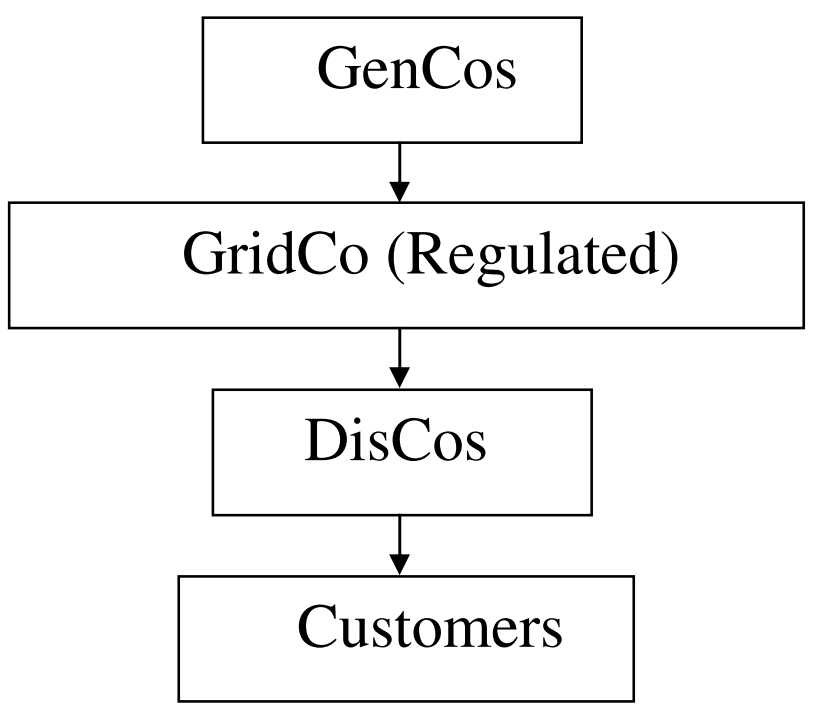

Fig. 1.2 A conventional electricity market.

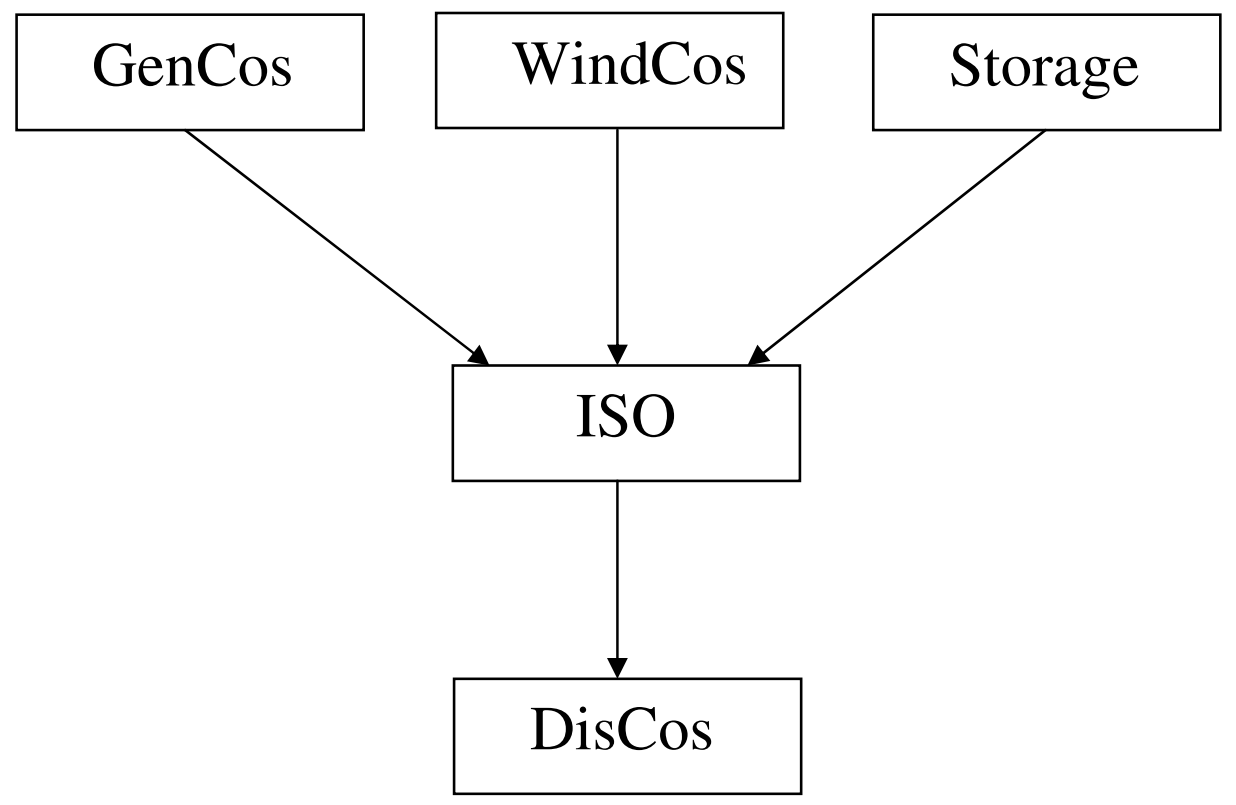

Fig. 1.3 A conventional electricity market with separation of WindCos. 


\subsubsection{Operating Reserve and Reserve Markets}

In the Ontario power network, the operating reserve (operating capacity) is required to meet forecast load, including an allowance for error, to provide protection against equipment failure which has a reasonably high probability of occurrence, and to provide adequate regulation of frequency and tie line power flow [5]. The operating reserve is made up of 10 minutes and 30 minutes reserve requirements:

- The 10 minutes reserve available to each Area shall at least be equal to its first contingency loss multiplied by the Contingency Reserve Adjustment Factor for the most recently completed quarter.

- The 30 minutes reserve available to each Area shall at least equal to one half of the second contingency.

In some other regions such as California, the terms of spinning or non-spinning reserve are used. Generators that intend to provide either spinning or non-spinning reserve should be able to reach their promised capacity within roughly ten minutes. Most power system guidelines require a significant fraction of their operating reserve to come from spinning reserve. This is because the spinning reserve is slightly more reliable (it doesn't suffer from start-up issues) and can respond immediately whereas with non-spinning reserve generators there is a delay as the generator starts-up offline $[6,7,8]$.

In addition, there are two other kinds of reserve power that are often discussed in combination with the operating reserve: the frequency-response reserve and the replacement reserve.

- The frequency-response reserve (also known as regulating reserve) is provided as an automatic reaction to a loss in supply. It occurs because immediately following a loss 
of supply, the generators slow down due to the increased load. To combat this slowing, many generators have a governor. By helping the generators to speed up, these governors provide a small boost to both the output frequency and the power of each generator. However, because the frequency-response reserve is often small and not at the discretion of the system operator it is not considered part of the operating reserves [9].

- The replacement reserve (also known as contingency reserve) is reserve power provided by generators that require a longer start-up time (typically thirty to sixty minutes). It is used to relieve the generators providing the spinning or non-spinning reserve and thus restore the operating reserve (confusingly the replacement reserve is sometimes known as the 30 or 60 -minute operating reserve) $[9,10]$.

In Ontario [11], there is a market for each of the three classes of operating reserve, allowing the ISO to efficiently purchase reserve to meet Ontario's needs. Prices and schedules are determined every five minutes, for each reserve class, in conjunction with the energy market. The dispatch algorithm simultaneously determines schedules for both energy and operating reserve through a process called ‘joint optimization'. Normally, operating reserve requirements are entirely met through the scheduling of resources based on participant offers. The ISO can also use 'control action operating reserve', which reflects the ability to use voltage reductions or forego meeting 30-minute requirements (under specific conditions) to meet operating reserve needs. In the following sections, both types of supply are considered. Market participants can offer operating reserve to the ISO-administered markets at the same time that they bid or offer energy. Imports and exports cannot provide synchronized reserve and may only offer on interties where there is agreement with the 
neighboring jurisdiction that transactions can be used to supply reserve to Ontario. Note that participants cannot sell reserve from Ontario to another jurisdiction. The dispatch algorithm builds an offer stack, from lowest to highest price, based on the submitted reserve offers. It can use offered reserve that is not required to satisfy one class to satisfy the requirements for a lower class. This means that if a participant offered only 10-minute synchronized reserve, it could be scheduled for 10-minute synchronized, 10-minute non-synchronized, 30-minute, or any combination of the three classes of operating reserve.

The Reserve Market consists of two distinct products for the provision of reserve capacity in New England [12]. This capacity is available for dispatch during system contingencies, which are unplanned disconnections of power system elements, such as transmission facilities or generators, from the electricity grid. The Forward Reserve Market (FRM) is the procurement mechanism for delivery of reserve products to meet 10-minute non-synchronous reserve (TMNSR) and 30-minute operating reserve (TMOR) requirements in New England during on-peak hours. Market Participants submit offers for FRM obligations in specific Reserve Zones to the Forward Reserve Market Auction, which occurs twice annually prior to each Seasonal Capability Period. (The Summer period is June September; the winter period is October - May). Payments for Forward Reserve delivery are made to Market Participants with FRM obligations based on the value of the Forward Reserve Clearing price for the appropriate Reserve Zone and product. In order for Participants to meet their obligations in the market, eligible forward reserve resources must be assigned in advance of the operating day to provide reserves on an hourly basis. RealTime Reserve capability on eligible assets is designated by the ISO during the operating day, 
and resources that provide these reserves will be paid based on the value of the hourly RealTime Reserve Clearing Price for the appropriate Reserve Zone and product.

The Market Participant with an obligation in the Forward Reserve Market will receive credits for service delivered, by zone and product, based on the Forward Reserve Clearing Prices determined in the Auction. Obligations in the Forward Reserve Market are obtained through clearing in the Auction; adjusted, as applicable, for bilateral trading of obligations. The Market Participant with ownership in a resource that provides Real-Time Reserves will receive credits for service during hours that the Reserve Market Clearing Price is not zero. However, payments are adjusted in order to prevent an asset for being compensated in both the Real-Time Reserve Market and the Forward Reserve Market at the same time. The hourly Real-Time Reserve Clearing Prices are determined in accordance with Market Rule 1.

\subsubsection{A survey in previous publications of Reserve Markets}

There are several research publications and suggestions about reserve markets which are reflected in this section. In these publications, ISO is always in charge to run and supervise the market and there is no trade between WindCos and GenCos outside of that market. Two types of reserve market model are introduced in [13], which are PoolCo Model and Bilateral Contracts Model. The advantages and disadvantages of these models are introduced and compared and the transition from the traditional structure to the competitive electricity market in China is discussed. Reference [13] firstly discusses the assigning the reserve responsibilities, and then the measures of assigning the reserve responsibilities between the generators, which are the Direct Assigning Measure and the Actual Value Convert Assigning Measure. Also the measures of assigning the reserve responsibilities between the suppliers and big Customers are discussed. 
Ref. [14] presents the market clearing model for the co-optimized real-time energyreserve market implemented in the ISO New England (ISO NE). In this model, reserve providers are procured on a zonal basis to satisfy the first and the second contingency protection criteria required by the ISO NE's real-time operations for both the entire area and typical import-constrained areas.

Ref. [15] proposes an integral framework of reserve market including the structure and operation mode. The proposed market is cleared according to reserve category in hourly basis. The objective function is maximizing the social welfare and the constraints include reliability requirement, the least reserve capacity for each area, the constraints of generators.

In [16], the problem of building the optimal bidding strategies for competitive suppliers in the California-type spinning reserve market is discussed. According to this model, every supplier submits a capacity bid and an energy bid at the same time, and selection of spinning reserve providers is based on the capacity bids and the reserve amount broadcasted by the ISO.

In [17] a combined energy and regulation reserve market model is proposed to encourage wind producers to regulate their short-term outputs. The proposed market considers lower deviation penalties for over or under production and wind producers can increase their revenue by optimally bidding in the energy and reserve markets to reduce their deviation penalties. In this model, part of the intra-hour wind variations is diverted into the system regulation reserve and the system will have less wind energy intra-hour variations and will demand less short-term reserve for wind variations. 
In [18] the optimization problem is modeled by introducing the economic concepts of utility and risk management. Expected value and standard deviation are used to measure revenue and risk in this model.

In [19] an algorithm of minimizing generating company costs in a spot market with bilateral trading is proposed. Cost minimization function is the criteria of the optimization task while energy, reserve and participation of the power plant in the market are variables in the model.

Ref. [20] focuses on evaluating the new bidding strategy from the perspective of system operation by simulating a day-ahead unit commitment problem. It concludes that in this new model, more secure system operation with lower dispatch cost can be achieved by comparing the scheduling results under different bidding strategies.

Ref. [21] presents the development of a spinning reserve market model framework for procurement of spinning reserve services, independent of the energy market auctions. The proposed model has suggested a biddable reserve calculation scheme and ac OPF is used to determine the spinning reserve procurement while taking into account system security constraints.

Ref. [22] discusses the localization of the current optimization methods for the reserve market with Interruptible Loads and generators as participants. The Pareto optimality method for the reserve market is used in order to ensure the maximal utility and the optimization of two kinds of reserves from Interruptible Loads and generators.

In [23] a method is described that utilizes intra-day optimization potentials, taking into account planning uncertainties, to determine the optimal intra-day operation strategy. 
In [24] the authors propose an integrated energy and reserve market. The proposed model has developed a spinning reserve calculation scheme which is independent of the energy market auctions and the full ac OPF is used to determine the spinning reserve.

In [25] a new spinning reserve market structure is proposed to utilize the available resources to achieve spinning reserve requirements with the security constraints in the context of an energy market.

Ref. [26] investigates the basic energy and reserve dispatch optimization (cooptimization) in the setting of a pool-based market. It models the lost opportunity cost introduced by reserve allocation. The marginal costs of energy and reserves under a variety of market designs are derived and the results are used to support the reserve market design and implementation in the ISO New England control area.

Ref. [27] assumes that operating reserve capacity in a power system is flexible and that one should optimize it by cost-benefit analysis. Based on the reliability evaluation of the generation system, a reserve market is proposed to determine the optimal reserve capacity and simultaneously clear the operating reserve market.

Ref. [28] suggests a new scheduling algorithm using grid security constraints which include one base case (intact system) and a list of possible contingencies (line-out, unit-lost, and load-growth) of the system. By following a cost-minimizing co-optimization procedure, both power and reserve are allocated spatially for the combined energy and reserve markets and the Lagrange multipliers reveal the locational shadow prices for the reserve and energy requirements. 
Ref. [29] Overviews frequency regulation services and reserve markets in which these regulation services are traded. Regulation service in four electricity markets, namely the PJM, New-England, Great Britain and German markets, are discussed in detail.

Ref. [30] shows that because of the stochastic call of operating reserves arbitrarily high equilibriums for the energy bids are possible in theory. It also concludes that market design with independent capacity and energy auctions cannot lead to prices near to the marginal costs.

A model and solution approach to a daily energy and spinning-reserve electricity markets clearing system is presented in [31]. This model considers offers for energy supply and reserve, bids for demand of energy and re-schedulable bilateral contracts. System security is considered with dc model. The model represents the clearing system used by an ISO in charge of both the market and system security using an Interior-Point Method (IPM).

In [32] reliability is explicitly valued in the reserve markets. The generator would get the insurance premium in advance from the consumers and they are responsible to secure consumers' power supply.

Ref. [33] proposes a coding scheme using Genetic Algorithm (GA) for optimal selection of standing reserve tenders in the most economical fashion.

Ref. [34] shows that the power sector characteristic and features are common to all the countries in the area of study and that the implementation of free market mechanisms gives rise to new problems for the restructuring process.

Ref. [35] addresses the self-scheduling problem for a price-taker hydro generating company. This company is comprised of several cascaded hydro plants along a river basin as well as a pumped-storage plant. Due to existence of a suitable zone as a natural reservoir, it is 
assumed that the hydro generating company has constructed a pumped-storage plant using the mentioned natural zone as upper reservoir and one of its hydro dams as lower reservoir. The objective of the paper is maximizing the profit of the company through participating in the day-ahead energy and ancillary service markets. In order to reach this goal, it is essential to have an appropriate approach to self-scheduling for the company. The spinning reserve and regulation markets are considered as ancillary services in which the company can participate. The self-scheduling problem of the hydro generating company is therefore formulated and solved as a mixed integer non-linear programming (MINLP) problem.

In [36] a probabilistic security constraint unit commitment problem is used to clear energy and spinning reserve simultaneously and to determine system spinning reserve requirements. Also, the expected load interruption costs of distribution companies are incorporated in the objective function. The IEEE reliability test system (IEEE-RTS) is used in this model.

Ref. [37] proposes the design of a spinning reserve service (SRS) market that can act as an effective tool to determine spinning reserve schedules in deregulated power systems. This method achieves uniform spinning reserve prices within a bid-based market structure considering market constraints, transmission constraints and reserve requirements.

Ref. [38] based on the current electricity market in China analyzes the mechanism of the compensation of the reserve service. A compensation model of the service with incentive mechanism based on the reserve cost is proposed.

Ref. [39] formulates the AC OPF problem for the simultaneous dispatch of energy, spinning reserve and interruptible load. A new probabilistic reserve criterion based on system inherent reliability data is utilized to assess the required system reserve and is implemented 
in a day-ahead market settlement. Interruptible loads, spinning reserve, system generation and demand have been considered in the development of the probabilistic reserve criterion.

Ref. [40] documents two parallel activities, the development of a market simulation model of forward and real time reserve trading, and the results and analysis of some experiments on those markets to validate the performance of the proposed model.

Ref. [41] introduces a computational model for co-optimizing energy and operating reserve (OR) products in real-time operation with linear programming (LP). Securityconstrained economic dispatch (SCED) is applied to problem formulation representing physical and functional requirements in the multi-interconnected control areas.

Ref. [42] presents the old Standing reserve services in the UK, and introduces the new Short-Term Operating Reserve procurement, and then investigates the necessity of these changes as well as the expected economic benefits of new regulations.

From the survey above, it is clear that reserves are primarily to provide frequency regulation via $\mathrm{AGC}$ and spinning reserves, 10-minute reserves and 30-minute reserves to overcome contingencies such as loss of a generator due to outage, etc. They are not created to overcome uncertainty and intermittency of wind power generation. The next section briefly introduces options contract theory from a branch of study called Financial Engineering and is subsequently used to develop a secondary intra-day reserve market to provide reserves for overcoming uncertainty in wind energy production.

\subsection{Option Pricing Theory}

In finance, a derivative is a financial instrument (or, more simply, an agreement between two parties) that has a value, based on the expected future price movements of the asset 
which is called the underlying asset such as a share or a currency. There are many kinds of derivatives, with the most common being swaps, futures, and options.

An option is a security that gives to its owner the right to trade underlying asset with a certain price at a certain time. The act of making this transaction is referred to as exercising the option. An option holder has the right to buy or sell a commodity at a future time for a predetermined price (strike price). There are several option trading models available that fall under two major categories: (1) a Call (the right to buy) option, and (2) a Put (the right to sell) option. Options have been traded for centuries, but they remained obscure financial instruments until the introduction of a listed options exchange in 1973. Since then, options' trading has enjoyed an expansion unprecedented in American securities markets [43]. Option contracts are considered a powerful financial tool in case of uncertainty.

A call option, often simply named a "call", is a financial contract between two parties, the buyer and the seller of this type of option. The buyer of the call option has the right, but not the obligation to buy an agreed quantity of a certain commodity (the underlying) from the seller of the option at a certain time (the expiration date) for a certain price (the strike price). The seller (or "writer") is obligated to sell the commodity if the buyer decides to exercise the right. The buyer pays a fee (called a premium) for this right. The buyer of a call option wants the price of the underlying instrument to rise in the future; the seller expects that it will not, or is willing to give up some of the upside (profit) from a price rise in return for the premium (paid immediately). Call options are most profitable for the buyer when the underlying instrument moves up, making the price of the underlying instrument closer to, or above the strike price. For the call buyer the risk is limited to the premium. The profit for the buyer can be very large, and is limited by how high underlying spot rises. When the price of the 
underlying instrument is greater than the strike price, the option is said to be "in the money". The call writer does not believe the price of the underlying security is likely to rise. The writer sells the call to collect the premium. The total loss, for the call writer, can be very large, and is limited by how high the underlying price rises. The initial transaction is not the supplying of a physical or financial asset (the underlying instrument). Rather it is the granting of the right to buy the underlying asset, in exchange for a premium. A put option often simply labelled a "put" is a financial contract between two parties, the writer (seller) and the buyer of the option. The buyer acquires a long position by purchasing the right to sell the underlying instrument to the seller of the option for a certain price (the strike price) during a certain period of time. If the option buyer exercises his right, the seller is obligated to buy the underlying instrument from him at the agreed-upon strike price, regardless of the current market spot price. In exchange for having this option, the buyer pays the seller or option writer a premium fee. By providing a guaranteed buyer and price for an underlying instrument, put options offer insurance against excessive loss [43].

\subsubsection{Binomial Tree and Option Pricing}

Option pricing of electricity has been a research subject of several researchers. Since the financial markets of electric power systems differ from traditional financial markets in certain important aspects, pricing and trading in 'electricity options' are challenging. Reference [44] considers the pricing of electricity swing options that hedge the electricity price risk and also partly the risks in the option owner's load pattern. Also [45] tries to use Black-Scholes formulation for electricity option pricing. Since there are no reliable option prices available, the most dependable way to analyze option pricing on electricity contracts is to estimate models for the underlying assets and, from these, derive the corresponding option 
prices [45]. "Given that many of the existing options on electricity contracts are, in fact, options on electricity forwards rather than on the actual spot price, this involves modeling both electricity spot and forward prices" [45]. In [46] the option price of spinning reserve is studied using the Black-Scholes formula. However no published study of Binomial option pricing has been found in any existing electricity market. Also the studies mentioned above consider the transaction between the demand (consumers) and supply (generators), and none of those was related to the transactions between generation companies. Furthermore, it is important to note that all existing published options literature deals with energy (commodity) and none with ancillary services such as reserves on an intra-day trade timeframe.

The binomial option pricing model was first proposed by Cox, Ross and Rubinstein in [47] and later was further discussed in [43]. Essentially, the model uses a "discrete-time" model of the changing price over time of the underlying financial instrument. The Binomial options pricing model approach is widely used because it is able to handle a variety of situations where other models cannot easily be applied. This is because the model is based on an underlying instrument over a period of time rather than a single point in time. As a consequence, it is used to value American options that are exercisable at any time in a given interval as well as Bermudan options that are exercisable at a specific time. Relatively simple, this model is easily implementable by computers. Although computationally slower than the Black-Scholes formula, it is more accurate, particularly for longer-dated options on securities with dividend payments [48]. In some literature like [49] the concept of trinomial tree instead of binomial tree in option pricing was investigated. However in this part of study we focus on the concept of binomial tree alone. Binomial trees are used in general when the evolution follows lognormal distribution. Fig. 1.4 shows a typical binomial option tree. $\mathrm{S}$ is 
the initial price of the stock or starting node. Each price node can move either upward or downward in the next time step. The upward coefficient is us and the downward coefficient is ds. The variable ps is the probability of stock price moving upward. In these equations, rs is one plus the interest rate for one step (1+interest rate). The variable $\sigma$ s is volatility of financial instrument for a specified period before expiration and $\mathrm{T}$ is the number of steps. The variable $t$ is the time period between the contract time and the maturity time divided by the time period of volatility calculation. In this study we calculate the volatility in such a way that $\mathrm{t}=1$. The tree can be built using [47]:

$$
\begin{aligned}
& u s=e^{\sigma s \sqrt{t / T}} \\
& d s=e^{-\sigma s \sqrt{t / T}} \\
& p s=(r s-d s) /(u s-d s)
\end{aligned}
$$

In general, one may write:

$[\mathrm{us}, \mathrm{ds}, \mathrm{ps}]=\mathrm{f}(\sigma \mathrm{s})$

The probability of reaching the $\mathrm{j}^{\text {th }}$ node in the final $\mathrm{T}^{\text {th }}$ time step is identified in the binomial tree. This value is: $\left(\frac{T !}{j !(T-j) !}\right) s^{j}(1-p s)^{T-j}$.

The $j^{\text {th }}$ node of the $T^{\text {th }}$ time step shows a possible value of the stock to be: $\mathrm{us}^{\mathrm{j}} \mathrm{ds}^{\mathrm{T}-\mathrm{j}} \mathrm{S}$. Accordingly, the deviation from the future stock price (or strike price) of $\mathrm{KS}$ at the $\mathrm{j}^{\text {th }}$ node in the final $\mathrm{T}^{\text {th }}$ time step is: $u \mathrm{~s}^{\mathrm{j}} \mathrm{ds}^{\mathrm{T}-\mathrm{j}} \mathrm{S}-\mathrm{KS}$. 


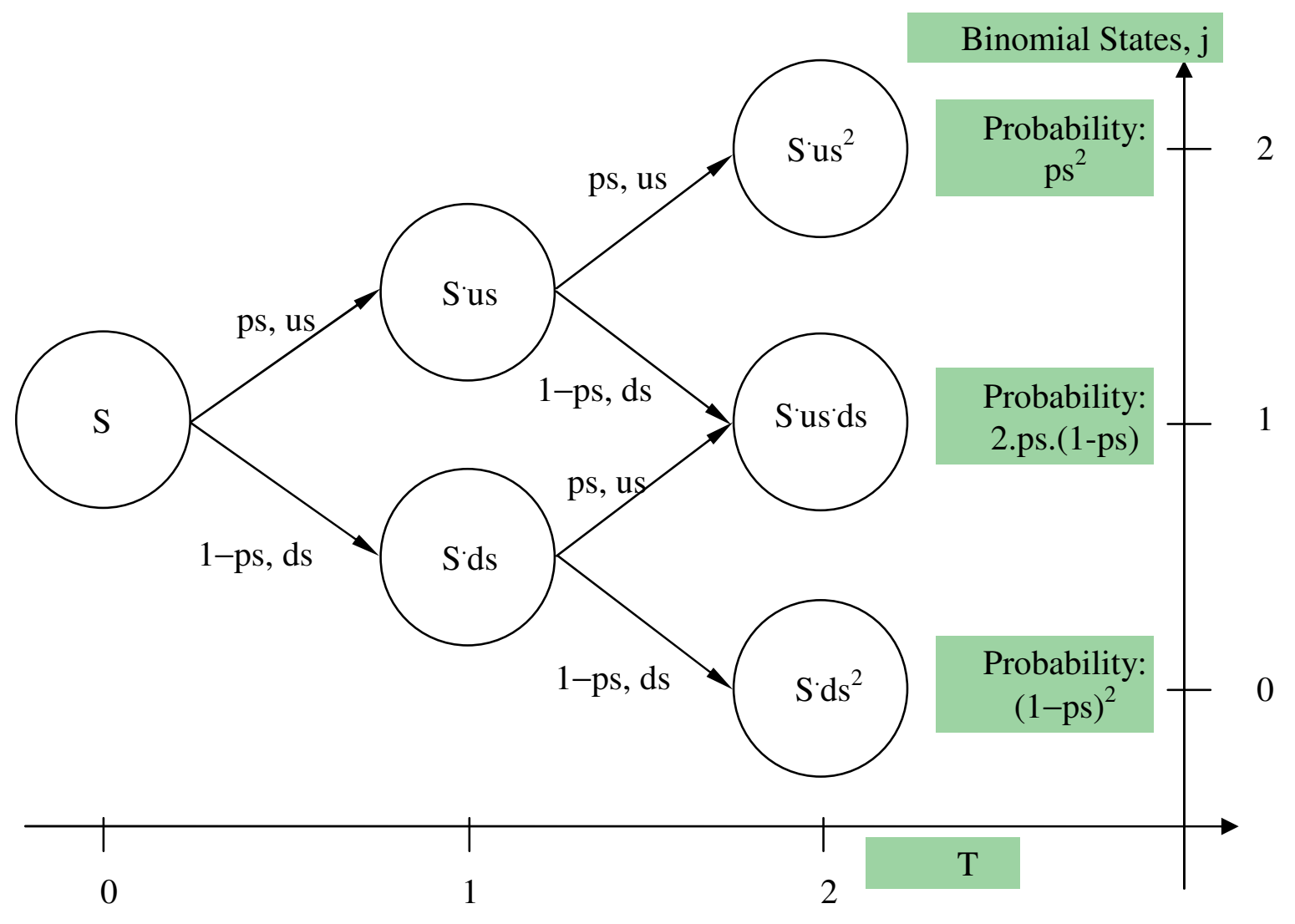

Fig. 1.4 Binomial tree for stock price ( $\mathrm{T}=2$ time steps). 


\subsubsection{Call Option}

When a party wishes to buy, then it would investigate a 'call option'. A call option, often simply labelled a "call", is a financial contract between two parties, the buyer and the seller of this type of option. The buyer of the call option has the right, but not the obligation to buy an agreed quantity of a certain commodity (the underlying) from the seller of the option at a certain time (the expiration date) for a certain price (the strike price). The seller (or "writer") is obligated to sell the commodity if the buyer decides to exercise the right to buy. The buyer pays a fee (called a premium or options price) for this right. In some cases the premium may become zero (premium neutral). The probable value for the call option at the $j^{\text {th }}$ node of the $\mathrm{T}^{\text {th }}$ time step can be calculated using the following equation considering a possible strike price of KSc for the call option:

$\frac{\mathrm{T} !}{\mathrm{j} !(\mathrm{T}-\mathrm{j}) !} \mathrm{ps}^{\mathrm{j}}(1-\mathrm{ps})^{\mathrm{T}-\mathrm{j}} \max \left\{0, \mathrm{us}^{\mathrm{j}} \mathrm{ds}^{\mathrm{T}-\mathrm{j}} \mathrm{S}-\mathrm{KSc}\right\} \quad \forall \mathrm{j}=0,1, \ldots \mathrm{T}$

From the above, it is obvious that certain nodes in the final time step (T) have no value. Now considering the entire final time step ( $\mathrm{T}^{\text {th }}$ time step), the total call option value can be computed as using (1.5):

$\mathrm{SC}=\sum_{\mathrm{j}=0}^{\mathrm{T}}\left[\frac{\mathrm{T} !}{\mathrm{j} !(\mathrm{T}-\mathrm{j}) !} \mathrm{ps} \mathrm{s}^{\mathrm{j}}(1-\mathrm{ps})^{\mathrm{T}-\mathrm{j}} \cdot \max \left[0, \mathrm{us} \mathrm{s}^{\mathrm{j}} \mathrm{ds}{ }^{\mathrm{T}-\mathrm{j}} \mathrm{S}-\mathrm{KSc}{\underset{\mathrm{rs}}{\mathrm{T}}}_{\frac{1}{\mathrm{~T}}}\right]\right.$

This value of SC reflects the premium, the buyer is expected to pay at time step zero to purchase the 'call option' (right to buy the stock) that would expire at the end of time period $\mathrm{T}$ at the call option strike price of KSc. 


\subsubsection{Put Option}

When a party wishes to sell, it investigates 'put option'. We may build the same tree for put option or simply labelled a "put". It is obvious that the put option has zero value if stock market price at a certain node is more than strike price.

A put is a financial contract between two parties. The buyer of the put option has the right, but not the obligation to sell an agreed quantity of a certain commodity (the underlying) to the seller of the option at a certain time (the expiration date) for a certain price (the strike price). The probable value for the call option at the $\mathrm{j}^{\text {th }}$ node of the $\mathrm{T}^{\text {th }}$ time step can be calculated using the following equation considering a possible put option strike price of $\mathrm{KSp}$ :

$\frac{\mathrm{T} !}{\mathrm{j} !(\mathrm{T}-\mathrm{j}) !} \mathrm{ps}^{\mathrm{j}}(1-\mathrm{ps})^{\mathrm{T}-\mathrm{j}} \max \left\{0, \mathrm{KSp}-\mathrm{us}^{\mathrm{j}} \mathrm{ds}^{\mathrm{T}-\mathrm{j}} \mathrm{S}\right\} \quad \forall \mathrm{j}=0,1, \ldots, \mathrm{T}$

From the above, it is obvious that certain nodes in the final time step ( $T^{\text {th }}$ time step), have no value. Now considering the entire final time step ( $\mathrm{T}^{\text {th }}$ time step), the total put option value can be computed as below using (1.7):

$\mathrm{SP}=\sum_{\mathrm{j}=0}^{\mathrm{T}} \frac{\mathrm{T} !}{\mathrm{j} !(\mathrm{T}-\mathrm{j}) !} \mathrm{ps}^{\mathrm{j}}(1-\mathrm{ps})^{\mathrm{T}-\mathrm{j}} \max \left[0, \mathrm{KSp}-\mathrm{us}^{\mathrm{j}} \mathrm{ds} \mathrm{s}^{\mathrm{T}-\mathrm{j}} \mathrm{S}\right] / \mathrm{rs}^{\mathrm{T}}$

This value SP reflects the premium, the seller is expected to pay at time step zero to purchase the 'put option' (right to sell the stock) that would expire at the end of time step T where the buyer has the right to buy at the put option strike price of KSp.

In summary, given a stock price ' $S$ ' and volatility os, one may create a binomial tree to predict changes in the stock price. The attributes of this binomial tree can be computed using (1.4). Collating information from the end nodes at the $\mathrm{T}^{\text {th }}$ time step, for given strike prices of 
$\mathrm{KSc}$ and KSp for call and put options respectively, one may determine premium values now at time zero to be SC and SP respectively.

\subsubsection{Black-Scholes Model and Option Pricing}

The Black-Scholes model for option pricing was first introduced in [50]. The formulae were developed by three economists Fischer Black, Myron Scholes and Robert Merton. It is perhaps globally the most widely used options pricing model. The Black-Scholes model is used to calculate the price of European put and call options on a particular stock, ignoring any dividends paid during the option's lifetime. The binomial tree model in finance is thoroughly discussed in [47], and [43]. The binomial model is a discrete-time model evaluating the stock price movements, in each time interval between price movements. The Black-Scholes model is a continuous model which can be used when the limiting distribution is considered as a lognormal distribution. In fact, if the number of time steps in binomial tree model approaches in to infinity, Black and Scholes and binomial models converge in to the same results. Binomial tree is very suitable in American options in which it is possible to exercise the right ahead of maturity time of option. The value of a call option premium on a stock in the Black-Scholes model can be calculated as a function of the following variables at hour t [50]:

$\mathrm{Cs}=\lambda \mathrm{s} . \mathrm{N}(\mathrm{d} 1 \mathrm{~s})-\mathrm{Ks} . \mathrm{e}^{-\mathrm{r} \cdot \mathrm{t}} \cdot \mathrm{N}(\mathrm{d} 2 \mathrm{~s})$

Where:

$$
\begin{aligned}
& \mathrm{d} 1 \mathrm{~s}=\frac{\ln (\lambda \mathrm{s} / \mathrm{Ks})+\left(\mathrm{r}+\sigma \mathrm{s}^{2} / 2\right) \cdot \mathrm{t}}{\sigma \mathrm{s} \sqrt{\mathrm{t}}} \\
& \mathrm{d} 2 \mathrm{~s}=\mathrm{d} 1 \mathrm{~s}(\mathrm{t})-\sigma \mathrm{s} \sqrt{\mathrm{t}}
\end{aligned}
$$


$\mathrm{N}(\mathrm{x} 0)$ is the cumulative distribution function of the standard normal distribution at point $\mathrm{x} 0$ :

$$
\left[\mathrm{N}(\mathrm{x} 0)=\frac{1}{\sqrt{2 \pi}} \int_{-\mathrm{inf}}^{\mathrm{x} 0} \mathrm{e}^{-\frac{1}{2} \mathrm{X}^{2}} \cdot \mathrm{dx}\right]
$$

The value of put option premium can be calculated using:

$$
\mathrm{Ps}=\mathrm{Cs}-\lambda \mathrm{s}+\mathrm{Ks} \cdot \mathrm{e}^{-\mathrm{r} \cdot \mathrm{t}}
$$

Volatility for a stock can be computed as shown below using a set of hourly historical values recorded for $\mathrm{TH}+1$ hour. Consider a set of stock price values, the volatility per hour may be computed as below:

$$
\sigma s=\sqrt{\frac{1}{\mathrm{TH}-1} \cdot \sum_{\mathrm{t}=1}^{\mathrm{TH}}\left[\ln \frac{\lambda \mathrm{s}(-\mathrm{t})}{\lambda \mathrm{s}(-\mathrm{t}-1)}-\left[\frac{1}{\mathrm{TH}} \sum_{\mathrm{t}=1}^{\mathrm{TH}} \ln \frac{\lambda \mathrm{s}(-\mathrm{t})}{\lambda \mathrm{s}(-\mathrm{t}-1)}\right]\right]^{2}}
$$

In theory the Black-Scholes model is only correct if the short term interest rate, rs is constant. In practice the formula is usually used with the interest rate, $\mathrm{r}$ being set as equal to the risk free interest rate on an investment that lasts for time $t$ [50]. When the stock price becomes very large, a call option is almost certain to be exercised and then becomes very similar to a forward contract because when $\lambda$ s becomes very large, $\mathrm{d} 1 \mathrm{~s}$ and $\mathrm{d} 2 \mathrm{~s}$ become very large too and therefore $\mathrm{N}(\mathrm{d} 1 \mathrm{~s})$ and $\mathrm{N}(\mathrm{d} 2 \mathrm{~s})$ are both close to one. Also when the stock price becomes very large, using the above analysis we can conclude that the put option would be zero i.e. the put option has no value. When the stock price becomes very small, $\mathrm{d} 1 \mathrm{~s}$ and $\mathrm{d} 2 \mathrm{~s}$ become very large negative values. $\mathrm{N}(\mathrm{d} 1 \mathrm{~s})$ and $\mathrm{N}(\mathrm{d} 2 \mathrm{~s})$ are both close to zero and call option price would be close to zero as well i.e. the call option has no value.

These financial engineering models of options contracts are used to develop secondary intra-day reserve market models to trade in reserves to overcome uncertainty in wind power production. 


\subsection{Energy Forecast Error Expectation}

\subsubsection{Wind Energy Forecast}

"Typically, meteorological models are used to produce wind speeds and these are converted to wind power output based on several engineering models of turbines. Weather models tend to produce overly smooth wind speeds (WWSIS 2008), so additional variability must be added in to represent fluctuations at the minute time scale." [55]. According to Ref. [58], a wind power forecast corresponds to an estimate of the expected production of one or more wind turbines (referred to as a wind farm) in the near future. By production we mean available power for the wind farm under consideration (with units $\mathrm{kW}$ or MW depending on the wind farm nominal capacity). Forecasts can also be expressed in terms of energy, by integrating power production over each time interval. Forecasting of the wind power generation may be considered at different time scales, depending on the intended application:

- From milliseconds up to a few minutes, forecasts can be used for the turbine active control. Such types of forecasts are usually referred to as very short-term forecasts.

- For the following 48-72 hours, forecasts are needed for the power system management or energy trading. They may serve for deciding on the use of conventional power plants (Unit commitment) and for the optimization of the scheduling of these plants (Economic dispatch). Regarding the trading application, bids are usually required during the morning of day $\mathrm{d}$ for day $\mathrm{d}+1$ from midnight to midnight. These forecasts are called short-term forecasts. For longer time scales (up to 5-7 days ahead), forecasts may be considered for planning the maintenance of wind farms, or conventional power plants or transmission lines. For the specific case of offshore wind farms maintenance costs may be prohibitive, and thus an 
optimal planning of maintenance operations is of particular importance. For the last two possibilities, the temporal resolution of wind power predictions ranges between 10 minutes and a few hours (depending on the forecast length). Lately, most of the efforts for improving wind power forecasting solutions have focused on using more and more data as input to the models involved, or alternatively on the providing of reliable uncertainty estimates along with the traditionally provided predictions[58].

\subsubsection{Wind Energy Forecast Errors}

In this thesis, four different models for energy forecast error are investigated. These models are the Gaussian, the Cauchy, the Binomial tree and the Black-Scholes mathematical models. Predicted near future energy absorbed by a specific wind farm in many researches is assumed to have a Gaussian distribution with a constant variance (No heteroskedasticity) i.e. it is assumed that the modeling errors are uncorrelated and normally distributed and that the variance does not vary with the effects being modeled. Many researches such as [51] to [53] made the same assumption for the amount of energy absorbed by a wind farm for a near future time span. However newer studies consider different models such as Hyperbolic and Cauchy. Early statistical approaches tend to assume that short-term fluctuations are distributed according to a Gaussian curve [55]. As an example the following graph in Fig. 1.5 shows the hourly wind power output and forecast wind power values for one week in the ERCOT system [56]. 


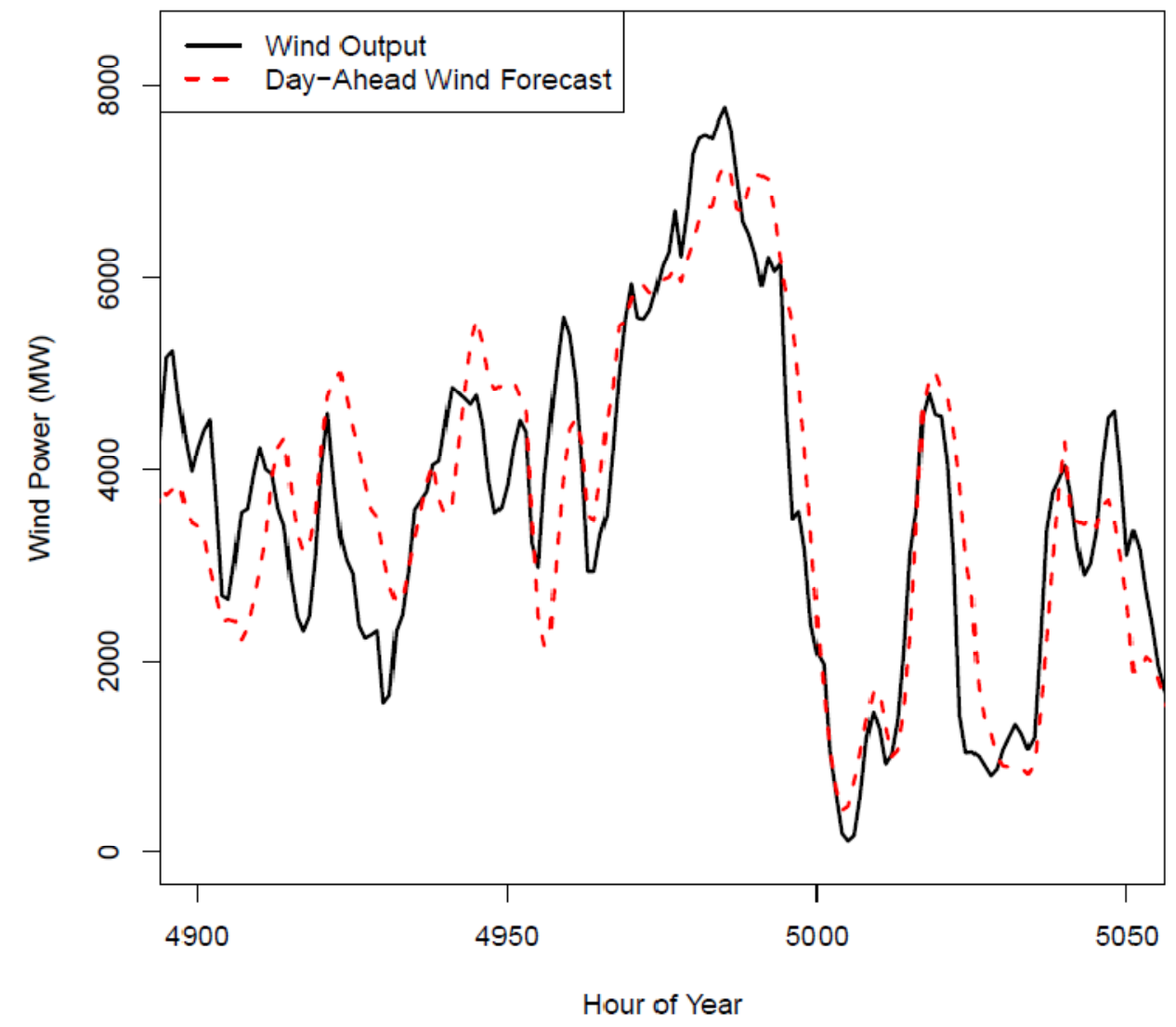

Fig. 1.5 Hourly wind power output and forecast wind power values for one week in the ERCOT system [56]. 


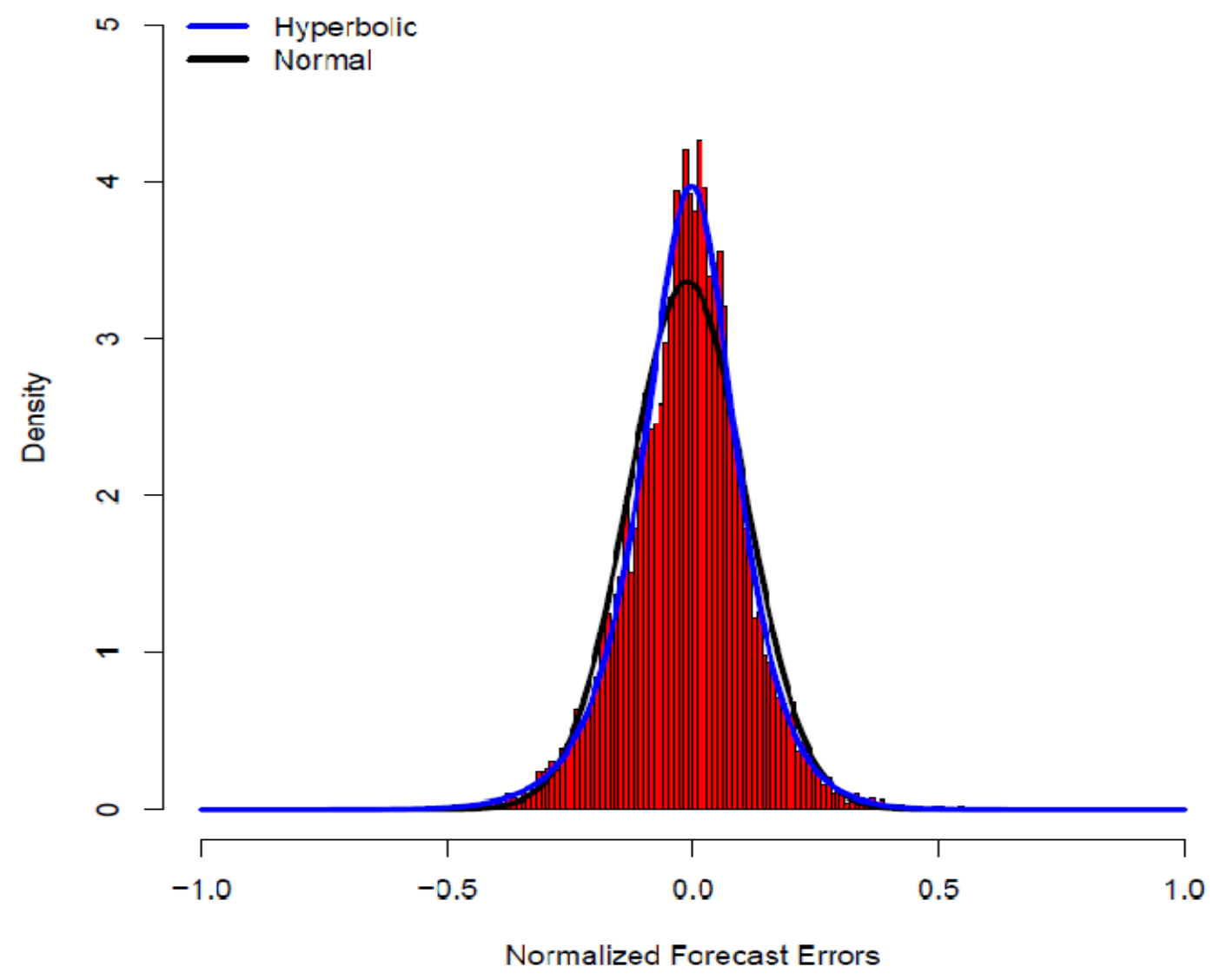

Fig. 1.6 The histogram of the distribution of day-ahead wind power forecasting errors for the ERCOT system [56]. 
Based on the above comparison, the histogram of the distribution of day-ahead wind power forecasting errors for the ERCOT system, normalized by the installed wind capacity is shown in Fig. 1.6 [56].

For the longer periods of forecast such as day ahead the forecast errors best matches with a hyperbolic distribution. "The load forecasting errors have larger kurtosis values, though kurtosis for wind power forecasting errors are very strongly dependent on the timescale of the forecast" [56]. We use Gaussian assumption to build our own model of reserve procurement as reported in Chapter 4. Ref. [54] compares several probability distribution functions including Gaussian, Weibull, Beta and Cauchy and concludes that Cauchy distribution appears to be the most natural fit. "While the Cauchy distribution produces more instances close to the mean than the normal distribution, it also has fat tails that indicate large deviations at the ends of the distribution, leading to narrow bounds for lower percentage confidence intervals and very wide bounds at high percentage confidence intervals".

In this dissertation, in addition to Gaussian and Cauchy distribution models, two more Energy Forecast Error distribution models, Binomial tree and Black-Scholes are investigated.

\subsection{Objectives of Dissertation and Chapter-wise Summary}

The aim of this research is to develop an intra-day secondary reserve market model and the associated theory. The secondary market is to procure reserve capacity to assist wind generators to overcome forecast errors. The reserve capacity is provided by providers such as

thermal generators, energy storage solutions, etc. Reserve providers output extra generation when wind generators fall short of forecast, which is termed as call option and wind generators call for reserves from reserve providers. Conversely, reserve providers absorb 
energy, which might be accomplished by reducing their output in case of thermal generators, when wind generators exceed forecast, which is termed as put option and wind generators output excess generation.

In summary, this research proposes a secondary reserve market for intra-day reserve trade between wind generators and reserve providers where wind generators purchase reserve from reserve providers to cover forecast errors, deficits or excess of wind energy, using Option Contract Theory concepts within a Power System optimization framework.

The intra-day wind power output forecast errors may be modeled using techniques such as Binomial Tree, Gaussian, Cauchy, etc. The reserve trade is formulated as options contract which may be modeled using Binomial Tree or Black and Scholes techniques. In this dissertation, several variants of intra-day secondary reserve market are developed using various combinations of wind power output forecast errors and options contract models. The following are the objectives of this research:

\subsubsection{Objective 1}

The first objective of this research (Chapter 2) is to develop an intra-day secondary reserve trade model considering one Wind Company and one Reserve provider. The basic secondary reserve market model is developed and presented. Options Contracts are built using a simple discrete Binomial Tree model. Wind energy forecast is computed using Binomial Tree for simplicity. This objective does not consider transmission network or its constraints. 


\subsubsection{Objective 2}

The second objective of this research (Chapter 3) is to develop an intra-day secondary reserve trade model considering several Wind Companies and several Reserve providers including security constraints to ensure that these models are physically feasible.

Options contracts in this objective are formulated using the discrete Binomial Tree model. In this objective the Cauchy model is used to model wind energy forecast errors. Given that numerous wind generators participate in this secondary market, numerous probabilistic situations are possible and hence, the market formulation results in a probabilistic optimization.Further, the transmission system is considered in this formulation so that network limits may be imposed and MVA flow limits may be observed. Relationships between network MVA limits and option pricing are examined.

\subsubsection{Objective 3}

The third objective of this research (Chapter 4) is to develop an intra-day secondary reserve trade model considering several Wind Companies and several Reserve providers including security constraints to ensure that these models are physically feasible. This step uses the Black-Scholes model for modeling options contracts and trade of reserves. Further, a Gaussian model for wind energy forecast error is used. A small size power system is assumed where all wind turbines have either underproduction or overproduction at the same time. The formulation considers the transmission system and its MVA flow limits. 


\subsubsection{Objective 4}

The fourth objective of this research (Chapter 5) is to develop an intra-day secondary reserve trade model considering several Wind Companies and several Reserve providers including security constraints to ensure that these models are physically feasible. This step uses the Black-Scholes model for formulating options contract model and trade of reserves.

Further, the Black-Scholes model is also used for wind energy forecast error modeling in a small size power system in which we assume that all wind turbines have either underproduction or overproduction at the same time. All formulations are coded and tested on Ontario wind farm cases to demonstrate efficacy of the proposed methods. Fig. 1.7 shows the block diagram connecting various chapters.

Chapter 2: Bilateral contract between one WindCo and one GenCo without network constraints.

Option model: $\quad$ Binomial Forecast error model: Binomial

Geographical size: No limit

\section{$\checkmark$}

Chapter 3: Secondary market includes several WindCos and several GenCos with network constraints.

Option model: $\quad$ Binomial $\quad$ Forecast error model: Cauchy

Geographical size: No limit

Chapter 4: Secondary market includes several WindCos and several GenCos with network constraints.

Option model: $\quad$ Black and Scholes $\quad$ Forecast error model: Gaussian

Geographical size: Small

Chapter 5: Secondary market includes several WindCos and several GenCos with network constraints.

Option model: $\quad$ Black and Scholes $\quad$ Forecast error model: Black and Scholes Geographical size: Small

Fig. 1.7 Block diagram of the dissertation 


\subsection{Chapter Summary}

This chapter introduces techno-economic challenges of wind energy integration into power systems arising out of wind power forecast uncertainties. Thereafter various forms of reserves are surveyed and their limitations are illustrated. Two widely used Option pricing methods - Binomial model and the Black-Scholes model - that are used in this research are introduced. Thereafter, models of errors in short-term wind energy forecast using Binomial tree, Black-Scholes technique, Cauchy and Gaussian models are surveyed. Finally objectives of this dissertation are presented. 


\section{Chapter 2: Options Based Reserve Procurement}

\section{Strategy for Wind Generators Using Binomial Trees}

\subsection{Introduction}

Wind is a mature form of renewable energy. Its intermittency poses technical and economic challenges. Technical challenges include load balancing, frequency regulation, etc. Economic challenges include providing least cost load balancing (reserves) services to these intermittent generators. This chapter and the rest of this dissertation consider a future electricity market situation wherein wind generators are required to forecast and bid to supply energy. The future electricity market treats wind generators similar to conventional generators penalizing for underproduction and paying poorly for overproduction. An intraday ( $<24$ hours) secondary market is proposed in this chapter where a wind generator and a reserve provider can bilaterally trade in reserves. Reserves are traded in the market by purchasing options to buy reserves at predetermined strike prices by paying premiums. These reserves include call and put options to address underproduction and overproduction. A binomial tree approach for estimating possible deviation from the forecast value is used. Further, a new optimization formulation is proposed that uses the binomial tree option pricing technique to determine optimal values of strike prices and premiums for call and put options. 


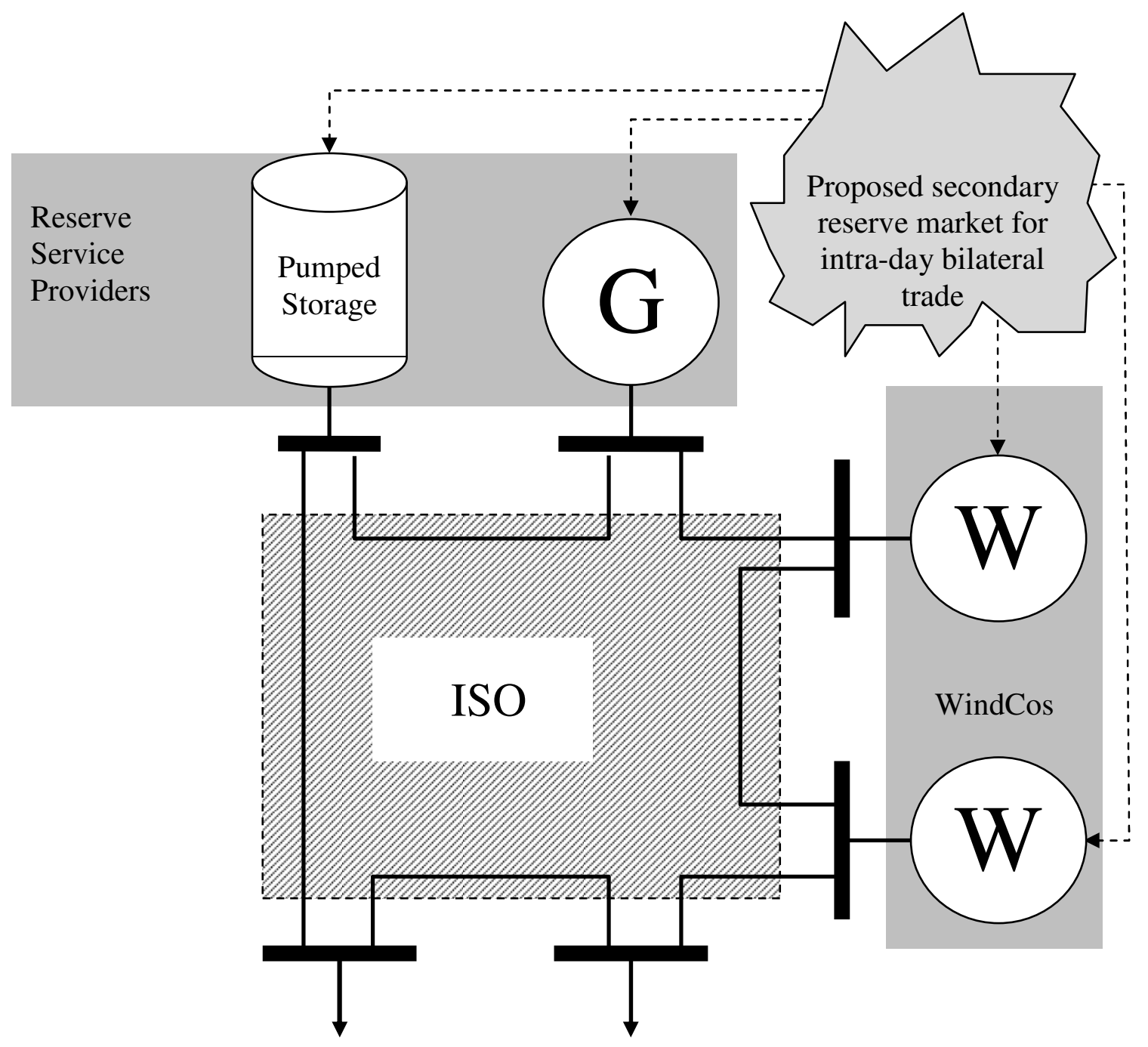

Fig. 2.1 Proposed secondary market 


\subsection{Proposed Model}

The proposed new model is shown in Fig. 2.1. This model intends to introduce a secondary market in which wind companies can buy reserve from reserve providers with a bilateral contract. The proposed secondary market model easily fits and complements commonly used electricity markets.

\subsection{The Options Model}

The issue of underproduction can be resolved by developing a market scheme that allows such facilities to buy the spinning reserve from other energy sources. A similar model for overproduction can also be used. Energy is a commodity and can be traded in the market. An "option" is a trading concept that is used to reduce the risk associated with buying or selling a commodity. The purpose of this research is to find proper financial tools in order to create a channel between renewable companies and other sources of reserves to reduce the effect of forecast uncertainty. In this direction, consider that the present forecasted value of spot price for the $\mathrm{T}^{\text {th }}$ hour is ' $\mathrm{m}$ '. Considering volatility in energy price equalling $\sigma \mathrm{m}$, similar to (1.4) one may compute the binomial tree values as below using:

$[\mathrm{um}, \mathrm{dm}, \mathrm{pm}]=\mathrm{f}(\sigma \mathrm{m})$

This binomial tree for the spot price of energy is shown in Fig. 2.2. Let the call option strike price for purchase of energy at the $\mathrm{T}^{\text {th }}$ hour be Kmc. Using the binomial tree, the differences between values at end nodes at the $T^{\text {th }}$ hour and call option strike price Kmc will determine the call option premium value. They are determined using (1.6) for call option as below: 
$\mathrm{mC}=\sum_{\mathrm{j}=0}^{\mathrm{T}} \frac{\mathrm{T} !}{\mathrm{j} !(\mathrm{T}-\mathrm{j}) !} \cdot \mathrm{pm}{ }^{\mathrm{j}} \cdot(1-\mathrm{pm})^{\mathrm{T}-\mathrm{j}} \cdot \max \left[0, \mathrm{um}^{\mathrm{j}} \cdot \mathrm{dm}{ }^{\mathrm{T}-\mathrm{j}} \cdot \mathrm{m}-\mathrm{Kmc}\right]$

Let the put option strike price for sale of energy at the $\mathrm{T}^{\text {th }}$ hour be Kmp. Using the binomial tree, the differences between values at end nodes at the $\mathrm{T}^{\text {th }}$ hour and put option strike price Kmp will determine put option premium value. They are determined using (1.8) for put options as below:

$m P=\sum_{j=0}^{T} \frac{T !}{j !(T-j) !} \cdot m^{j} \cdot(1-p m)^{T-j} \cdot \max \left[0, K m p-u m^{j} \cdot d m^{T-j} \cdot m\right]$

Because the financial transactions take place only a few hours ahead of real energy delivery, the interest rate factor which is an important factor in finance is not considerable here and is assumed to be equal to one. The value of $\mathrm{Kmc}$ and $\mathrm{Kmp}$ are the strike prices for call and put options respectively if reserves are used at the $\mathrm{T}^{\text {th }}$ hour. The values of $\mathrm{mC}$ and $\mathrm{mP}$ are premiums to be paid by the wind generator to the reserve provider at hour zero to obtain the right for call and put options. These values shall be determined through optimization process described in the next sections.

\subsection{Binomial Tree Model of Energy Forecast Error}

Wind Energy output from a wind turbine is forecasted in the near term and such forecasts have large errors. In this chapter, we propose the use of binomial trees to model potential variation of wind energy output from the forecasted value. This facilitates computing the amount of purchases or sales in call or put options respectively. 


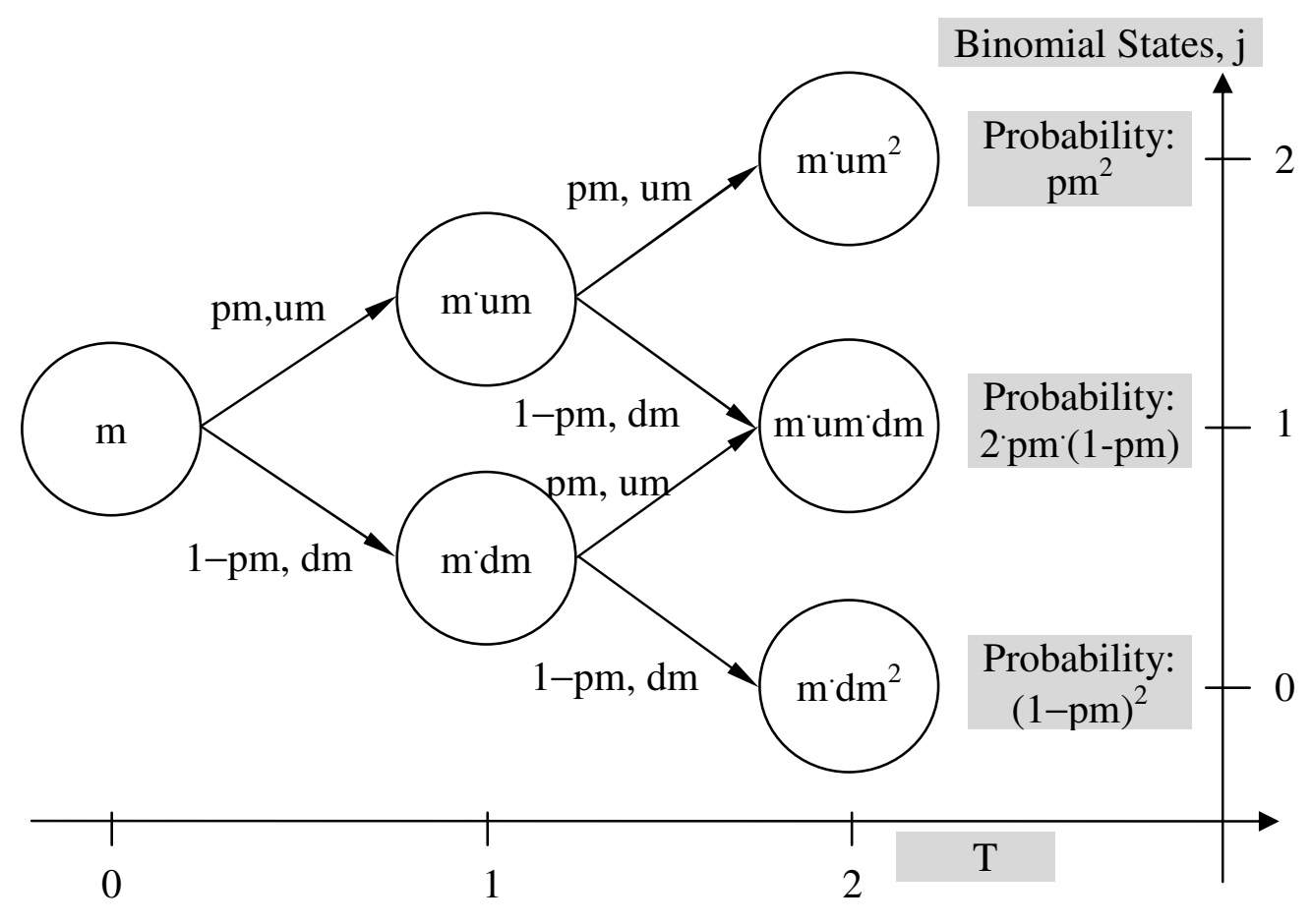

Fig. 2.2 Binomial tree for spot price of energy ( $\mathrm{T}=2$ time steps)

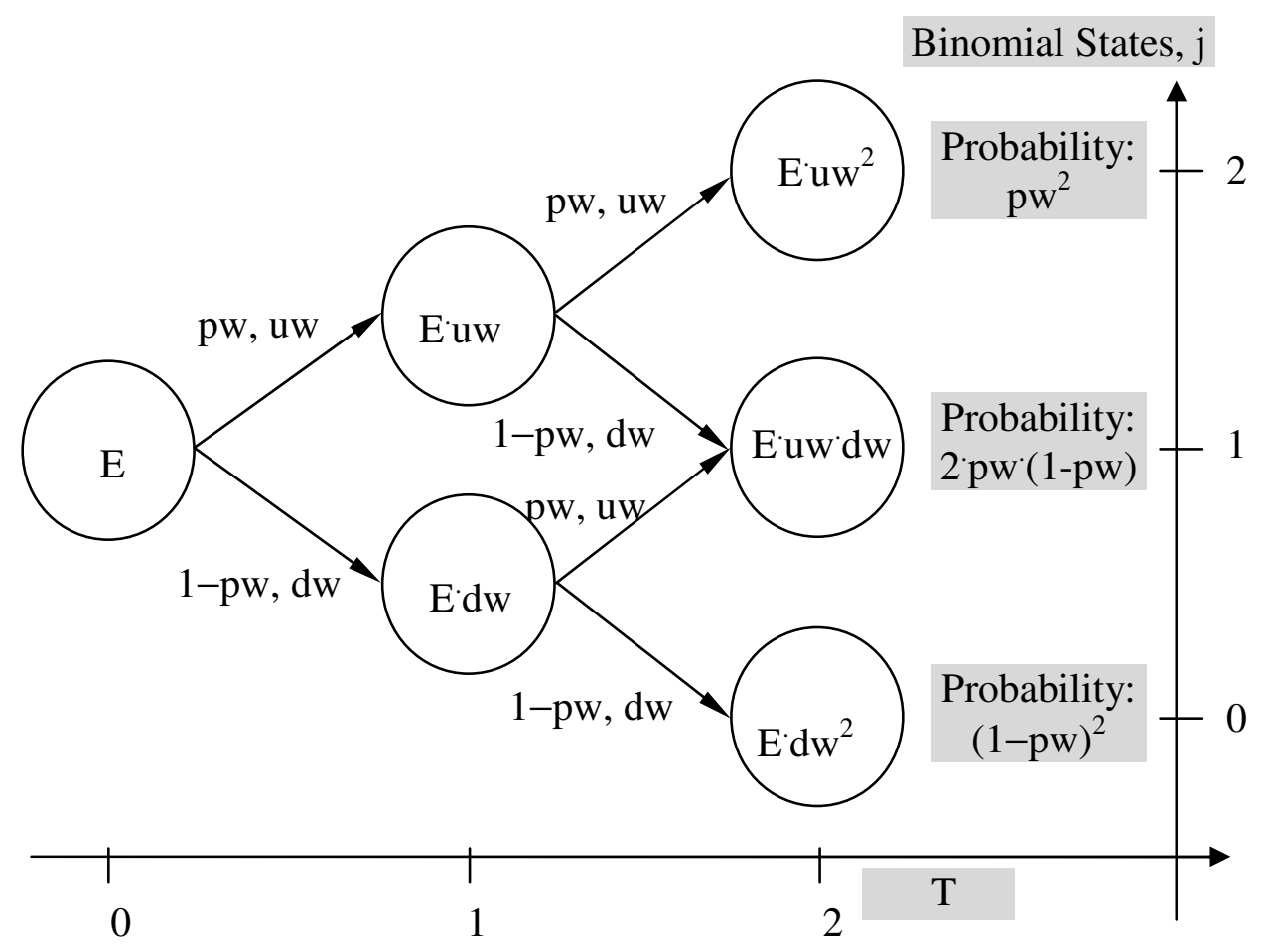

Fig. 2.3 Binomial tree for wind energy forecast error ( $\mathrm{T}=2$ time steps) 
Fig. 2.3 shows the evolution of a wind forecast Binomial tree. $\mathrm{E}$ is the present forecast of wind energy at $\mathrm{T}^{\text {th }}$ hour. Here energy is the variable just like stock market prices. The volatility is $\sigma \mathrm{w}$ and it is used to calculate the upward coefficient uw, the downward coefficient $\mathrm{dw}$ and the probability of moving upward pw. The relationships among these are determined as before:

$[\mathrm{uw}, \mathrm{dw}, \mathrm{pw}]=\mathrm{f}(\sigma \mathrm{w})$

Call options deal with underproduction. Hence it is expected that future values are lower than E. Hence we compare the energy values of the nodes in the $\mathrm{T}^{\text {th }}$ hour with $\mathrm{E}$. If the future value turns out to be less than $\mathrm{E}$, the expected deficit will be realized as:

$$
\overline{\mathrm{EC}}=\sum_{\mathrm{j}=0}^{\mathrm{T}}\left[\frac{\mathrm{T} !}{\mathrm{j} !(\mathrm{T}-\mathrm{j}) !} \mathrm{pw} \mathrm{w}^{\mathrm{j}}(1-\mathrm{pw})^{\mathrm{T}-\mathrm{j}} \cdot \max \left[0, \mathrm{E}-\mathrm{uw} \mathrm{w}^{\mathrm{j}} \mathrm{dw} \mathrm{w}^{\mathrm{T}-\mathrm{j}} \mathrm{E}\right]\right]
$$

Put options deal with overproduction. Hence we expect future values are higher than E. If the future value turns out to be higher than E, then, the put option will be realized. In general for T number of time steps the expected overproduction is:

$\overline{E P}=\sum_{j=0}^{T}\left[\frac{T !}{j !(T-j) !} p w^{j}(1-p w)^{T-j} \cdot \max \left[0, u w^{j} d^{T} w^{T-j} E-E\right]\right]$

\subsection{Proposed Formulation}

The players in the market, wind generator and reserve provider, must determine possible shortage or excess of energy in the $\mathrm{T}^{\text {th }}$ hour and determine optimal values of strike prices $\mathrm{Kmc}$ and $\mathrm{Kmp}$ and corresponding option prices (mC and $\mathrm{mP}$ ). These optimal values should maximize the profits of wind generator and reserve provider. 


\subsubsection{Objectives}

This section formulates objectives of the optimization problem. There are two possible scenarios, under and overproduction. These are dealt with hereunder to derive terms for the objectives.

\subsubsection{Underproduction}

This case will happen when the wind generator produces less than what it has committed to sell to the electricity market at the $\mathrm{T}^{\text {th }}$ hour, i.e. the committed energy E. The wind generator will potentially buy a call option contract from the reserve provider at a premium of $\mathrm{mC}$ and elect to use it in the case of actual shortfall at the strike price of kmc. Through this contract, both wind generator and reserve provider will gain. The premise of the gain stems from the fact that in the case of underproduction, if the wind generator does not have a contract with the reserve provider, it will have to buy the shortfall from the ISO at a rate $\mathrm{m}^{\prime}(1+\gamma)$. The factor $\gamma$ represents the additional costs (penalty) incurred by the ISO to arrange for this energy delivery at short notice. For a shortfall of EC then this will total to: EC $m \cdot(1+\gamma)$. On the other hand if the wind generator procures the shortfall directly from a reserve provider, it will cost the wind generator: $\mathrm{EC} \cdot(\mathrm{kmc}+\mathrm{mC})$. Therefore the wind generator profits from the avoidable loss equalling:

$\mathrm{GWC}=\mathrm{EC}[(1+\gamma) \cdot \mathrm{m}-(\mathrm{kmc}+\mathrm{mC})-\mathrm{CCC}]$

EC is the amount of energy in call option contracts which will be found through optimization as will be discussed later and it has a maximum and minimum given in (2.19). CCC is the Capacity Cost for Call option and is a function of market price and the amount of capacity to be purchased. In other words it is the price for each MWh of reserve capacity and can be 
formulated as:

$\mathrm{CCC}=\mu \cdot \mathrm{m} \cdot \mathrm{EC}$

The coefficient of $\mu$ may change in different times and markets. We choose $\mu=0.01 / \mathrm{MWh}$. It should be mentioned that the strike price, $\mathrm{kmc}$ is the price of actual energy (if the call option is exercised) and is different from the cost of reserve capacity.

At the same time, the thermal generators will gain from selling this energy to the wind generator as they get to sell EC amount of energy at a call option strike price of kmc and also receive a premium of $\mathrm{mC}$ instead of selling at the market rate of ' $\mathrm{m}$ '. Assuming that the same reserve provider is already scheduled by ISO as priority reserve provider, the profit for reserve provider is:

$\mathrm{GTC}=\mathrm{EC} \cdot(\mathrm{kmc}+\mathrm{mC}-\mathrm{m})$

A simple sharing formula that is based upon wind energy volatility and volume of energy being traded is suggested. By using this sharing formula, we can make sure that neither wind company or thermal company can earn more than A times of the other one's profit. It can be demonstrated as below:

$1 / \mathrm{A}<\mathrm{GWC} / \mathrm{GTC}<\mathrm{A}$

$\mathrm{A}=\mathrm{k} \cdot \sigma \mathrm{w} /\left|\left(1-\mathrm{e}^{\sigma \mathrm{w}}\right)\right|$

The following attributes were used to define the value of $\mathrm{A}$ as below:

(1) When wind energy volatility is zero, this profit ratio must not be a real number (No contract will exist).

(2) With increasing volatility, the profits should move from wind generator to the reserve service provider. 


\subsubsection{Overproduction}

This case will happen when the wind generator produces more than what it has committed to sell to the electricity market at the $\mathrm{T}^{\text {th }}$ hour; i.e. the committed energy $\mathrm{E}$.

The wind generator will potentially buy a put option contract from the reserve provider at a premium of $\mathrm{mP}$ and elect to exercise this contract at the strike price of $\mathrm{kmp}$ in the case of actual excess production. Through this contract, both wind generator and reserve provider will gain. The premise of the gain stems from the fact that in the case of overproduction, if the wind generator did not have a contract with the reserve provider, it would have to sell its overproduction to the ISO (independent system operator) at a rate m.(1- $\gamma)$. The factor $\gamma$ represents the additional costs incurred by the ISO to arrange for this energy absorption at short notice. For an excess of EP then this would amount to: EP.m. (1- $\gamma)$. On the other hand if the wind generator sells the overproduction directly to a reserve provider, it will be paid this amount: EP.(kmp - mP). Therefore the wind generator profits from the avoidable loss equalling

$\mathrm{GWP}=\mathrm{EP} \cdot[(\mathrm{kmp}-\mathrm{mP})-(1-\gamma) \cdot \mathrm{m}-\mathrm{CCP}]$

EP is the amount of energy in put option contract which will be found through optimization as will be discussed later. $\mathrm{CCP}$ is the Capacity Cost for Put option and is a function of market price and the amount of capacity. In other words it is the price for each MWh of negative reserve capacity and can be formulated as:

$\mathrm{CCP}=\mu \cdot \mathrm{m} \cdot \mathrm{EP}$

The coefficient of $\mu=0.01 / \mathrm{MWh}$ may change in different times and markets. It should be mentioned that the strike price, $\mathrm{kmp}$ is the price of actual energy (if the put option exercised) and is different from the cost of negative reserve capacity. 
At the same time, the reserve provider will gain from buying this energy from the wind generator as they get to sell EP amount of energy at a put option strike price of $\mathrm{kmp}$ and also receive a premium of $\mathrm{mP}$ instead of selling at the market rate of ' $\mathrm{m}$ '. The profit for the reserve provider will be:

$\mathrm{GTP}=\mathrm{EP} \cdot(\mathrm{m}+\mathrm{mP}-\mathrm{kmp})$

Just as in (2.11), a simple sharing formula is suggested that is based upon volatility and volume of energy:

$1 / \mathrm{A}<\mathrm{GWP} / \mathrm{GTP}<\mathrm{A}$

$\mathrm{A}=\mathrm{k} \cdot \sigma \mathrm{w} /\left|\left(1-\mathrm{e}^{\sigma \mathrm{w}}\right)\right|$

The objective of this proposed formulation is to maximize the avoidable costs for the wind generator both for call and put options caused by underproduction and overproduction scenarios respectively. Therefore maximum additional profits from avoided costs are:

Max: GWC + GWP

Subjected to:

Energy that might be required:

$\overline{E C}=\sum_{j=0}^{T}\left[\frac{T !}{j !(T-j) !} p w^{j}(1-p w)^{T-j} \cdot \max \left[0, E-u w^{j} d w^{T-j} E\right]\right]$

This constraint limits the amount of purchased energy for underproduction:

$0<\mathrm{EC}<\overline{\mathrm{EC}}$

$\overline{\mathrm{EP}}=\sum_{j=0}^{\mathrm{T}}\left[\frac{\mathrm{T} !}{\mathrm{j} !(T-j) !} \mathrm{pw}^{\mathrm{j}}(1-\mathrm{pw})^{\mathrm{T}-\mathrm{j}} \cdot \max \left[0, \mathrm{uw}^{\mathrm{j}} \mathrm{dw^{T-j }} \mathrm{E}-\mathrm{E}\right]\right]$

This constraint limits the amount of sold energy for overproduction:

$0<\mathrm{EP}<\overline{\mathrm{EP}}$ 
Reserve Provider Profits:

$\mathrm{GTC}=\mathrm{EC} \cdot(\mathrm{kmc}+\mathrm{mC}-\mathrm{m})$

$\mathrm{GTP}=\mathrm{EP} \cdot(\mathrm{m}+\mathrm{mP}-\mathrm{kmp})$

Profit sharing Constraints:

$1 / \mathrm{A}<\mathrm{GWC} / \mathrm{GTC}<\mathrm{A}$

$1 / \mathrm{A}<\mathrm{GWP} / \mathrm{GTP}<\mathrm{A}$

In which:

$\mathrm{A}=\mathrm{k} \cdot \sigma \mathrm{w} /\left|\left(1-\mathrm{e}^{\sigma \mathrm{w}}\right)\right|$

Call and Put Option Premium Costs:

$m C=\sum_{j=0}^{T}\left[\frac{T !}{j !(T-j) !} p^{j}(1-p m)^{T-j} \cdot \max \left[0, u^{j} d^{T-j} m-K m c\right]\right.$
$m P=\sum_{j=0}^{T}\left[\frac{T !}{j !(T-j) !} p^{j}(1-p m)^{T-j} \cdot \max \left[0, K m p-u^{j} m^{j} m^{T-j} m\right]\right.$

By maximizing (2.17) subject to (2.18) to (2.28) we can reach the optimal values of energy and prices.

\subsection{Results and Analysis}

\subsubsection{Simple Case}

The proposed method is programmed to optimally price and procure reserves considering arbitrary wind energy volatility values from 0.6 to 1.0 in steps of 0.1 and market volatility values from 0.1 to 0.3 in steps of 0.05 and $\mathrm{k}=5$. Table 2.1 provides details of data used in this problem. 
Table 2.1 Data for example 1

\begin{tabular}{|l|l|}
\hline Constant & Quantity \\
\hline $\mathrm{m}$ & $\$ 60 / \mathrm{MWh}$ \\
\hline$\sigma \mathrm{m}$ & 0.1 to 0.3 \\
\hline$\sigma \mathrm{w}$ & 0.6 to 1.0 \\
\hline
\end{tabular}

\begin{tabular}{|l|l|}
\hline Constant & Quantity \\
\hline $\mathrm{E}$ & $100 \mathrm{MWh}$ \\
\hline$\gamma$ & 0.5 \\
\hline $\mathrm{T}$ & 4 hours \\
\hline
\end{tabular}

On optimizing by solving the proposed formulation presented in (2.17)-(2.28), the solution provides optimal values of strike prices, amount of energy to be purchased or sold and premiums for call and put options for a given wind energy volatility $(\sigma w)$ and market price volatility $(\sigma \mathrm{m})$. Fig. 2.4 and 2.5 provide details of variations in the call and put strike prices respectively with changing wind and market volatility. As the volatility increases, larger uncertainty results in corresponding larger possible deviation from forecasted wind power output. It is clearly seen that as the volatility (uncertainty) increases, the call strike prices become more favourable to the reserve provider for smaller market volatility values (Fig. 2.4). Similarly, a larger volatility and larger volume of uncertain energy results in lower put strike prices for smaller market volatility values (Fig. 2.5). The formulation of $(2.17)-(2.28)$ when solved maximizes the sum of avoidable costs for wind generator for both cases: when there is (1) underproduction (call option) and (2) overproduction (put option) for a given wind/market volatility. The graph in Fig. 2.6 depicts these optimal values for various wind and market volatility values. The descending shape of avoidable costs for smaller market volatility values is due to the fact that larger wind volatility results in larger reserve capacity cost payable to the thermal unit. Fig. 2.7 and 2.8 depict the variation of premiums in this example. 


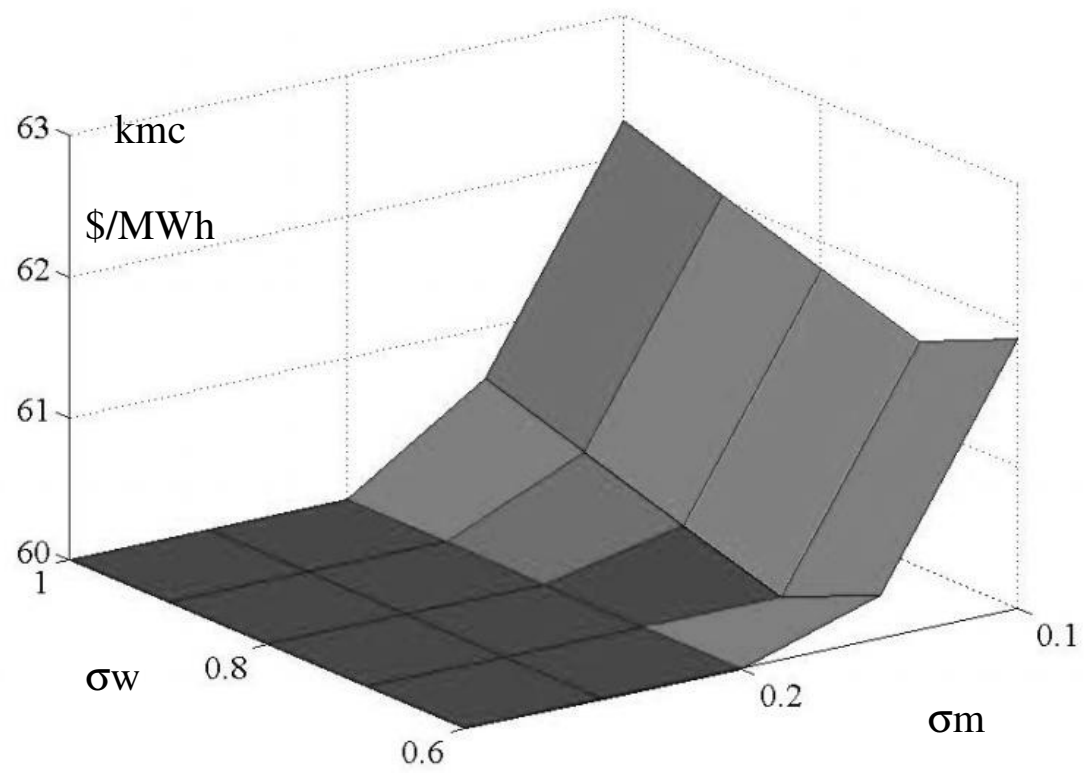

Fig. 2.4 Wind and market volatility versus call strike prices

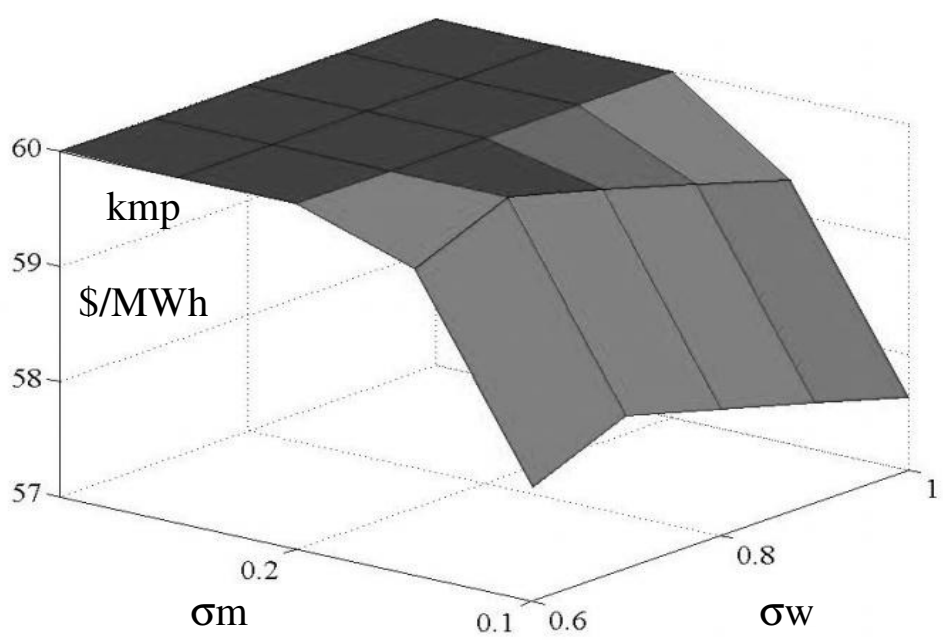

Fig. 2.5 Wind and market volatility versus put option strike prices 


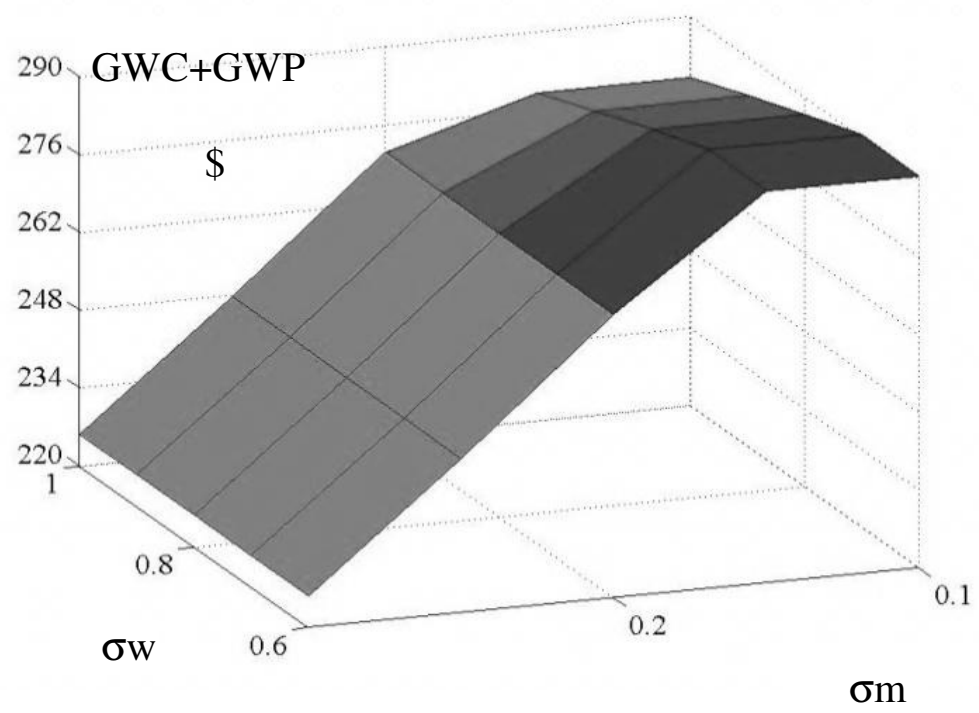

Fig. 2.6 Optimal values of avoidable costs of wind generator for various wind and market volatility values

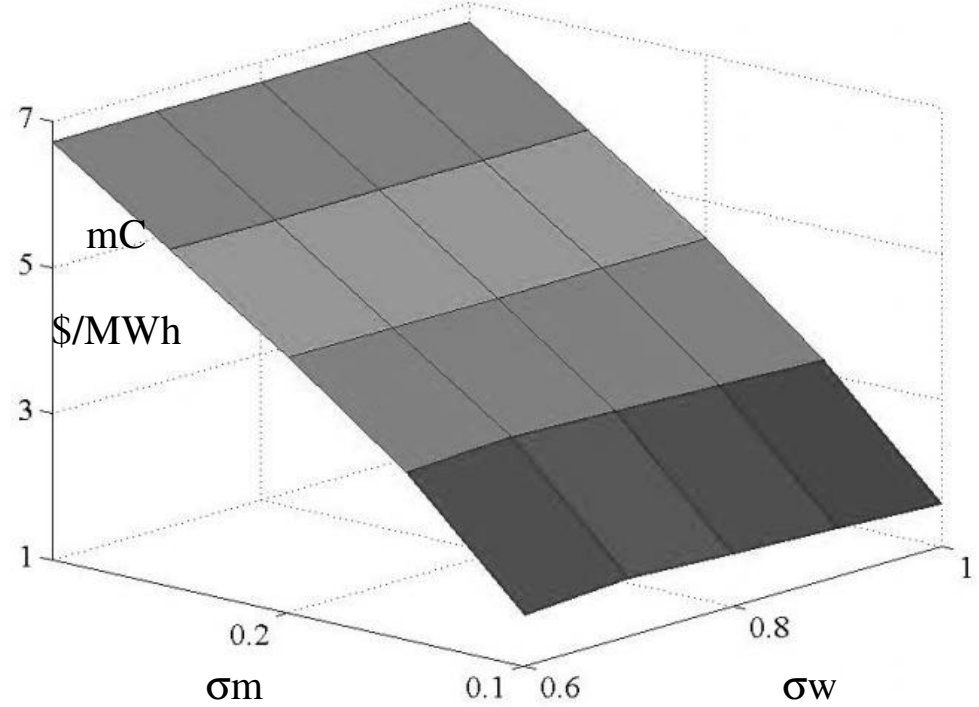

Fig. 2.7 Optimal values of call option premiums 


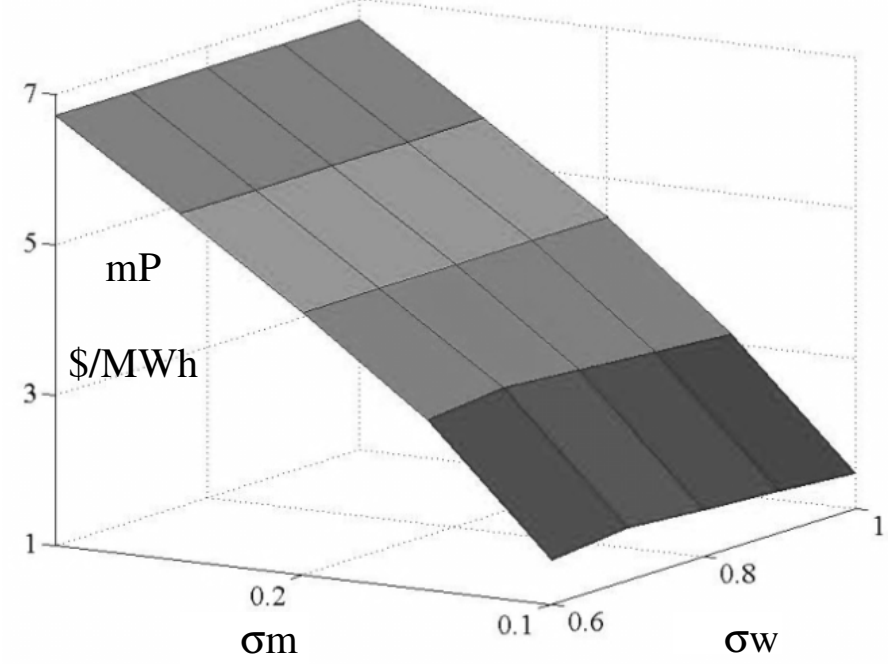

Fig. 2.8 Optimal values of put option premiums 


\subsubsection{Ontario Wind Farm Example}

In this example, actual wind energy produced by Port Alma wind farm in Ontario, Canada is used for analysis [57]. It is assumed that 5 separate call and put contracts are needed for 5 consecutive dates of March 1, 2012 to March 5, 2012. All contracts are needed for each day at 13:00 hours and must be made 4 hours ahead at 9:00 hours. Fig. 2.9 shows recorded data of wind energy injected to the grid for 12 hours prior to the contract time (9:00 hours). Fig. 2.10 shows recorded nodal prices of energy at Port Alma for 12 hours prior to the contract time (9:00 hours).

The above 12 hours data is used to calculate both energy and market historical volatility values for each contract. Historical volatility is a statistical calculation that tells option traders how rapid price movements have been over a given period. The most common method of calculating historical volatility is called the Standard Deviation. Standard Deviation measures the dispersion of a set of data points from its average. The more disperse (spread out) the data is, the higher the deviation. This deviation is referred as historical volatility. The historical data in this Chapter is assumed to have a log-normal distribution. For example if market price at 1:00 hours is 19.86 \$/MWh and at 2:00 hours is 20.82 $\$ / \mathrm{MWh}$, the logarithmic change is $\ln (20.82 / 19.86)=0.047$. After calculating logarithmic change at each hour, it is possible to calculate the historical volatility. In general if $\mathrm{N}+1$ is the

number of points in the historical data and $S_{n}$ is stock price at end of $n^{\text {th }}$ interval and $T$ is number of time steps from contract to maturity, we can define SA:

$$
\mathrm{SA}=\left[\frac{1}{\mathrm{~N}} \sum_{\mathrm{n}=1}^{\mathrm{N}} \ln \frac{\mathrm{S}_{\mathrm{n}+1}}{\mathrm{~S}_{\mathrm{n}}}\right]
$$




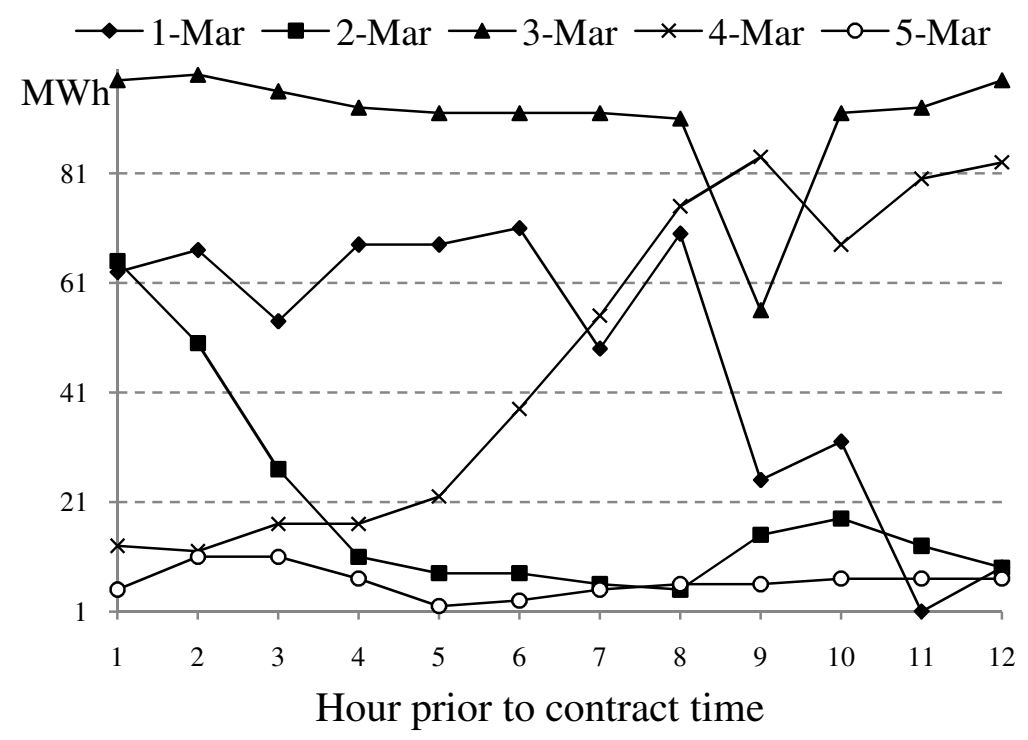

Fig. 2.9 Recorded data of wind energy injected to the grid at Port Alma for 12 hours prior to the contract time (9:00 hours)

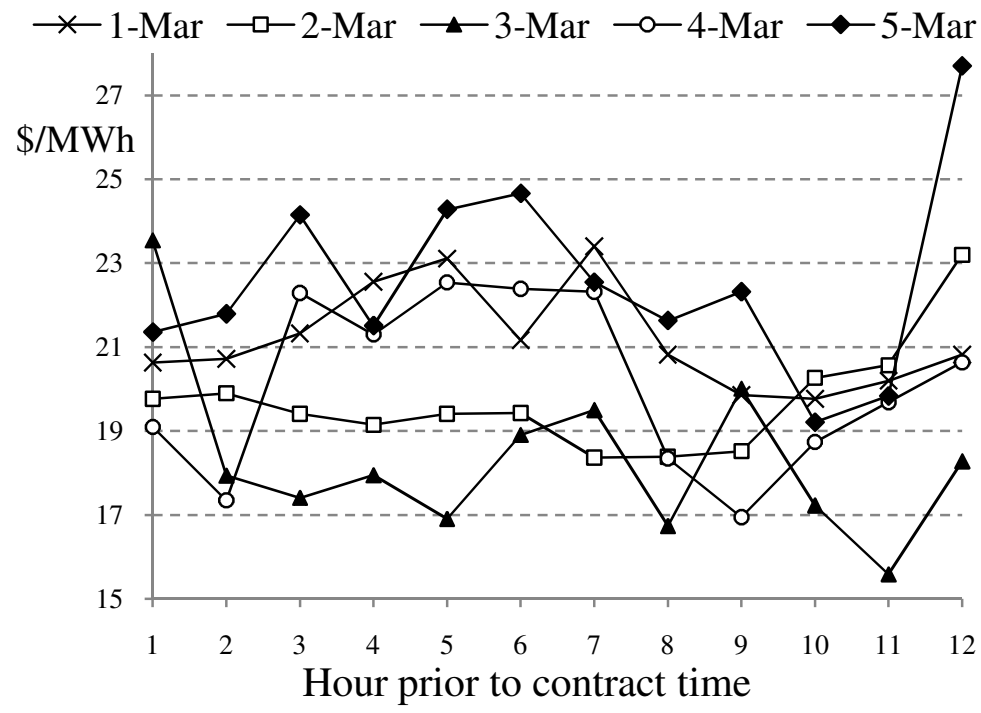

Fig. 2.10 Recorded data of market nodal prices at Port Alma for 12 hours prior to the contract time (9:00 hours) 
And calculate stock price volatility as below:

$\sigma S=\sqrt{\frac{T}{N-1} \cdot \sum_{n=1}^{N}\left[\left(\ln \frac{S_{n+1}}{S_{n}}\right)-S A\right]^{2}}$

In this example, $\mathrm{T}=4$ and $\mathrm{N}=12$. The same concept is used to calculate wind energy forecast error historical volatility. The calculated price and energy volatility values are shown in Table 2.3. The forecasted values (prepared by forecasting organizations) and the actual values (what really happened at that time) of wind energy and market price for 13:00 hours for each day is shown in Table 2.4. On optimizing by solving the proposed formulation presented in (2.17)-(2.28), the solution provides optimal values of strike prices, amount of energy to be purchased or sold and premiums for call and put options for each day (Mar 1 to Mar 5, 2012) at 13:00 hours. The penalty and discount factor is assumed to be similar to Example 1. Fig. 2.11 shows the optimal call and put option strike prices for each day and Fig. 2.12 shows the forecasted profit of the wind generator and the reserve service provider for each day at 13:00 hours. Fig. 2.13 shows the actual revenue of wind generator with and without contract using the actual wind energy amounts and market prices that occurred at 13:00 hours of each day (Table 2.4). It is obvious that on March $1^{\text {st }}$ and $2^{\text {nd }}$ at 13:00 hours, wind generator over produced and on March $3^{\text {rd }}$ to $5^{\text {th }}$ at 13:00 hours, wind generator under produced. In order to calculate the actual revenue of wind generator, we must compare the total energy available and the total energy contracted for each day at 13:00 hours. Taking mA as the actual value of market price at 13:00 hours and EA as the actual value of wind energy available at 13:00 hours, two cases each might exist for under and over production scenarios. These cases are outlined in Table 2.2. 
Table 2.2 Revenue of Wind Generator in different scenarios

\section{Underproduction Revenue $(\mathrm{EA}<\mathrm{E})$}

No contract

Revenue $=\mathrm{mA} \cdot \mathrm{EA}-(1+\gamma) \cdot \mathrm{mA} \cdot(\mathrm{E}-\mathrm{EA})$

\section{With Contract}

Case 1: $\mathrm{EA}+\mathrm{EC}<\mathrm{E}$

Revenue $=\mathrm{mA} \cdot(\mathrm{EA}+\mathrm{EC})-(\mathrm{Kmc}+\mathrm{mC}+\mathrm{CCC}) \cdot \mathrm{EC}-(1+\gamma) \cdot \mathrm{mA} \cdot(\mathrm{E}-\mathrm{EA}-\mathrm{EC})$

Case 2: $\mathrm{EA}+\mathrm{EC}>\mathrm{E}$

Revenue $=\mathrm{mA} \cdot \mathrm{E}-(\mathrm{Kmc}+\mathrm{mC}+\mathrm{CCC}) \cdot \mathrm{EC}-(1-\gamma) \cdot \mathrm{mA} \cdot(\mathrm{E}-\mathrm{EA}-\mathrm{EC})$

\section{Overproduction Revenue $(\mathrm{EA}>\mathrm{E})$}

\section{No Contract}

Revenue $=\mathrm{mA}^{\cdot} \mathrm{E}-(1-\gamma)^{\prime} \mathrm{mA} \cdot(\mathrm{E}-\mathrm{EA})$

\section{With Contract}

Case 1: $\mathrm{EA}-\mathrm{EP}>\mathrm{E}$ :

Revenue $=\mathrm{mA} \cdot \mathrm{E}+(\mathrm{Kmp}-\mathrm{mP}-\mathrm{CCP}) \cdot \mathrm{EP}-(1-\gamma)^{\cdot} \mathrm{mA} \cdot(\mathrm{E}-\mathrm{EA}+\mathrm{EP})$

Case 2: $\mathrm{EA}-\mathrm{EP}<\mathrm{E}$ :

Revenue $=\mathrm{mA} \cdot(\mathrm{EA}-\mathrm{EP})+(\mathrm{Kmp}-\mathrm{mP}-\mathrm{CCP}) \cdot \mathrm{EP}-(1+\gamma) \cdot \mathrm{mA} \cdot(\mathrm{E}-\mathrm{EA}+\mathrm{EP})$ 
Table 2.3 Port Alma energy and price volatility values

\begin{tabular}{|c|c|c|c|c|c|}
\hline $\begin{array}{l}\text { Date: } \\
\text { at 13:00 hours }\end{array}$ & $\begin{array}{l}01 \text { Mar } \\
2012\end{array}$ & $\begin{array}{l}02 \text { Mar } \\
2012\end{array}$ & $\begin{array}{l}03 \text { Mar } \\
2012\end{array}$ & $\begin{array}{l}04 \text { Mar } \\
2012\end{array}$ & $\begin{array}{r}05 \text { Mar } \\
2012\end{array}$ \\
\hline $\begin{array}{c}\text { Volatility of wind energy } \\
\text { forecast error }(\sigma \mathrm{E})\end{array}$ & 2.682 & 1.019 & 0.441 & 0.446 & 1.071 \\
\hline $\begin{array}{l}\text { Volatility of reserve price } \\
\qquad(\sigma \mathrm{m})\end{array}$ & 0.125 & 0.099 & 0.282 & 0.233 & 0.267 \\
\hline
\end{tabular}

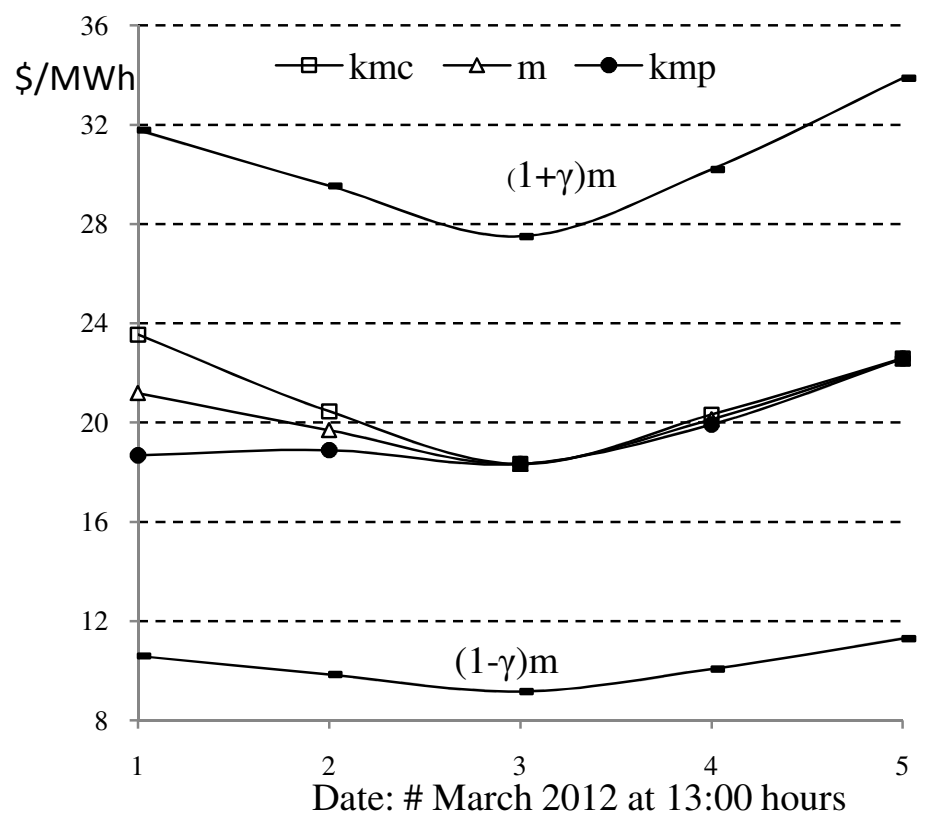

Fig. 2.11 Daily Variation of strike prices and market price at 13:00 hours during March 1, 2012 to March 5, 2012 


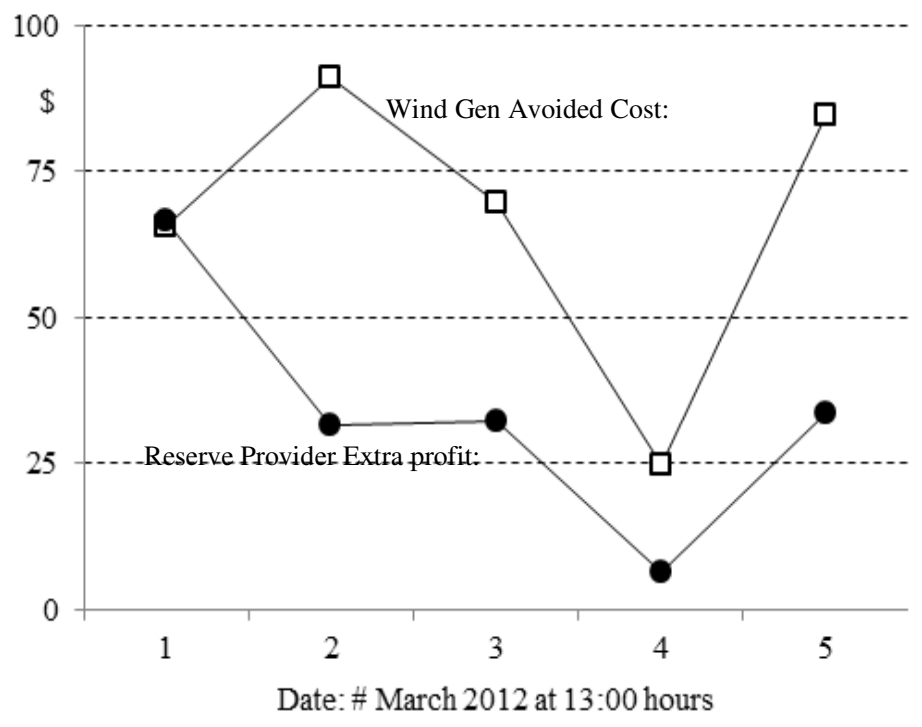

Fig. 2.12 Daily Variation of Call and put option forecasted profits of both entities at 13:00 hours during March 1, 2012 to March 5, 2012

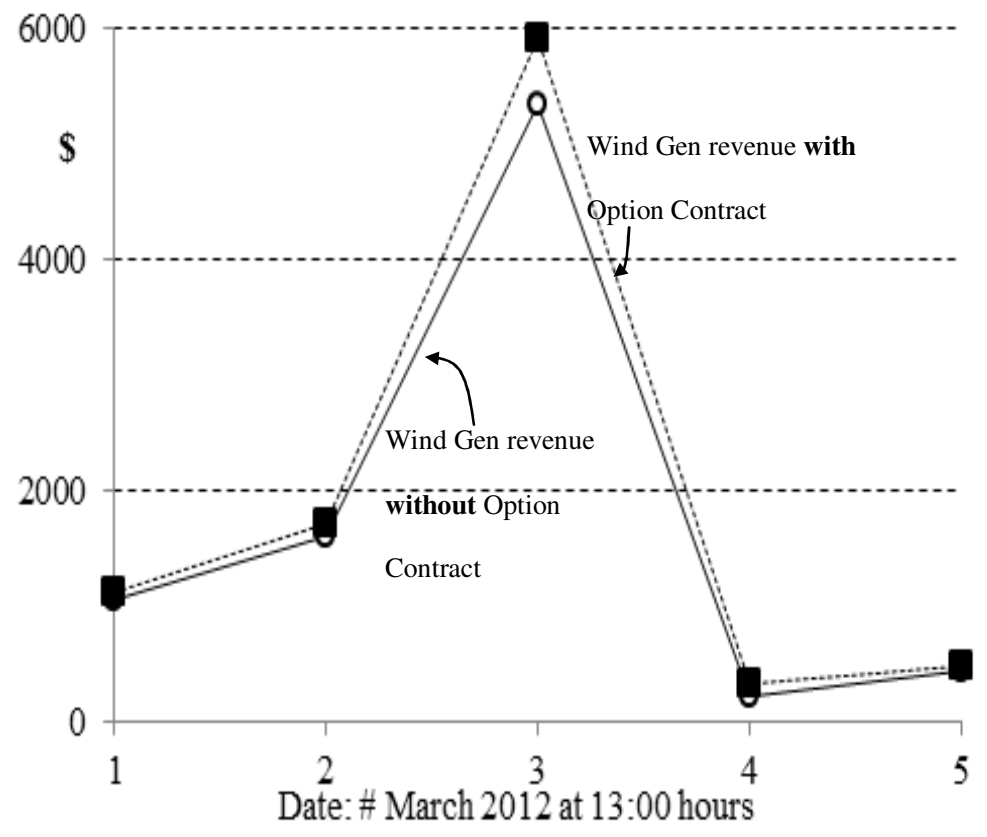

Fig. 2.13 Actual revenues for wind generator with and without option contract 
Table 2.4 Port Alma actual and forecasted data

\begin{tabular}{|c|c|c|c|c|c|}
\hline $\begin{array}{l}\text { Date: \# March } 2012 \\
\text { at 13:00 hours }\end{array}$ & $\begin{array}{l}01 \text { Mar } \\
2012\end{array}$ & $\begin{array}{l}02 \text { Mar } \\
2012\end{array}$ & $\begin{array}{l}03 \text { Mar } \\
2012\end{array}$ & $\begin{array}{l}04 \text { Mar } \\
2012\end{array}$ & $\begin{array}{l}05 \text { Mar } \\
2012\end{array}$ \\
\hline $\begin{array}{l}\text { Actual Energy } \\
\text { EA (MWh) }\end{array}$ & 63 & 96 & 98 & 16 & 32 \\
\hline $\begin{array}{l}\text { Actual Price } \\
\mathrm{mA}(\mathrm{S} / \mathrm{MWh})\end{array}$ & 21.65 & 19.38 & 58.12 & 20.62 & 20.8 \\
\hline $\begin{array}{l}\text { Forecasted Energy } \\
\qquad \mathrm{E}(\mathrm{MWh})\end{array}$ & 35 & 70 & 102 & 20 & 39 \\
\hline $\begin{array}{c}\text { Forecasted Price } \\
\mathrm{m}(\mathrm{S} / \mathrm{MWh})\end{array}$ & 21.19 & 19.69 & 18.33 & 20.13 & 22.58 \\
\hline $\begin{array}{l}\text { Optimally Procured Call option Reserve } \\
\qquad \text { EC (MWh) }\end{array}$ & 25 & 25 & 16.75 & 3.32 & 14.95 \\
\hline $\begin{array}{l}\text { Optimally Procured Put option Reserve } \\
\qquad \text { EP (MWh) }\end{array}$ & 25 & 25 & 16.75 & 3.32 & 14.95 \\
\hline $\begin{array}{c}\text { Case \# } \\
\text { (Refer to Table 2.2) }\end{array}$ & $\begin{array}{c}1 \\
\text { Over } \\
\text { Prod. }\end{array}$ & $\begin{array}{c}1 \\
\text { Over } \\
\text { Prod. }\end{array}$ & $\begin{array}{c}2 \\
\text { Under } \\
\text { Prod. }\end{array}$ & $\begin{array}{c}1 \\
\text { Under } \\
\text { Prod. }\end{array}$ & $\begin{array}{c}2 \\
\text { Under } \\
\text { Prod. }\end{array}$ \\
\hline $\begin{array}{l}\text { Difference in Revenue with and without } \\
\text { contract }\end{array}$ & $\$ 59.9$ & $\$ 95.1$ & $\$ 560.8$ & $\$ 109.8$ & $\$ 24.9$ \\
\hline
\end{tabular}


As shown in Table 2.4, on March 1st and $2^{\text {nd }}$ there was overproduction with the condition of case 1 of Table 2.2. On March $3^{\text {rd }}$ and $5^{\text {th }}$ there was underproduction with the condition of Case 2 of Table 2.2 and on March $4^{\text {th }}$ there was underproduction with the condition of Case 1 of Table 2.2. The results show that in the five-day period of study and only for 13:00 hours of each day, the wind generator can save the total amount of $\$ 850.5$ by using the proposed method. It must be noted that if the wind company decides to go with both call and put contracts for each hour, an extra premium cost per hour and an extra capacity cost per hour must be deducted from its total revenue.

\subsection{Chapter Summary}

This chapter is targeted to address challenges faced by wind generators due to their production uncertainties in a future electricity market that is devoid of market subsidies to wind energy and develop an appropriate mitigation strategy. Towards this end, an intra-day secondary market for procuring reserves by intermittent renewable generators to overcome forecast uncertainties and market participation commitment deviations is proposed. Electricity market spot prices and wind energy output forecasts are propagated through binomial trees characterized by volatility to determine possible deviations in committed energy to the market. Call options are used to procure energy from the reserve provider in cases of underproduction by wind generator. In the event of overproduction by the wind generator, put options are used to sell excess production to the reserve provider. In both cases of call (underproduction) and put (overproduction) options, both the wind generator and the reserve provider benefit by getting a better economic return than that offered by the ISO that applies a penalty for the wind generator and market rate for the reserve provider. Option 
pricing strategies are used to relate volatility in energy prices to call and put option strike prices and associated premium costs. These relationships are used to formulate an optimization problem that optimizes strike prices, premium costs and amount of reserve to be purchased or sold for call and put options such that profits of the wind generator and the reserve service provider are maximized. Two illustrative examples demonstrate the benefit of creation of this intra-day secondary market. The results demonstrate how the wind generator's eroded profits in the face of increasing forecast uncertainties can be restored by taking optimal mitigating actions - procuring reserve options through the proposed secondary market. 


\section{Chapter 3: Network Constrained Model for Options Based Reserve Procurement by Wind Generators}

\section{Using Binomial Tree}

\subsection{Introduction}

In the last chapter (Chapter 2) we introduced a secondary options market to mitigate this uncertainty effect of wind energy production. In that chapter we estimated the wind energy

forecast error by using the Binomial tree model for simplicity. However, that model only considers one wind company going through a bilateral contract with only one reserve provider as a simplified experiment to prove the concept of a secondary option market. A comprehensive secondary market with multiple players was missing in that simple model.

A secondary electricity market, with no subsidies, is assumed in this Chapter where multiple wind generators and reserve providers will participate in. Further, the Cauchy-Lorentz model is used for wind energy forecast error estimation instead of the Binomial tree model. In addition, security limits of transmission lines are included in the formulation. Finally, as we do not consider any geographical size limitation, we need to calculate various probabilistic scenarios of underproduction and overproduction for each wind farm and aggregate the results at the end. The market equilibrium amongst participants will be reached with our proposed optimization and the lambda (LaGrange) multiplier associated with power balance equation at each bus determines the optimal values of both premiums and strike prices. 


\subsection{Proposed Secondary Market Model}

In this chapter, the proposed secondary model shown in Fig. 2.1 intends to introduce a secondary market in which several wind companies can buy reserve from several reserve providers with consideration of the transmission system security constraints. The proposed model considering various forecast error scenarios results in a Monte Carlo probabilistic optimization model. The Binomial Tree model is used to create Options contract for reserves and the wind energy forecast error model used in this chapter is Cauchy-Lorentz.

\subsection{Options Model for Prices}

When wind generators under produce, they have to procure their energy deficits through an active options based market. In the case of overproduction wind generators need an active options based market to sell their energy surplus at the best prices which must be higher than the ISO's discounted prices. The purpose of this section is to form this active networkconstrained options market with multiple participants to mitigate the forecast errors. By assuming that the forecasted value of energy price at a certain bus i for the $\mathrm{T}^{\text {th }}$ hour is ' $\lambda \mathrm{m}$ ' and volatility of energy price is $\sigma \mathrm{m}$; using the binomial tree option pricing scheme explained before using (1.4) we can write:

$[\mathrm{um}, \mathrm{dm}, \mathrm{pm}]=\mathrm{fudp}(\sigma \mathrm{m})$

Also we can calculate the premiums for call and put options using binomial tree option pricing scheme: 
$\mathrm{omc}_{\mathrm{i}}=\sum_{\mathrm{j}=0}^{\mathrm{T}}\left[\mathrm{fpm}_{\mathrm{i}}(\mathrm{j}, \mathrm{T}) \cdot \max \left\{0, \mathrm{um}_{\mathrm{i}}{ }^{\mathrm{j}} \cdot \mathrm{dm}_{\mathrm{i}}{ }^{\mathrm{T}-\mathrm{j}} \cdot \lambda \mathrm{m}_{\mathrm{i}}-\mathrm{kmc}_{\mathrm{i}}\right\}\right]$

$\mathrm{omp}_{\mathrm{i}}=\sum_{\mathrm{j}=0}^{\mathrm{T}}\left[\mathrm{fpm}_{\mathrm{i}}(\mathrm{j}, \mathrm{T}) \cdot \max \left\{0, \mathrm{kmp}_{\mathrm{i}}-\mathrm{um}_{\mathrm{i}}{ }^{\mathrm{j}} \cdot \mathrm{dm}_{\mathrm{i}}{ }^{\mathrm{T}-\mathrm{j}} \cdot \lambda \mathrm{m}_{\mathrm{i}}\right\}\right]$

Where $\operatorname{fpm}_{\mathrm{i}}(\mathrm{j}, \mathrm{T})=\frac{\mathrm{T} !}{\mathrm{j} !(\mathrm{T}-\mathrm{j}) !} \mathrm{pm}_{\mathrm{i}}^{\mathrm{j}} \cdot\left(1-\mathrm{pm}_{\mathrm{i}}\right)^{\mathrm{T}-\mathrm{j}}$

The variables $\mathrm{kmc}_{\mathrm{i}}$ and $\mathrm{kmp}_{1}$ are call and put option strike prices respectively for reserve at the $\mathrm{i}^{\text {th }}$ bus. The variables $\mathrm{um}_{\mathrm{i}}, \mathrm{dm}_{\mathrm{i}}$ and $\mathrm{pm}_{\mathrm{i}}$ are increasing (up) coefficient, decreasing (down) coefficient and probability of increasing (up), respectively, in a binomial tree time step for energy price at $i^{\text {th }}$ bus, refer Fig. 2.2. The variable $\lambda m_{i}$ is the energy market price at $\mathrm{i}^{\text {th }}$ bus. The option buyers here are always wind generators and the option sellers are always reserve providers. Optimal values for option quantities and prices must be found using an optimization model which is presented in the next section.

\subsection{Cauchy-Lorentz distribution model Wind Energy Forecast Error}

In this Chapter we adopt the Cauchy distribution model in order to calculate the wind energy forecast errors. Fig. 3.1 is an Illustration of the fitted probability distributions on the $\mathrm{x}$-interval $[0,1]$ for a specific Wind plant using hour average data for the winter time period. Blue is the beta distribution with shape parameters $\alpha=25.2414$ and $\beta=25.2692$. The Weibull distribution is shown in green with $k=7.1940$ and $\lambda=0.5285$. The Cauchy distribution is in red with xo $=0.4996$ and $\gamma=0.0215$ [54]. It is obvious in this Fig. 3.2 that the Cauchy distribution is the best fit to histogram compared to other distribution models. 
Ref. [54] also indicates that the Cauchy distribution fit was better than beta and the Weibull distribution in $89 \%$ and $95 \%$ of the 55 cases, respectively.

Let us assume that the forecasted energy of the wind farm at a certain time in near future (4 to 5 hours from now for one hour period) is $\overline{\overline{\mathrm{EF}_{\mathrm{w}}}}$. If after 5 hours the extracted wind energy by this wind farm is less than the forecasted value $\left(\overline{\overline{\mathrm{EF}_{\mathrm{w}}}}\right)$, the wind farm will face a situation of underproduction and if the extracted power is more than $\overline{\overline{\mathrm{EF}_{\mathrm{w}}}}$, it will face another situation of overproduction. Now let us assume that the random variable $\mathrm{EF}_{\mathrm{w}}$ represents the amount of extracted energy for the chosen future hour.

For a value of $\mathrm{EF}_{\mathrm{w}}$ between $\mathrm{EF}_{\mathrm{w}, \mathrm{m}}$ and $\overline{\mathrm{EF}_{\mathrm{w}, \mathrm{m}}}$ in the $\mathrm{m}^{\text {th }}$ segment the probability of underproduction can be determined as below:

$\mathrm{pu}_{\mathrm{w}, \mathrm{m}}=\frac{1}{\pi \cdot \gamma} \int_{\underline{\mathrm{EF}_{\mathrm{w}, \mathrm{m}}}}^{\overline{\mathrm{EF}_{\mathrm{w}, \mathrm{m}}}}\left[\left(\frac{\mathrm{EF}_{\mathrm{w}}-\overline{\overline{\mathrm{EF}_{\mathrm{w}}}}}{\gamma}\right)^{2}+1\right]^{-1} \mathrm{dEF}_{\mathrm{w}}$

For a value of $x$ between $\mathrm{EF}_{\mathrm{w}, \mathrm{m}}$ and $\overline{\mathrm{EF}_{\mathrm{w}, \mathrm{m}}}$, the amount of underproduction is $\left(\overline{\overline{\mathrm{EF}_{\mathrm{w}}}}-\right.$ $\mathrm{EF}_{\mathrm{w}}$ ) in the $\mathrm{m}^{\text {th }}$ segment, we can calculate the expected under produced energy by using the following equation:

$\overline{\mathrm{EU}_{\mathrm{w}, \mathrm{m}}}=\frac{1}{\pi \cdot \gamma} \int_{\underline{\underline{\mathrm{EF}_{\mathrm{w}, \mathrm{m}}}}}^{\overline{\mathrm{EF}_{\mathrm{w}, \mathrm{m}}}}\left(\overline{\overline{\mathrm{EF}_{\mathrm{w}}}}-\mathrm{EF}_{\mathrm{w}}\right) \cdot\left[\left(\frac{\mathrm{EF}_{\mathrm{w}}-\overline{\overline{\mathrm{EF}_{\mathrm{w}}}}}{\gamma}\right)^{2}+1\right]^{-1} \mathrm{dEF}_{\mathrm{w}}$

In the above equation, $\gamma$ defines the Cauchy distribution. Similarly for any value of $\mathrm{EF}_{\mathrm{w}}$ more than $\overline{\overline{\mathrm{EF}_{\mathrm{w}}}}$ the amount of overproduction is $\left(\mathrm{EF}_{\mathrm{w}}-\overline{\overline{\mathrm{EF}_{\mathrm{w}}}}\right)$. Considering the symmetry of 
the Cauchy distribution around $\overline{\overline{\mathrm{EF}_{\mathrm{w}}}}$, we can calculate the expected over produced energy by using the following equation for $\mathrm{m}^{\text {th }}$ segments under and overproduction around the mean value:

$\overline{\mathrm{EO}_{\mathrm{w}, \mathrm{m}}}=\overline{\mathrm{EU}_{\mathrm{w}, \mathrm{m}}}$

The corresponding probability of overproduction for the $\mathrm{m}^{\text {th }}$ segment is computed similarly to be:

$\mathrm{po}_{\mathrm{w}, \mathrm{m}}=\mathrm{pu}_{\mathrm{w}, \mathrm{m}}$

In larger power systems we can face more complicated situations in which some of our wind plants may have underproduction and some may have overproduction simultaneously in the future. In order to evaluate such a complicated situation we can divide each wind plant's PDF into several small narrow segments and do the integration separately for each segment and create all possible scenarios by combining these segments and their corresponding probabilities. Here it is assumed that wind plants are independent and no joint probability exists.

\subsection{Probabilistic Model and Optimization}

Fig. 3.2 shows the Cauchy Probability Distribution Function of several wind plants each divided by $m$ segments. Assuming that we have total of $n$ number of wind plants we can create $\mathrm{m}^{\mathrm{n}}$ scenarios for each hour for which we contract. For each scenario we calculate a specific probability and we run the optimization model which will be explained later. It is

obvious that for call option only half left segments and for put option only half right segments of the Probability Distribution Function are considered. Finally by using all of the results and their corresponding probability we can calculate all the expected prices. 


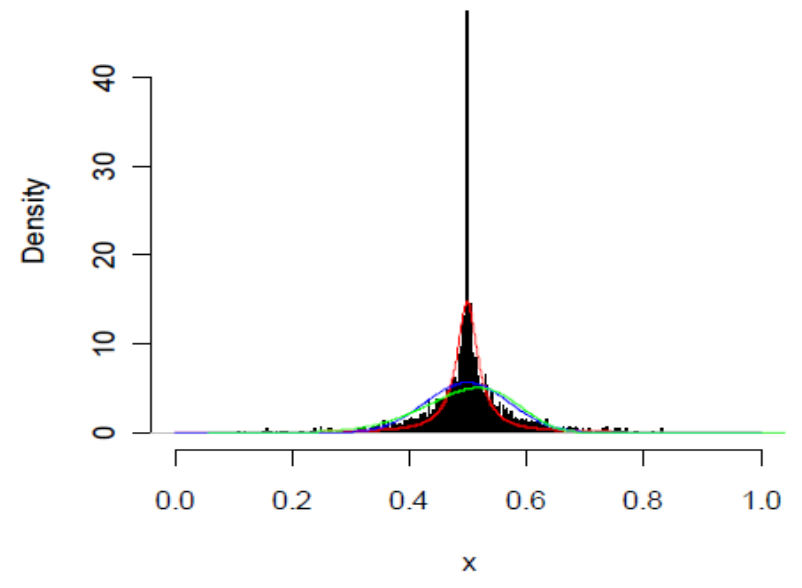

Fig. 3.1 Illustration of the fitted probability distributions on the $x$-interval $[0,1]$ for wind plant \#8 of ERCOT using hour average data for the winter time period. Blue is the beta distribution with shape parameters $\alpha=25.2414$ and $\beta=25.2692$. The Weibull distribution is shown in green with $k=7.1940$ and $\lambda=0.5285$. The Cauchy distribution is in red with $x o=0.4996$ and $\gamma=0.0215[54]$. 


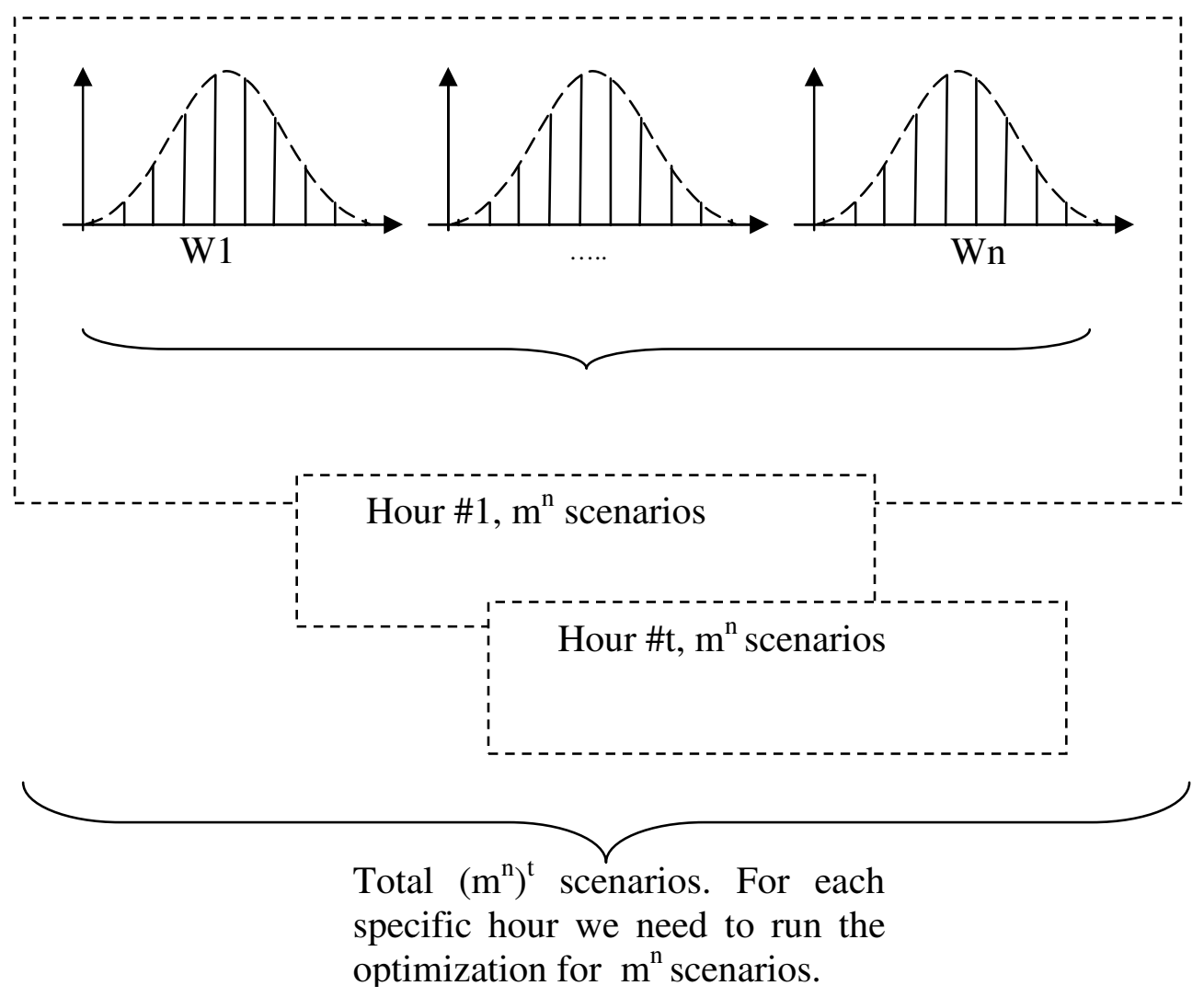

Fig. 3.2 Illustration of the probable scenarios of under/over production at each wind connected bus 


\subsection{Problem Formulation and Objectives}

In this section, the overall formulation of the proposed model is discussed. The proposed options market participants, wind generators and reserve providers, must calculate the expected shortage or excess of energy in the $\mathrm{T}^{\text {th }}$ hour and determine optimal strike and option prices at each bus in the system. These optimal values should maximize the participants' welfare for the market. This section formulates the objective function and constraints of the optimization problem for under and over production.

\subsubsection{Underproduction objective and constraints}

Let us assume that $\mathrm{w}^{\text {th }}$ wind plant under produces at the $\mathrm{T}^{\text {th }}$ hour considering the $\mathrm{m}^{\text {th }}$ probable segment. In this case, should the wind plant take no action, the ISO shall procure this energy deficit and charge the wind generator for additional costs. In this model, yo represents a factor corresponding to additional fee (penalties) on top of the market price required by the ISO for arranging these energy deliveries at short notice. Hence, potential loss for $\mathrm{w}^{\text {th }}$ wind generator located at bus i would be, in the event of production shortfall and inaction:

$\overline{\mathrm{EU}_{\mathrm{w}, \mathrm{m}}} \cdot(1+\gamma \mathrm{o}) \cdot \lambda \mathrm{m}_{\mathrm{i}}$

Instead of taking no action, these wind generators could make use of the amount of reserve they already contracted for in the options market. It is assumed that they have already paid call option premiums to one or more reserve providers located at different buses. For this option market to be financially viable, wind generators and reserve providers must earn more revenue than in the same situation without this option market. By using the proposed 
option market, the total avoidable loss for wind companies for call options is equal to the difference in compensating underproduction from the ISO and the options market (assuming no line restriction), respectively considering that $\mathrm{w}^{\text {th }}$ wind generator at the $\mathrm{i}^{\text {th }}$ bus is in the mw ${ }^{\text {th }}$ segment:

$\mathrm{TAWC}=\left[\prod_{\mathrm{w}=1}^{\mathrm{NW}} \mathrm{pu}_{\mathrm{w}, \mathrm{mw}}\right] \cdot\left(\sum_{\substack{\mathrm{w}=1 \\ \mathrm{i} \in \mathrm{w}}}^{\mathrm{NW}} \mathrm{EU}_{\mathrm{w}, \mathrm{mw}} \cdot(1+\gamma \mathrm{o}) \cdot \lambda \mathrm{m}_{\mathrm{f}}-\sum_{\substack{\mathrm{w}=1 \\ \mathrm{i} \in \mathrm{w}}}^{\mathrm{NW}} \mathrm{EU}_{\mathrm{w}, \mathrm{mw}} \cdot\left(\mathrm{kmc}_{1}+\mathrm{omc}_{1}\right)\right)$

Assuming that the same reserve providers would have been called by ISO with the same market price, the total extra profit for all reserve providers including capacity costs for call options is the difference between selling reserves to the options market and ISO:

$\mathrm{TERC}=\left[\prod_{\mathrm{w}=1}^{\mathrm{NW}} \mathrm{pu}_{\mathrm{w}, \mathrm{mw}}\right] \cdot\left(\sum_{\substack{\mathrm{k}=1 \\ \mathrm{i} \in \mathrm{k}}}^{\mathrm{NK}} \mathrm{EC}_{\mathrm{k}} \cdot\left(\mathrm{kmc}_{\mathrm{i}}+\mathrm{omc}_{\mathrm{i}}-\lambda \mathrm{m}_{\mathrm{i}}\right)\right)$

$\mathrm{EC}_{\mathrm{k}}$ is the amount of energy sold by $\mathrm{k}^{\text {th }}$ reserve provider in call option contract and $\mathrm{EU}_{\mathrm{w}}$ is the purchased energy by $\mathrm{w}^{\text {th }}$ wind generator which will be found through optimization. TAWC and TERC are two indicators and must not be confused with objective function. The objective function in call option is to maximize social welfare (amongst the option market participants), using market equilibrium concept to determine optimal values of volume of trade $\left(E U_{w}\right.$ and $\left.E C_{k}\right)$ and prices for each scenario discussed in Fig. 3.3, which is the difference between offers from buyers and offers from sellers. The overall social welfare for the proposed network constrained intra-day secondary reserve market for call option can be aggregated by considering all possible scenarios: 


$$
\mathrm{OBJ}_{\mathrm{C}}=\sum_{\substack{\text { all } \\ \text { probabilistic } \\ \text { scenarios }}}\left[\prod_{\mathrm{w}=1}^{\mathrm{NW}} \mathrm{pu}_{\mathrm{w}, \mathrm{mw}}\right] \cdot\left(\sum_{\substack{\mathrm{w}=1 \\ \mathrm{i} \in \mathrm{w}}}^{\mathrm{NW}} \mathrm{EU}_{\mathrm{w}, \mathrm{mw}} \cdot\left(1+\gamma \mathrm{w}_{\mathrm{w}}^{\mathrm{C}}\right) \cdot \lambda \mathrm{m}_{\mathrm{i}}-\sum_{\substack{\mathrm{k}=1 \\ \mathrm{i} \in \mathrm{k}}}^{\mathrm{NK}} \mathrm{EC}_{\mathrm{k}} \cdot\left(1+\gamma \mathrm{r}_{\mathrm{k}}^{\mathrm{C}}\right) \cdot \lambda \mathrm{m}_{\mathrm{i}}\right)
$$

The factor $\gamma \mathrm{r}_{\mathrm{k}}^{\mathrm{C}}$ (in the range of 0 to 1 ) represents the factor of marginal price that the $\mathrm{k}^{\text {th }}$ reserve provider wants to sell (including capacity cost) and the factor $\gamma \mathrm{w}_{\mathrm{w}}^{\mathrm{C}}$ (in the range of 0 to 1) represents the factor of marginal price that the $\mathrm{w}^{\text {th }}$ wind generator wants to buy. Constraints on energy in the call option for buyers and sellers:

$$
\begin{aligned}
& 0 \leq \mathrm{EU}_{\mathrm{w}, \mathrm{mw}} \leq \overline{\mathrm{EU}_{\mathrm{w}, \mathrm{mw}}} \\
& 0 \leq \mathrm{EC}_{\mathrm{k}} \leq \overline{\mathrm{EC}_{\mathrm{k}}}
\end{aligned}
$$

Power Balance Equations at bus $i(i \in\{1,2, \ldots, N B\})$ :

$$
\mathrm{P}_{\mathrm{i}}(\mathrm{V}, \delta)=\mathrm{PG}_{\mathrm{i}}+\frac{\mathrm{EC}_{\mathrm{k} \in \mathrm{i}}}{1 \text { hour }}-\frac{\mathrm{EU}_{\mathrm{w}, \mathrm{mw} \in \mathrm{i}}}{1 \text { hour }}-\mathrm{PD}_{\mathrm{i}}=\sum_{\mathrm{j}=1}^{\mathrm{NB}} \mathrm{V}_{\mathrm{i}} \mathrm{V}_{\mathrm{j}} \mathrm{Y}_{\mathrm{ij}} \cos \left(\theta_{\mathrm{ij}}+\delta_{\mathrm{j}}-\delta_{\mathrm{i}}\right)
$$

Reactive Power Balance Equations at bus $i(i \in\{1,2, \ldots, N B\})$ :

$$
\mathrm{Q}_{\mathrm{i}}(\mathrm{V}, \delta)=\mathrm{QG}_{\mathrm{i}}-\mathrm{QD}_{\mathrm{i}}=-\sum_{\mathrm{j}=1}^{\mathrm{NB}} \mathrm{V}_{\mathrm{i}} \mathrm{V}_{\mathrm{j}} \mathrm{Y}_{\mathrm{ij}} \sin \left(\theta_{\mathrm{ij}}+\delta_{\mathrm{j}}-\delta_{\mathrm{i}}\right)
$$

Maximum and Minimum Reactive Power at bus $\mathrm{i}=$ all buses:

$\underline{\mathrm{QG}_{\mathrm{i}}} \leq \mathrm{QG}_{\mathrm{i}} \leq \overline{\mathrm{QG}_{\mathrm{i}}}$

Above power balance equations (3.14)-(3.15) include deviations in power injected into connected buses by wind generators and reserve providers. $\mathrm{PG}_{\mathrm{i}}$ at generators buses are fixed. Reactive power output from generators is assumed to be variable.

Line constraints $l=1$ to all lines and transformers:

$$
-\overline{\mathrm{S}_{l}} \leq \mathrm{S}_{l}(\mathrm{~V}, \delta) \leq \overline{\mathrm{S}_{l}}
$$


Voltage magnitude constraints at $\mathrm{i}^{\text {th }}$ bus:

$\mathrm{V}_{\mathrm{i}}(\min ) \leq \mathrm{V}_{\mathrm{i}} \leq \mathrm{V}_{\mathrm{i}}(\max )$

\subsubsection{Locational marginal prices for underproduction}

The value of the Lagrangian multiplier associated with the real power balance equation (3.14) at each bus must be equal to the total amount of money payable at that bus.

$\lambda \mathrm{m}_{\mathrm{i}}^{\mathrm{OC}}=\mathrm{kmc}_{\mathrm{i}}+\mathrm{omc}_{\mathrm{i}}$

Where call option strike price $\left(\mathrm{kmc}_{\mathrm{i}}\right)$ and call options premium $\left(\mathrm{omc}_{\mathrm{i}}\right)$ are related using the following equation:

$\mathrm{omc}_{\mathrm{i}}=\sum_{\mathrm{j}=0}^{\mathrm{T}}\left[\mathrm{fpm}_{\mathrm{i}}(\mathrm{j}, \mathrm{T}) \cdot \max \left\{0, \mathrm{um}_{\mathrm{i}}^{\mathrm{j}} \cdot \mathrm{dm}_{\mathrm{i}}^{\mathrm{T}-\mathrm{j}} \cdot \lambda \mathrm{m}_{\mathrm{i}}-\mathrm{kmc}_{\mathrm{i}}\right\}\right]$

Thus by optimizing each scenario of (3.11) subject to (3.12) - (3.20), the aggregation of optimal solutions of all scenarios will determine the bus-wise call option strike prices $\left(\mathrm{kmc}_{\mathrm{i}}\right)$, premiums $\left(\mathrm{omc}_{\mathrm{i}}\right)$, and optimal quantity of energy to be purchased $\left(\mathrm{EU}_{\mathrm{w}}\right)$ and sold $\left(\mathrm{EC}_{\mathrm{k}}\right)$.

\subsubsection{Overproduction objective and constraints}

Let us assume that $\mathrm{w}^{\text {th }}$ wind plant has overproduction at the $\mathrm{T}^{\text {th }}$ hour considering $\mathrm{mw}^{\text {th }}$ segment of the probabilistic distribution (refer to Fig. 3.2). In the absence of any action from wind generators to curb this excess power, the ISO has to instruct other generators to reduce their output. Accordingly, this action has a financial cost that is used as a disincentive. In case of oversupply, the $\mathrm{w}^{\text {th }}$ wind generator located at bus $\mathrm{i}$ is paid at a discounted rate from the market price for the excess energy as $\overline{\mathrm{EO}_{w}} \cdot(1-\gamma 0) \cdot \lambda \mathrm{m}_{\mathrm{i}}$ where the factor $\gamma_{0}$ is the penalty factor as defined earlier. Instead of taking no action, these wind generators could make use of the amount of negative reserve they already contracted in the options market. It is assumed 
that it has already paid put option premiums to one or more reserve providers located at different buses. For a financially viable option market, wind generators and reserve providers must earn more revenue than in the same situation without the proposed option market. By using the proposed option market, the total avoidable loss for wind generators for put option is equal to the difference between selling to the options market and the ISO respectively considering that $\mathrm{w}^{\text {th }}$ wind generator at the $\mathrm{i}^{\text {th }}$ bus is in the $\mathrm{mw}^{\text {th }}$ segment:

$\mathrm{TAWP}=\left[\prod_{\mathrm{w}=1}^{\mathrm{NW}} \mathrm{po}_{\mathrm{w}, \mathrm{mw}}\right] \cdot\left(\sum_{\substack{\mathrm{w}=1 \\ i \in w}}^{\mathrm{NW}} \mathrm{EO}_{\mathrm{w}, \mathrm{mw}} \cdot\left(\mathrm{kmp}_{1}-\mathrm{omp}_{1}\right)-\sum_{\substack{\mathrm{w}=1 \\ \mathrm{i} \in \mathrm{w}}}^{\mathrm{NW}} \mathrm{EO}_{\mathrm{w}} \cdot(1-\gamma \mathrm{o}) \cdot \lambda \mathrm{m}_{\mathrm{i}}\right)$

Assuming that $\mathrm{w}^{\text {th }}$ wind generator operates in $\mathrm{mw}^{\text {th }}$ probabilistic segment, the total extra profit including capacity costs for all reserve providers for put option is the difference between selling energy to the ISO at market rate and buying it at a discounted rate in the options market:

$\mathrm{TERP}=\left[\prod_{\mathrm{w}=1}^{\mathrm{NW}} \mathrm{po}_{\mathrm{w}, \mathrm{mw}}\right] \cdot\left(\sum_{\substack{\mathrm{k}=1 \\ \mathrm{i} \in \mathrm{k}}}^{\mathrm{NK}} \mathrm{EP}_{\mathrm{k}} \cdot\left[\lambda \mathrm{m}_{\mathrm{i}}-\left(\mathrm{kmp}_{\mathrm{i}}-\mathrm{omp}_{\mathrm{i}}\right)\right]\right)$

$\mathrm{EP}_{\mathrm{k}}$ is the amount of energy purchased by $\mathrm{k}^{\text {th }}$ reserve provider in put option contract and $\mathrm{EO}_{\mathrm{w}}$ is the energy sold by the $\mathrm{w}^{\text {th }}$ wind generator in put option contract, and these values will be found through optimization. TAWP and TERP are two indicators and must not be confused with objective function. The objective function of put option for each scenario discussed in Fig. 3.2 is the difference between (1) offers from reserve providers to buy overproduction and (2) offers from wind generators to sell overproduction (using market 
equilibrium concept). Overall social welfare can be aggregated by considering all possible scenarios:

$$
\mathrm{OBJ}_{\mathrm{P}}=\sum_{\substack{\text { all } \\ \text { probabilistic } \\ \text { scenarios }}}\left[\prod_{\mathrm{w}=1}^{\mathrm{NW}} \mathrm{po}_{\mathrm{w}, \mathrm{mw}}\right] \cdot\left(\sum_{\substack{\mathrm{k}=1 \\ i \in \mathrm{k}}}^{\mathrm{NK}} \mathrm{EP}_{\mathrm{k}} \cdot\left(1-\gamma \mathrm{r}_{\mathrm{k}}^{\mathrm{P}}\right) \cdot \lambda \mathrm{m}_{\mathrm{i}}-\sum_{\substack{\mathrm{w}=1 \\ \mathrm{i} \in \mathrm{w}}}^{\mathrm{NW}} \mathrm{EO}_{\mathrm{w}, \mathrm{mw}} \cdot\left(1-\gamma \mathrm{w}_{\mathrm{w}}^{\mathrm{P}}\right) \cdot \lambda \mathrm{m}_{\mathrm{i}}\right)
$$

The factor $\gamma \mathrm{r}_{\mathrm{k}}^{\mathrm{P}}$ (in the range 0 to 1 ) represents the discount factor of marginal price that the $\mathrm{k}^{\text {th }}$ reserve provider wants to buy and the factor $\gamma \mathrm{w}_{\mathrm{w}}^{\mathrm{P}}(0$ to 1$)$ represents the discount factor of marginal price that the $\mathrm{w}^{\text {th }}$ wind generator wants to sell.

Subject to constraints:

Constraints on energy in the put option for buyers and sellers:

$0 \leq \mathrm{EO}_{\mathrm{w}, \mathrm{mw}} \leq \overline{\mathrm{EO}_{\mathrm{w}, \mathrm{mw}}}$

$0 \leq \mathrm{EP}_{\mathrm{k}} \leq \overline{\mathrm{EP}_{\mathrm{k}}}$

Power Balance Equations at bus $i(i \in\{1,2, \ldots, N B\})$ :

$$
\mathrm{P}_{\mathrm{i}}(\mathrm{V}, \delta)=\mathrm{PG}_{\mathrm{i}}-\frac{\mathrm{EP}_{\mathrm{k} \in \mathrm{i}}}{1 \text { hour }}+\frac{\mathrm{EO}_{\mathrm{w}, \mathrm{mw} \in \mathrm{i}}}{1 \text { hour }}-\mathrm{PD}_{\mathrm{i}}=\sum_{j=1}^{N B} V_{i} V_{j} Y_{i j} \cos \left(\theta_{i j}+\delta_{j}-\delta_{i}\right)
$$

Reactive Power Balance Equations at bus $i(i \in\{1,2, \ldots, N B\})$ :

$$
\mathrm{Q}_{\mathrm{i}}(\mathrm{V}, \delta)=\mathrm{QG}_{\mathrm{i}}-\mathrm{QD}_{\mathrm{i}}=-\sum_{j=1}^{N B} V_{i} V_{j} Y_{i j} \sin \left(\theta_{i j}+\delta_{j}-\delta_{i}\right)
$$

Maximum and Minimum Reactive Power at bus $\mathrm{i}=1$ to all buses:

$$
\underline{\mathrm{QG}_{\mathrm{i}}} \leq \mathrm{QG}_{\mathrm{i}} \leq \overline{\mathrm{QG}_{\mathrm{i}}}
$$

The above power balance equations (3.26)-(3.27) include deviations in power injected into connected buses by wind generators and reserve providers. $\mathrm{PG}_{\mathrm{i}}$ at generators buses are fixed. Reactive power output from generators is assumed to be variable. 
Line constraints $l=1$ to all lines and transformers:

$-\overline{\mathrm{S}_{l}} \leq \mathrm{S}_{l}(\mathrm{~V}, \delta) \leq \overline{\mathrm{S}_{l}}$

Voltage magnitude constraints at each $\mathrm{i}^{\text {th }}$ bus:

$\mathrm{V}_{\mathrm{i}}(\min ) \leq \mathrm{V}_{\mathrm{i}} \leq \mathrm{V}_{\mathrm{i}}(\max )$

\subsubsection{Locational marginal prices for overproduction}

The value of the Lagrangian multiplier associated with the real power balance equation (3.26) at each bus must be equal to the total amount of money receivable at that bus.

$\lambda \mathrm{m}_{\mathrm{i}}^{\mathrm{OP}}=\mathrm{kmp}_{\mathrm{i}}-\mathrm{omp}_{\mathrm{i}}$

In which $\mathrm{kmc}_{1}$ and $\mathrm{omc}_{1}$ are related using the following equation:

$\mathrm{omp}_{1}=\sum_{\mathrm{j}=0}^{\mathrm{T}}\left[\mathrm{fpm}(\mathrm{j}, \mathrm{T}) \cdot \max \left\{0, \mathrm{kmp}_{1}-\mathrm{um}_{1}^{\mathrm{j}} \cdot \mathrm{dm}_{1}^{\mathrm{T}-\mathrm{j}} \cdot \lambda \mathrm{m}_{\mathrm{i}}\right\}\right]$

Thus, by maximizing each scenario of (3.23) subject to (3.24) - (3.32), the aggregation of optimal solutions of all scenarios will give the bus-wise put option strike prices $\left(\mathrm{kmp}_{\mathrm{i}}\right)$, premiums $\left(\mathrm{omp}_{\mathrm{i}}\right)$, and optimal energy to be sold $\left(\mathrm{EO}_{\mathrm{w}}\right)$ and purchased $\left(\mathrm{EP}_{\mathrm{k}}\right)$.

\subsection{Algorithm}

Fig. 3.3 shows the proposed model's algorithm. As mentioned before, grid data is essential in order to evaluate the network feasibility of each transaction. In addition to grid data, all quoted prices and ISO estimated prices and forecasted wind energies are collected at the beginning of the optimization process. 


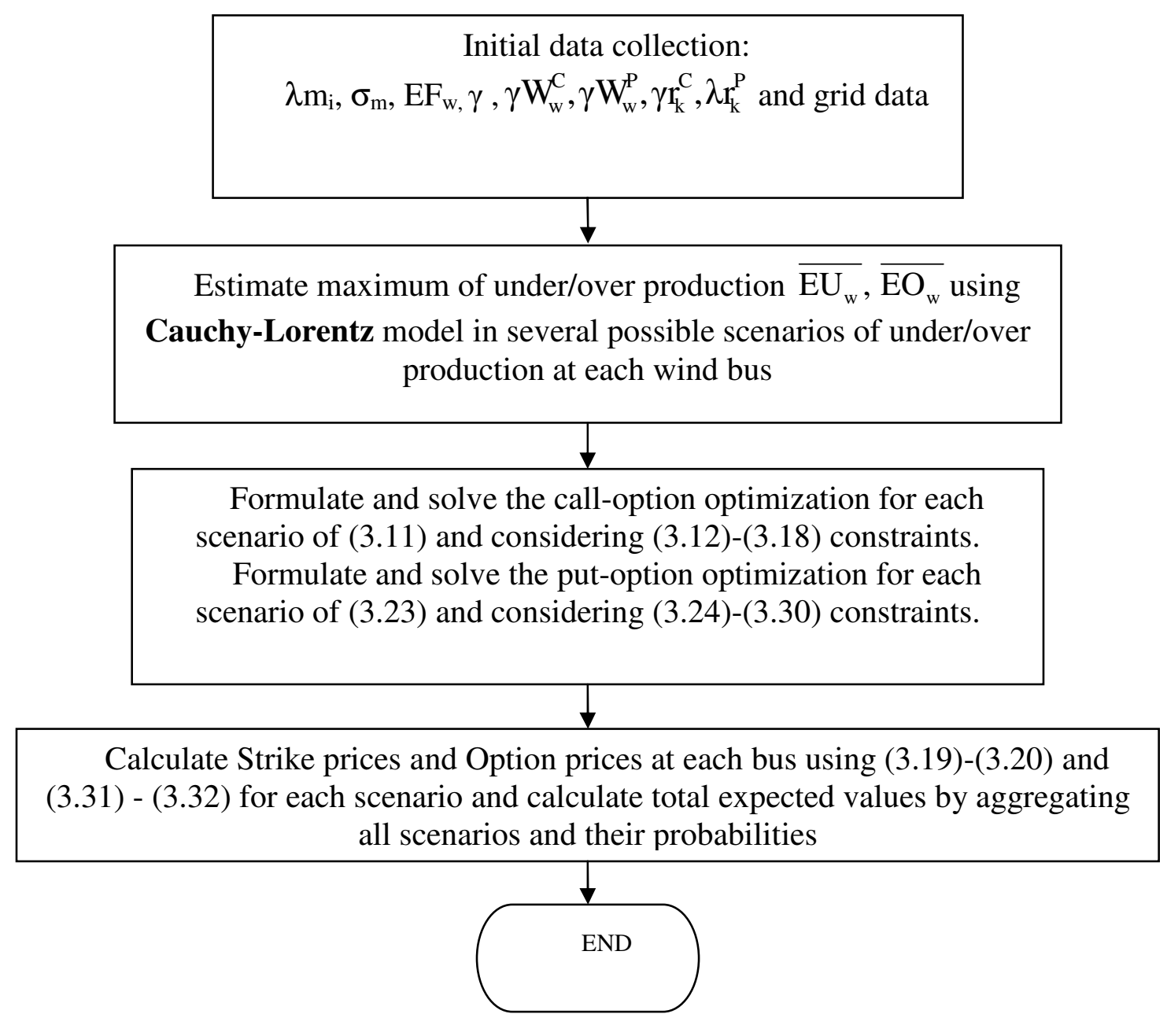

Fig. 3.3 Proposed model's flow chart 


\subsection{Results and Analysis}

\subsubsection{5-bus test system}

The 5-bus test system is shown in Fig. 3.4. We assume that two wind farms W1 and W2 are connected to buses 4 and 5 respectively. We also assume that two reserve providers G1 and G2 located at buses 2 and 3 respectively participate in the option contracts market. The problem is to settle intra-day secondary market for reserve trade four (4) hours from now. The committed energy supply by each wind farm is $150 \mathrm{MWh}$ at the contract time, 4 hours from now. The maximum capacity of reserve for G1 and G2 are 20 and $40 \mathrm{MWh}$ respectively. The ratio of $\gamma / \mathrm{EF}_{\mathrm{w}}$ in Cauchy distribution at each wind bus is varied from 2 to 10 percent (at the same time and kept identical for all wind plants) for this study. The market price volatility $(\sigma \mathrm{m})$ is assumed to be 0.2 . The market prices for all buses are estimated by the ISO and projected to be $43,45.1,43.7,45.8$ and $45 \$ / \mathrm{MWh}\left(\lambda \mathrm{m}_{\mathrm{i}}\right)$ for buses 1 to 5 respectively.

For underproduction, prices quoted (the minimum price of selling) by reserve providers (G1 and G2) are taken as $10 \%$ and $20 \%\left(\gamma_{\mathrm{k}}^{\mathrm{C}}\right)$ higher than their corresponding nodal market prices respectively. The purchase price offers (maximum prices of buying) by wind farms (W1 and W2) are assumed to be $40 \%$ and $30 \%\left(\gamma \mathrm{w}_{\mathrm{w}}^{\mathrm{C}}\right)$ higher than their corresponding nodal market prices respectively.

For overproduction, the prices quoted (the maximum prices of buying) by reserve providers (G1 and G2) are taken as $20 \%$ and $5 \%\left(\gamma_{\mathrm{k}}^{\mathrm{P}}\right)$ lower than their corresponding nodal market prices respectively. The purchase price offers (minimum prices of selling) by wind farms (W1 and W2) are assumed to be $40 \%$ and $30 \%\left(\gamma \mathrm{w}_{\mathrm{w}}^{\mathrm{P}}\right)$ lower than their corresponding nodal 
market prices respectively.

As mentioned, this nodal price data would have been determined through day-ahead dispatch in a real market. We assume that the penalty factor imposed by the ISO for under or over production is equal to $\gamma_{\mathrm{o}}=0.5$. The loads connected to buses 4 and 5 are $200+\mathrm{j} 20$ MVA each and the reactive power of each generator is between \pm 200 MVar. Line impedance values are shown in Table 3.1. Table 3.2 presents results from solving the proposed formulation using this data for varying values of $\gamma / \mathrm{EF}_{\mathrm{w}}$. For this analysis, line 2-4 flow limit is restricted to $250 \mathrm{MVA}(\overline{\mathrm{S} 2-4})$.

In this example it is assumed that each wind plant's PDF is divided into 6 segments and for each $\gamma / \mathrm{EF}_{\mathrm{w}}$ we need to run 36 different optimizations in order to aggregate the final expected values. Fig. 3.5 shows strike prices across the system at all buses for varying values of $\gamma / \mathrm{EF}_{\mathrm{w}}$ in Cauchy distribution. Each strike price with a certain $\gamma / \mathrm{EF}_{\mathrm{w}}$ and at a certain bus is calculated by aggregation of 36 different prices and their probabilities. Fig. 3.6 shows aggregated option prices. Increase in $\gamma$ increases uncertainty in power output of wind generators. This increases demand for energy through call options, leading to higher prices. Fig. 3.7 shows Variation of contracted energy for reserve providers and TAWC, TERC with respect to varying values of $\gamma / \mathrm{EF}_{\mathrm{w}}$ in Cauchy distribution. The MVA limit of line $2-4$ ( $\overline{\mathrm{S} 2-4})$ is studied for 4 different cases $(15,20,25$ and 30 MVA). Fig. 3.8 shows Variation of contracted energy for reserve providers and strike and option prices at bus- 4 with respect to security constraint. It is clear that tight security constraint restricts wind farms to buy more from $\mathrm{G} 2$ instead of G1 and that increases the prices. If there are line flow limits, they will become restrictive in allowing reserve trade. Clearly, sensitivity of prices to wind forecast error and security constraints is demonstrated through this analysis. 


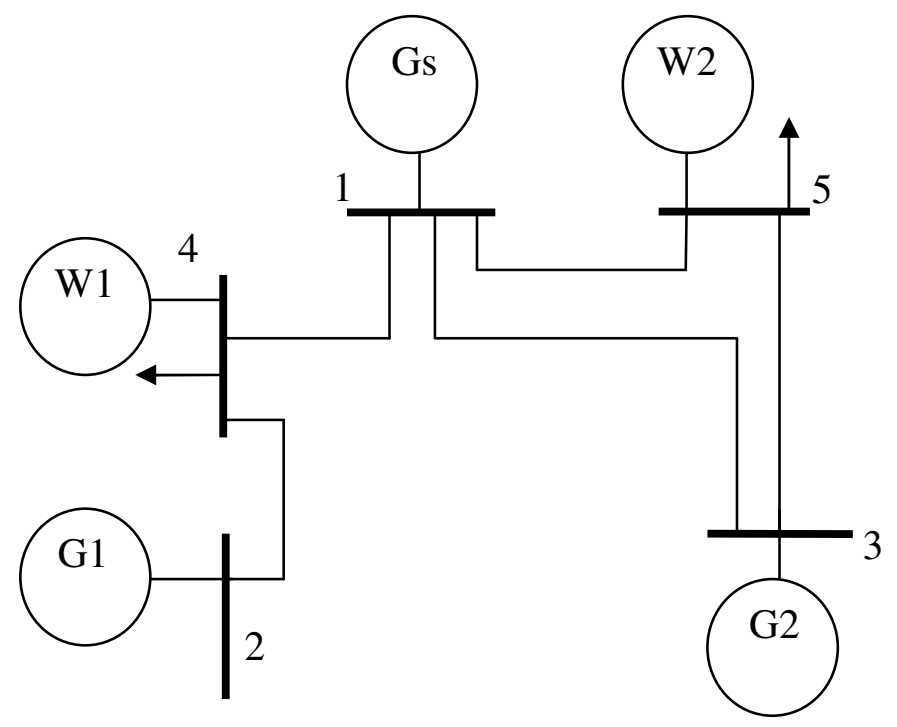

Fig. 3.4 5-Bus test system

Table $3.1 \quad 5$-Bus test system line data

\begin{tabular}{|c|c|c|c|c|}
\hline & $\begin{array}{c}\text { From Bus } \\
\text { Number }\end{array}$ & $\begin{array}{c}\text { To Bus } \\
\text { Number }\end{array}$ & $\begin{array}{c}\text { Resistance } \\
\text { (p.u.) }\end{array}$ & $\begin{array}{c}\text { Inductance } \\
\text { (p.u.) }\end{array}$ \\
\hline Line & 1 & 4 & 0.1 & 0.218 \\
\hline Line & 4 & 2 & 0.1 & 0.270 \\
\hline Line & 1 & 5 & 0.1 & 0.207 \\
\hline Line & 5 & 3 & 0.1 & 0.240 \\
\hline Line & 1 & 3 & 0.1 & 0.250 \\
\hline
\end{tabular}


Table 3.2 Results of Study on 5-bus System by aggregation of $\mathbf{3 6}$ scenarios for each Cauchy distribution ratio

\begin{tabular}{|c|c|c|c|c|c|}
\hline Cauchy & Avoided Costs & Additional & Wind Gen & Wind Gen & Wind Gen \\
\hline Distribution & for Wind & Profits for & Expected & Extra & Extra \\
\hline Ratio & Generator & Reserve & Revenues & Revenues & Revenues \\
\hline$\gamma / \mathrm{EF}_{\mathrm{w}}$ & TAWC & Providers & without & with Contract & with Contract \\
\hline \multirow[t]{5}{*}{$\%$} & + & TERC & Contract & for both & for both \\
\hline & TAWP & + & for both & under/over & under/over \\
\hline & $\$$ & TERP & under/over & production & production \\
\hline & & $\$$ & production & $\$$ & $\%$ \\
\hline & & & $\$$ & & \\
\hline 2 & 103.15 & 18.60 & 13,564 & 13,616 & 0.38 \\
\hline 4 & 160.62 & 24.49 & 13,528 & 13,609 & 0.60 \\
\hline 6 & 203.87 & 41.88 & 13,498 & 13,600 & 0.76 \\
\hline 8 & 243.59 & 55.24 & 13,469 & 13,591 & 0.91 \\
\hline 10 & 280.73 & 71.20 & 13,439 & 13,579 & 1.04 \\
\hline
\end{tabular}

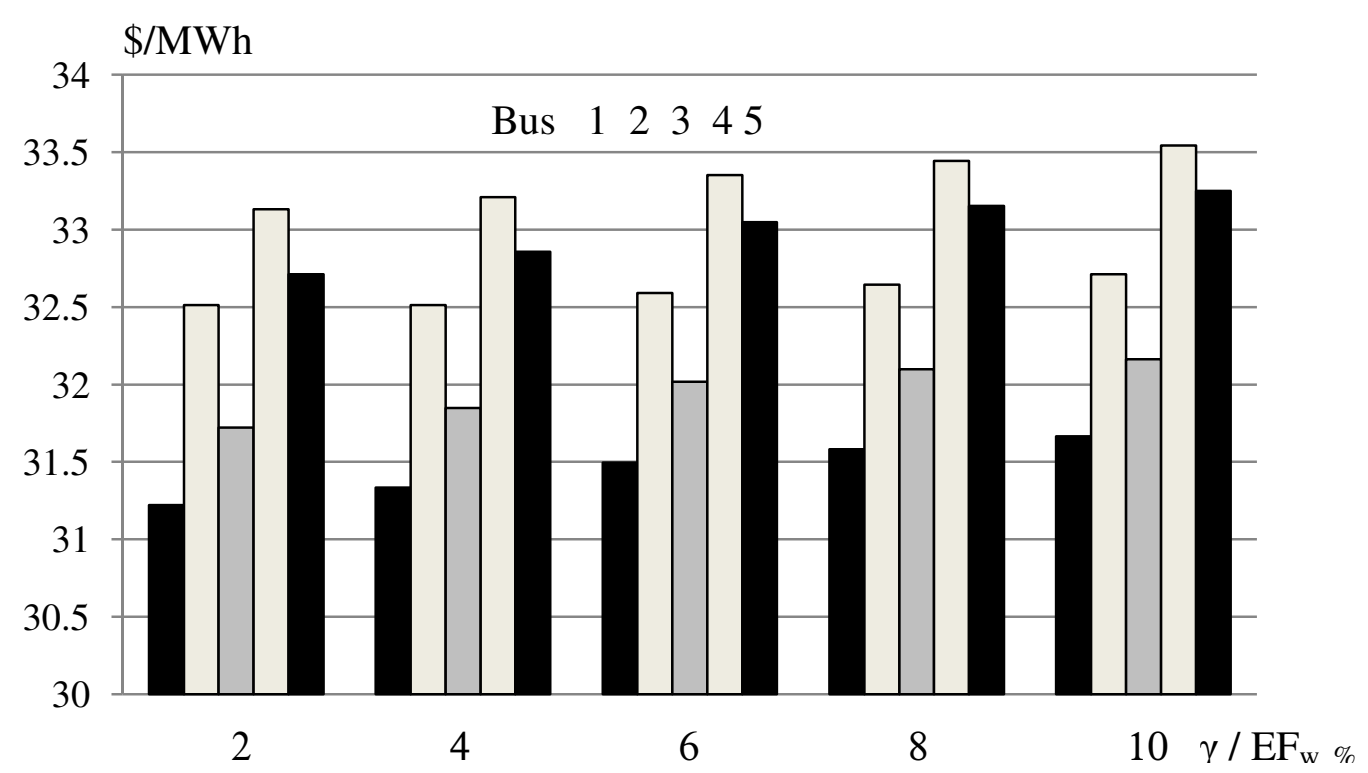

Fig. 3.5 Aggregated strike prices for call option at all buses for increasing $\gamma / \mathbf{E F}_{w}$ 


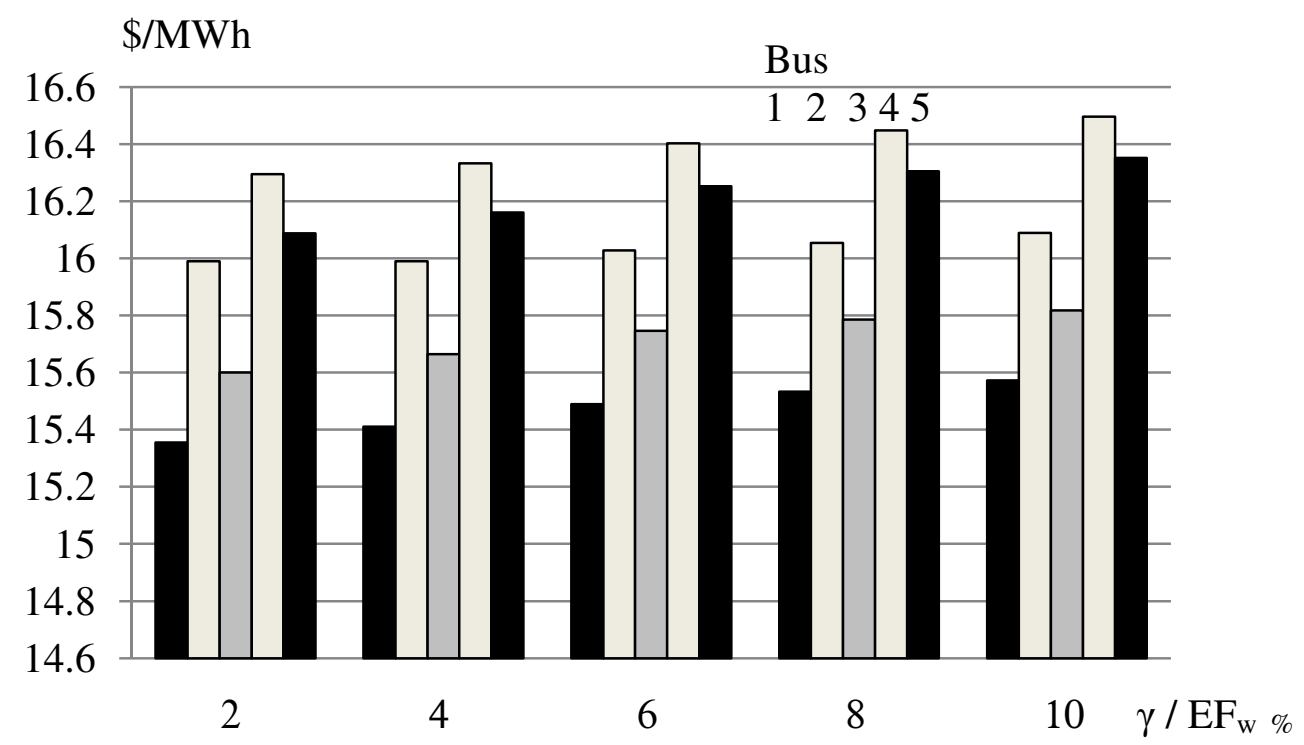

Fig. 3.6 Aggregated option (premium) prices for call option at all buses for increasing $\gamma$ / $\mathbf{E F}_{\mathrm{w}}$ in Example 1. Each option price with a certain $\gamma / \mathbf{E F}_{\mathbf{w}}$ and at a certain bus is calculated by aggregation of $\mathbf{3 6}$ different prices and their probabilities.

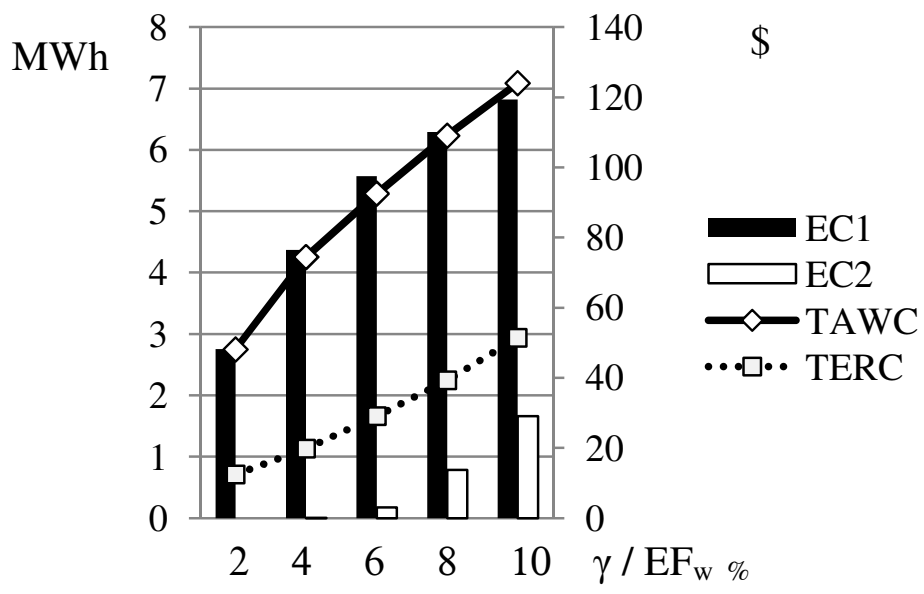

Fig. 3.7 Variation of aggregated contracted energy for reserve providers and aggregated TAWC, TERC with respect to $\gamma / \mathbf{E F}_{\mathrm{w}}$ 


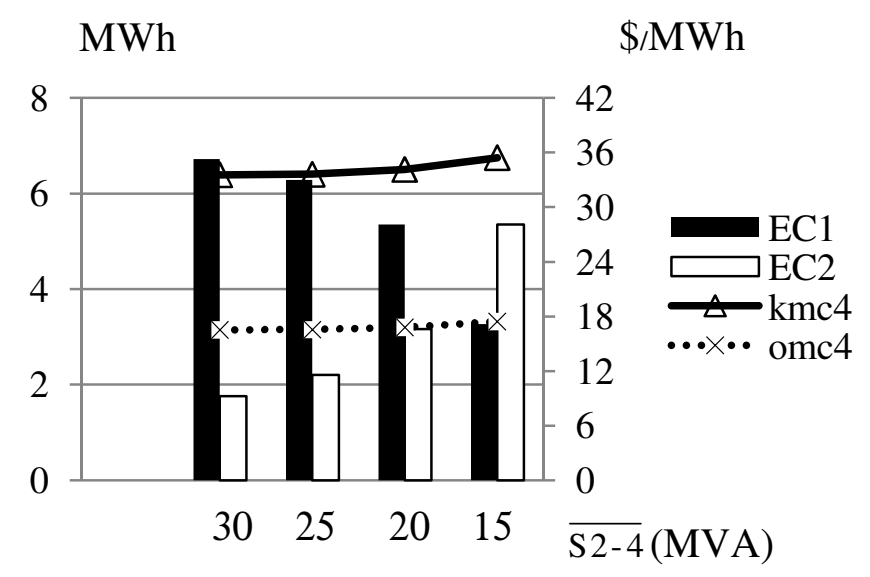

Fig. 3.8 Variation of aggregated contracted energy for reserve providers and aggregated call strike and premium prices at bus-4 with respect to security constraint $(\gamma$

$$
\left./ \mathbf{E F}_{\mathrm{w}}=\mathbf{1 0 \%}\right)
$$




\subsubsection{IEEE 118-bus test system with realistic wind farms data}

In this system we assume that 3 wind farms are connected to buses 1,4 and 8 (W1 to W3) and four reserve providers are connected to buses 10, 66, 65 and 26 (G1 to G4). The actual wind energy outputs at Kingsbridge, Paroches and Port Alma2 wind farms in Ontario, Canada are used for analysis. It is also assumed that 4 different reserve providers located in southern Ontario (Desjoachims, Nanticoke, Beck2 and Lambton) can enter into the proposed option contracts. Fig. 3.9 shows the regional map of Ontario South West Generators. It is assumed that 3 separate call and put contracts are needed for 3 consecutive hours (1:00 pm to 3:00 pm) on March 1, 2012. All contracts are needed 4 hours ahead at 9:00 am to 11:00 am. The maximum capacity of each reserve provider is assumed to be $10 \mathrm{MWh}$ and finally it is assumed that the penalty factor imposed by the ISO for under/over production is equal to $\gamma=0.5$. The forecasted nodal prices for wind plant and reserve providers are shown in Tables 3.3 and 3.4. The prices quoted by wind farms (W1 to W3) are assumed to be $37 \%, 38 \%$ and $42 \%$ higher than their corresponding nodal market prices shown in Table 3.3 respectively. The prices quoted by reserve providers (G1 to G4) are assumed to be $23 \%, 14 \%, 7 \%$ and $8 \%$ higher than their corresponding nodal market prices shown in Table 3.4 (all underproduction) respectively. Fig. 3.10 shows the recorded wind energy production at different wind farms on March 1, 2012. The Cauchy factor $\gamma / \mathrm{EF}_{\mathrm{w}}$ is assumed to be $10 \%$ at this time of the year. The market volatility is assumed to be $20 \%$. In this example we assume that each wind plant's PDF is divided into 6 segments and therefore we need to run 216 different optimizations in order to aggregate the final expected values. For calculation of the actual revenue of wind generators, the total energy available and the total energy contracted in each hour must be compared. Taking $\lambda \mathrm{A}_{\mathrm{i}}$ as the actual value of market price very close to 
the ISO estimated prices, $\mathrm{EF}_{\mathrm{w}}$ as the forecasted energy for a certain time and $\mathrm{EA}_{\mathrm{w}}$ as the actual value of wind energy available at that time, four different cases may occur which are shown in Table 3.5.

On solving the proposed formulations and comparing the results with actual data, Table 3.6 gives us the related case numbers that happened in real time based on Table 3.5 scenarios (all underproduction). Fig. 3.11 shows the total amount of revenue of each wind farm with the option contract compared to without the contract. The results show that in the three hour period of study, the wind generators save a total amount of $\$ 812.76$ by using the proposed method. It must be noted that if a wind company decides to go with both call and put contracts for each hour, an extra premium cost per hour must be deducted from its total revenue.

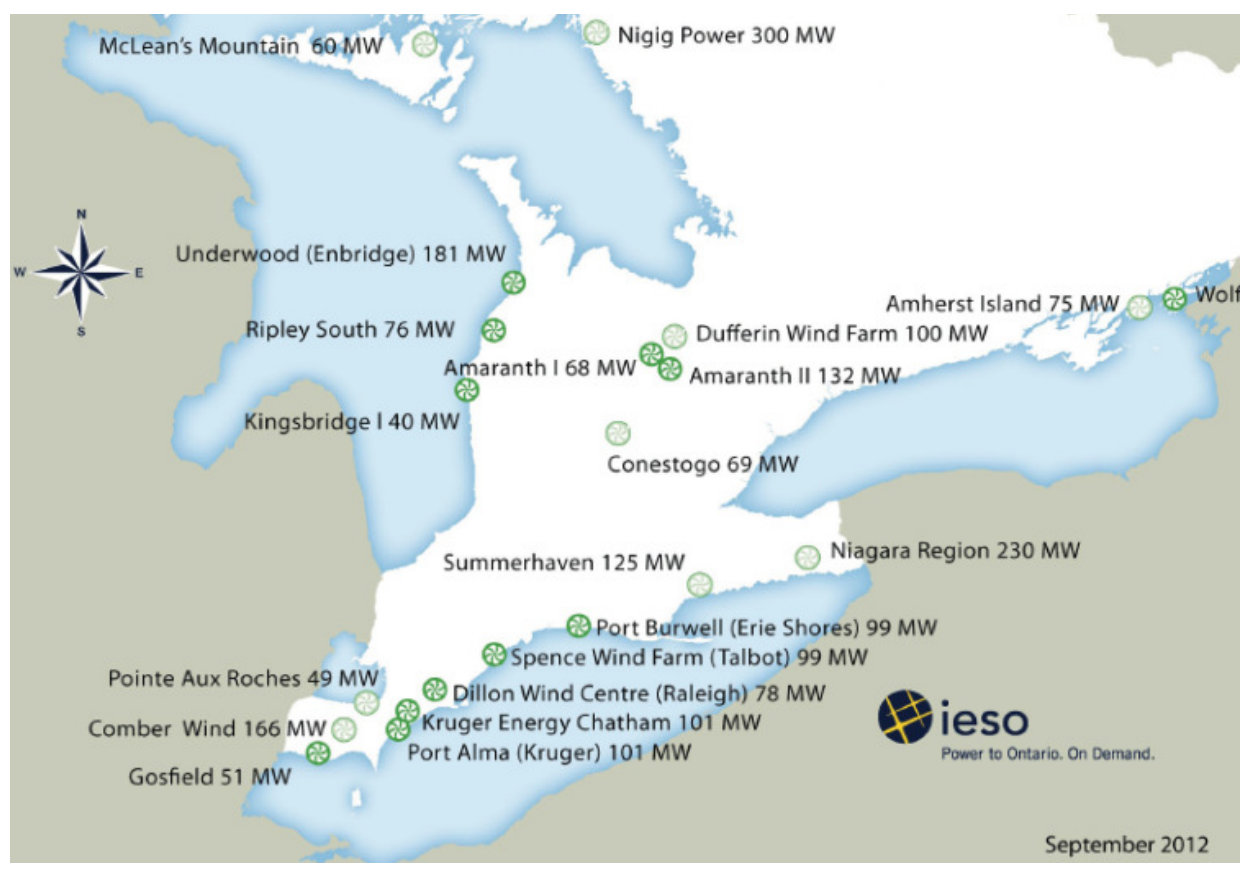

Fig. 3.9 Ontario South-West Generators [59] 
Table 3.3 Nodal market prices at wind farms (\$/MWh)

\begin{tabular}{l|l|l|l}
\hline Wind Farm & $1: 00 \mathrm{pm}$ & $2: 00 \mathrm{pm}$ & $3: 00 \mathrm{pm}$ \\
\hline Kingsbridge & 59.46 & 60.37 & 60.41 \\
\hline Paroches & 58.40 & 59.24 & 59.27 \\
\hline Port Alma2 & 58.68 & 59.49 & 59.52 \\
\hline
\end{tabular}

Table 3.4 Nodal market prices at reserve providers (\$/MWh)

\begin{tabular}{c|c|c|c}
\hline Wind Farm & $1: 00 \mathrm{pm}$ & $2: 00 \mathrm{pm}$ & $3: 00 \mathrm{pm}$ \\
\hline Desjoachims & 56.2 & 57.0 & 57.3 \\
\hline Nanticoke & 58.8 & 59.4 & 59.6 \\
\hline Beck2 & 58.5 & 59.0 & 59.1 \\
\hline Lampton & 59.0 & 59.6 & 59.8 \\
\hline
\end{tabular}




\section{Table 3.5 Actual Revenue of Wind Generators}

\section{No contract- Underproduction}

Revenue $=\lambda \mathrm{A}_{\mathrm{i}} \cdot \mathrm{EA}_{\mathrm{w}}-(1+\gamma \mathrm{o}) \cdot \lambda \mathrm{A}_{\mathrm{i}} \cdot\left(\mathrm{EF}_{\mathrm{w}}-\mathrm{EA}_{\mathrm{w}}\right)$

\section{With Contract-Underproduction}

Case 1: $\mathrm{EA}_{\mathrm{w}}+\mathrm{EC}_{\mathrm{k}}<\mathrm{EF}_{\mathrm{w}}$

Revenue $=\lambda \mathrm{A}_{\mathrm{i}} \cdot\left(\mathrm{EA}_{\mathrm{w}}+\mathrm{EC}_{\mathrm{k}}\right)-\left(\mathrm{kmc}_{\mathrm{i}}+\mathrm{omc}_{\mathrm{i}}\right) \cdot \mathrm{EC}_{\mathrm{k}}-(1+\gamma \mathrm{o}) \cdot \lambda \mathrm{A}_{\mathrm{i}} \cdot\left(\mathrm{EF}_{\mathrm{w}}-\mathrm{EA}_{\mathrm{w}}-\mathrm{EC}_{\mathrm{k}}\right)$

Case 2: $\mathrm{EA}_{\mathrm{w}}+\mathrm{EC}_{\mathrm{k}}>\mathrm{EF}_{\mathrm{w}}$

Revenue $=\lambda \mathrm{A}_{\mathrm{i}} \cdot\left(\mathrm{EF}_{\mathrm{w}}\right)-\left(\mathrm{kmc}_{\mathrm{i}}+\mathrm{omc}_{\mathrm{i}}\right) \cdot \mathrm{EC}_{\mathrm{k}}+\left(1-\gamma_{\mathrm{o}}\right) \cdot \lambda \mathrm{A}_{\mathrm{i}} \cdot\left(\mathrm{EA}_{\mathrm{w}}+\mathrm{EC}_{\mathrm{k}}-\mathrm{EF}_{\mathrm{w}}\right)$

\section{No Contract -Overproduction}

Revenue $=\lambda \mathrm{A} \cdot \mathrm{EF}_{\mathrm{w}}+(1-\gamma \mathrm{O}) \cdot \lambda \mathrm{A} \cdot\left(\mathrm{EA}_{\mathrm{w}}-\mathrm{EF}_{\mathrm{w}}\right)$

\section{With Contract -Overproduction}

Case 3: $\mathrm{EA}_{\mathrm{w}}-\mathrm{EP}_{\mathrm{k}}>\mathrm{EF}_{\mathrm{w}}$

Revenue $=\lambda \mathrm{A}_{\mathrm{i}} \cdot \mathrm{EF}_{\mathrm{w}}+\left(\mathrm{kmp}_{\mathrm{i}}-\mathrm{Omp}_{\mathrm{i}}\right) \cdot \mathrm{EP}_{\mathrm{k}}+\left(1-\gamma_{\mathrm{o}}\right) \cdot \lambda \mathrm{A}_{\mathrm{i}} \cdot\left(\mathrm{EA}_{\mathrm{w}}-\mathrm{EF}_{\mathrm{w}}-\mathrm{EP}_{\mathrm{k}}\right)$

Case 4: $\mathrm{EA}_{\mathrm{w}}-\mathrm{EP}_{\mathrm{k}}<\mathrm{EF}_{\mathrm{w}}$

Revenue $=\lambda A_{i} \cdot\left(\mathrm{EA}_{\mathrm{w}}-\mathrm{EP}_{\mathrm{k}}\right)+\left(\mathrm{kmp}_{\mathrm{i}}-\mathrm{omp}_{\mathrm{i}}\right) \cdot \mathrm{EP}_{\mathrm{k}}-(1+\gamma \mathrm{o}) \cdot \lambda \mathrm{A}_{\mathrm{i}} \cdot\left(\mathrm{EF}_{\mathrm{w}}-\mathrm{EA}_{\mathrm{w}}+\mathrm{EP}_{\mathrm{k}}\right)$

Table 3.6 Case number / Wind forecast data (MWh) (Refer to table 3.5)

\begin{tabular}{l|l|l|l}
\hline Wind Farm & $1: 00 \mathrm{pm}$ & $2: 00 \mathrm{pm}$ & $3: 00 \mathrm{pm}$ \\
\hline Kingsbridge & $1 / 20$ & $1 / 16$ & $1 / 15$ \\
\hline Paroches & $1 / 30$ & $1 / 30$ & $1 / 25$ \\
\hline Port Alma2 & $1 / 80$ & $1 / 50$ & $1 / 55$ \\
\hline
\end{tabular}




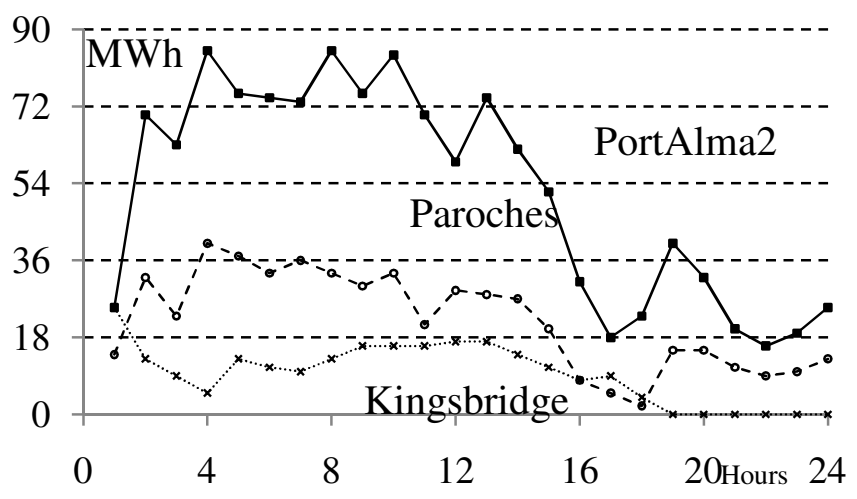

Fig. 3.10 Actual recorded wind energy production at different wind farms in March 1,2012 (24 hours)

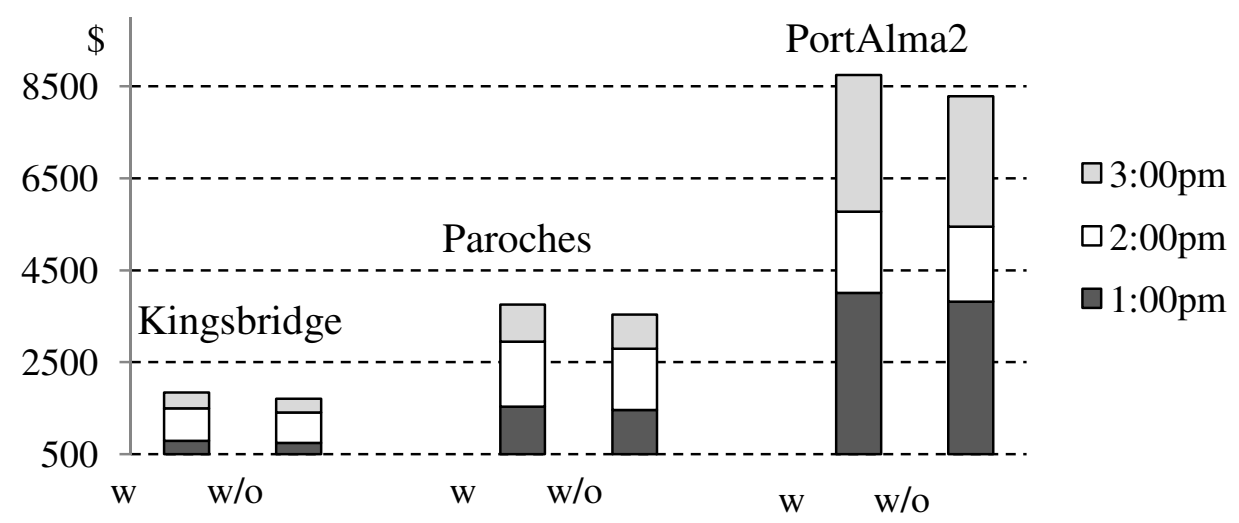

Fig. 3.11 Total revenue of wind farms with (w) and without (w/o) contract by aggregation of 216 scenarios for each hour 


\subsection{Chapter Summary}

This Chapter proposes an option based intra-day secondary market model with several wind plants and several reserve providers to trade in reserves by optimally determining nodal strike prices and option premiums. To ensure network feasibility of these option contracts, MVA limits on transmission lines and transformers are enforced. This Chapter considers an electricity market where no subsidy or favourable consideration is given to wind generators a possible future electricity market scenario whereby they are required to compete with conventional plants on equal footings. The market model determines optimal values for premiums, strike prices and quantum of energy trade via a market settlement formulation. In both cases of call (underproduction) and put (overproduction) options, both wind generators and reserve providers benefit by getting a better economic outcome than that offered by the ISO. Two examples are studied: A 5-bus example brings out the key features of the proposed model and the effect of line flow restrictions. The IEEE 118-bus system with real Ontario wind farm data highlights the applicability of the proposed method to a larger system with real wind generators. 


\section{Chapter 4: Energy Reserve Trade Optimization for Wind Generators Using Black-Scholes Options in}

\section{Small Size Power Systems}

\subsection{Introduction}

In the second chapter of this dissertation we introduced a secondary market model that only works for two participants, one option buyer and one option seller. In the third chapter of this dissertation we expanded the market to include several buyers and sellers. We also included the network security constraints in a power system of unlimited geographical size.

In the previous chapters 2 and 3, we used discrete type binomial trees to model options. In this chapter, the use of the Black-Scholes financial model, a continuous model, for pricing options is proposed. Further, the short term wind power forecast error is modeled using a Gaussian distribution. When it comes to procuring reserve from different reserve providers in the system, the feasibility of delivery and network security must be assessed. This chapter integrates $\mathrm{AC}$ network security constraints into the reserve trading framework via our proposed option market formulation.

In this chapter we look into a small size power system in which all wind farms have either underproduction or overproduction at the same time. Similar to the previous chapter, in this chapter, it is proposed that wind generators buy options for reserves from providers ahead of the generation hour in a secondary reserve market. Wind generators will exercise their options at the generation hour as required by calling upon reserve providers to absorb their wind energy overproduction or supply energy to supplement their wind energy 
underproduction. Reserve options are purchased by paying premiums and options are exercised by paying strike prices. The problem then focuses on determining the optimum volume of reserves traded, optimum premium values and optimum strike prices.

\subsection{Proposed Secondary Market Model}

The proposed model intends to introduce a secondary market in which several Wind companies can buy reserve from several reserve providers with consideration of the security constraints. Gaussian model is used for the calculation of wind energy forecast errors and Black and Scholes model is used for option pricing. The proposed secondary intra-day reserve model is shown in Fig. 2.1 and is used in this work.

\subsection{Options Model for Prices}

In the case of underproduction, all wind generators need to procure their energy shortfalls from other available reserve providers at the least cost. In the case of overproduction all wind generators need to sell their excess energy at the best possible prices. In the proposed model, it is assumed that wind generators with underproduction will face a penalty factor of $\gamma 0$ which marks up the market price for the energy it must buy from the market to compensate for its underproduction. Similarly it is also assumed that wind generators with overproduction will face a discount factor of $\gamma 0$ which marks down the market price for the over produced energy it sells to the market. The factor $\gamma 0$ represents the additional costs borne by the ISO to arrange for these reserves and transfers them to wind generators. The purpose of this research is to form an intra-day secondary market including renewable generators and reserve providers to reduce the effect of wind energy forecast errors and 
provide better economic options for market participants. Call options are considered in the case of underproduction and Put options are considered in the case of overproduction. Let us assume that $\lambda E_{i}$ is the marginal energy price determined by the day-ahead unit commitment process at the $\mathrm{i}^{\text {th }}$ bus. At the $\mathrm{i}^{\text {th }}$ bus, let $\mathrm{Kc}_{\mathrm{i}}$ and $\mathrm{Kp}$ be call and put options strike prices. Using (1.9) to (1.11) and considering a zero interest rate for call option contract and assuming different market price volatility for different buses, we can write an equation to compute call option premiums:

$\mathrm{Cm}_{\mathrm{i}}=\lambda \mathrm{E}_{\mathrm{i}} \cdot \mathrm{N}\left(\mathrm{d} 1 \lambda_{\mathrm{i}}\right)-\mathrm{Kc}_{\mathrm{i}} \cdot \mathrm{N}\left(\mathrm{d} 2 \lambda_{\mathrm{i}}\right)$

Where

$\mathrm{d} 1 \lambda_{\mathrm{i}}=\frac{\ln \left(\lambda \mathrm{E}_{\mathrm{i}} / \mathrm{Kc}_{\mathrm{i}}\right)+\left(\sigma \lambda_{\mathrm{i}}^{2} / 2\right) \cdot \mathrm{t}}{\sigma \lambda_{\mathrm{i}} \sqrt{\mathrm{t}}}$

$\mathrm{d} 2 \lambda_{\mathrm{i}}=\mathrm{d} 1 \lambda_{\mathrm{i}}-\sigma \lambda_{\mathrm{i}} \sqrt{\mathrm{t}}$

And for put option contract using (1.13) we can write an expression for premium as below:

$\mathrm{Pm}_{\mathrm{i}}=\lambda \mathrm{E}_{\mathrm{i}} \cdot \mathrm{N}\left(\mathrm{d} 1 \lambda_{\mathrm{i}}\right)-\mathrm{Kp}_{\mathrm{i}} \cdot \mathrm{N}\left(\mathrm{d} 2 \lambda_{\mathrm{i}}\right)-\lambda \mathrm{E}_{\mathrm{i}}+\mathrm{Kp}_{\mathrm{i}}$

Where

$\mathrm{d} 1 \lambda_{\mathrm{i}}=\frac{\ln \left(\lambda \mathrm{E}_{\mathrm{i}} / \mathrm{Kp} \mathrm{p}_{\mathrm{i}}\right)+\left(\sigma \lambda_{\mathrm{i}}^{2} / 2\right) \cdot \mathrm{t}}{\sigma \lambda_{\mathrm{i}} \sqrt{\mathrm{t}}}$

$\mathrm{d} 2 \lambda_{\mathrm{i}}=\mathrm{d} 1 \lambda_{\mathrm{i}}-\sigma \lambda_{\mathrm{i}} \sqrt{\mathrm{t}}$

These parameters will be calculated using the proposed optimization algorithm. The participants of the proposed model, wind generators and reserve providers, must calculate the expected underproduction or overproduction of wind energy at the future time (maturity of an option), and determine the optimal strike and option prices at each bus of the power system. These optimal values should maximize the social welfare amongst all participants, 
i.e. sellers (reserve providers) and buyers (wind generators). In small size power systems all wind plants usually have either underproduction or overproduction and they can't have the benefit of smoothing effects that occur in large size power systems.

In the case of underproduction, it is assumed that all of wind generators participating in an option market have underproduction at the maturity time. This assumption results in an optimization formulation that shall provide the highest call option prices considering maximum participants. Based on results of this proposed call option, wind generators will purchase reserves from the call option market to avoid penalties imposed by the ISO for underproduction.

In the case of overproduction, it is assumed that all of wind generators participating in an option market have overproduction at the maturity time. This assumption leads to maximum participation and thus the highest put option prices. These wind generators can use the amount of negative reserve they purchased in the option market to avoid discounted prices imposed by the ISO.

The optimization process must assure wind generators and reserve providers that these two groups are better off and can earn more revenue by adopting our proposed method than what they would earn without any options.

\subsection{Distribution model for Wind Energy Forecast Error}

Let's assume that the forecasted energy of a certain wind farm for a certain time in the near future (4 to 5 hours from now for an hour period) is $\mathrm{EF}_{\mathrm{w}}$. The Gaussian probability distribution function of absorbed energy for this wind farm is shown in Fig. 4.1. If after 5 
hours the absorbed wind energy by this wind farm is less than the mean value $\left(\mathrm{EF}_{\mathrm{w}}\right)$, the wind farm will face an underproduction scenario and if the absorbed power is more than $\mathrm{EF}_{\mathrm{w}}$, it will face an overproduction scenario. Now let's assume that the random variable $\mathrm{x}$ represents the amount of absorbed energy for that one hour period. For any $\mathrm{x}$ less than $\mathrm{EF}_{\mathrm{w}}$, the amount of underproduction is $\mathrm{EF}_{\mathrm{w}}-\mathrm{x}$ and we can calculate the expected under produced energy by using the following equation:

$$
\left[\overline{E U_{w}}=\frac{1}{\sigma E_{w} \cdot \sqrt{2 \pi}} \int_{-i n f}^{E F_{w}}\left(E F_{w}-x\right) \cdot e^{\frac{-\frac{1}{2}\left(X-E F_{w}\right)^{2}}{\sigma E_{w}{ }^{2}}} \cdot d x\right]
$$

In the above equation, $\sigma \mathrm{E}_{\mathrm{w}}$ means the standard deviation associated with the forecast Gaussian distribution. Similarly For any $\mathrm{x}$ more than $\mathrm{EF}_{\mathrm{w}}$, the amount of overproduction is $\mathrm{x}-\mathrm{EF}_{\mathrm{w}}$ and we can calculate the expected over produced energy by using the following equation:

$$
\left[\overline{\mathrm{EO}_{\mathrm{w}}}=\frac{1}{\sigma \mathrm{E}_{\mathrm{w}} \cdot \sqrt{2 \pi}} \int_{\mathrm{EF}_{\mathrm{w}}}^{+\mathrm{inf}}\left(\mathrm{x}-\mathrm{EF}_{\mathrm{w}}\right) \cdot \mathrm{e}^{\frac{-\frac{1}{2}\left(\mathrm{X}-\mathrm{EF}_{\mathrm{w}}\right)^{2}}{\sigma \mathrm{E}_{\mathrm{w}}{ }^{2}}} \cdot \mathrm{dx}\right]
$$




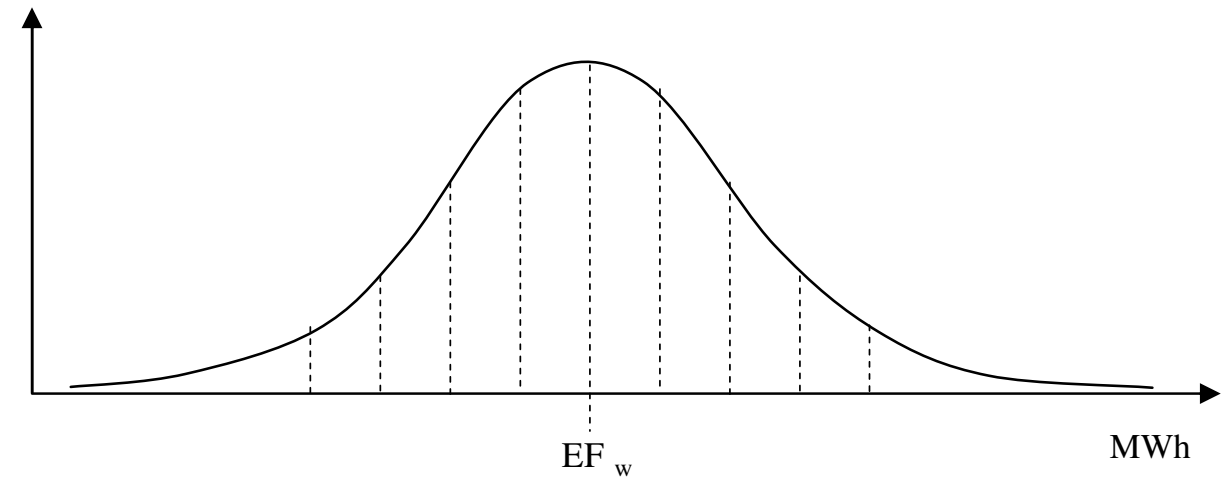

Fig. 4.1 Probability Distribution Function of the wind energy absorbed by a wind farm in near future time span. 


\subsection{Problem Formulation and Objectives}

In this section, the overall formulation of the proposed model is discussed.

\subsubsection{Underproduction objective and constraints}

The objective function in call option is to maximize social welfare amongst the call option market participants using the quoted offers to determine $\mathrm{EU}_{\mathrm{w}}$ and $\mathrm{EC}_{\mathrm{k}}$ :

$\mathrm{OBJ}_{\mathrm{C}}=\sum_{\mathrm{w}=1}^{\mathrm{NW}} \mathrm{EU}_{\mathrm{w}} \cdot \lambda \mathrm{E}_{\mathrm{w}}^{\mathrm{QC}}-\sum_{\mathrm{k}=1}^{\mathrm{NK}} \mathrm{EC}_{\mathrm{k}} \cdot \lambda \mathrm{E}_{\mathrm{k}}^{\mathrm{QC}}$

Subject to:

Limits on Energy Purchase: $0 \leq \mathrm{EU}_{\mathrm{w}} \leq \overline{\mathrm{EU}_{\mathrm{w}}}$

Limits on Energy Capacity: $0 \leq \mathrm{EC}_{\mathrm{k}} \leq \overline{\mathrm{EC}_{\mathrm{k}}}$

Power Balance Equations at bus $i(i \in\{1,2, \ldots, N B\})$ :

$\mathrm{P}_{\mathrm{i}}(\mathrm{V}, \delta)=\mathrm{PG}_{\mathrm{i}}+\frac{\mathrm{EC}_{\mathrm{k} \in \mathrm{i}}}{1 \text { hour }}-\frac{\mathrm{EU}_{\mathrm{w} \in \mathrm{i}}}{1 \text { hour }}-\mathrm{PD}_{\mathrm{i}}$

Reactive Power Balance Equations at bus $i(i \in\{1,2, \ldots, N B\})$ :

$\mathrm{Q}_{\mathrm{i}}(\mathrm{V}, \delta)=\mathrm{QG}_{\mathrm{i}}-\mathrm{QD}_{\mathrm{i}}$

Power flow limits $l^{\text {th }}$ line / transformer:

$-\overline{\mathrm{S}_{l}} \leq \mathrm{S}_{l}(\mathrm{~V}, \delta) \leq \overline{\mathrm{S}_{l}}$

Voltage magnitude constraints at each $\mathrm{i}^{\text {th }}$ bus:

$\underline{\mathrm{V}_{\mathrm{i}}} \leq \mathrm{V}_{\mathrm{i}} \leq \overline{\mathrm{V}}_{\mathrm{i}}$

\subsubsection{Locational marginal prices for underproduction}

The lambda multiplier corresponding to the $\mathrm{i}^{\text {th }}$ bus in the equality constraint (4.12) is $\lambda \mathrm{E}_{\mathrm{i}}^{\mathrm{OC}}$. 
The value of the Lagrangian multiplier associated with the real power balance equation at each bus must be equal to the total amount of money payable at that bus.

$\lambda \mathrm{E}_{\mathrm{i}}^{\mathrm{OC}}=\mathrm{Kc}_{\mathrm{i}}+\mathrm{Cm}_{\mathrm{i}}$

After determining $\lambda E_{1}^{\mathrm{OC}}$ by optimizing (4.9)-(4.15), solving (4.1) and (4.16), one can determine $\mathrm{Kc}_{\mathrm{i}}$ and $\mathrm{Cm}_{\mathrm{i}}$. If the solution benefits both reserve service providers and wind generators, the following must be true:

$\lambda \mathrm{E}_{\mathrm{i}} \leq \lambda \mathrm{E}_{\mathrm{i}}^{\mathrm{OC}} \leq(1+\gamma 0) \cdot \lambda \mathrm{E}_{\mathrm{i}}$

\subsubsection{Overproduction objective and constraints}

The objective function in put option is to maximize social welfare amongst the put option market participants using the quoted offers to determine $\mathrm{EP}_{\mathrm{k}}$ and $\mathrm{EO}_{\mathrm{w}}$ :

$\mathrm{OBJ}_{\mathrm{P}}=\sum_{\mathrm{k}=1}^{\mathrm{NK}} \mathrm{EP}_{\mathrm{k}} \cdot \lambda \mathrm{E}_{\mathrm{k}}^{\mathrm{QP}}-\sum_{\mathrm{w}=1}^{\mathrm{NW}} \mathrm{EO}_{\mathrm{w}} \cdot \lambda \mathrm{E}_{\mathrm{w}}^{\mathrm{QP}}$

Subject to:

Limits on Energy sold: $0 \leq \mathrm{EO}_{\mathrm{w}} \leq \overline{\mathrm{EO}_{\mathrm{w}}}$

Limits on Energy Capacity: $0 \leq \mathrm{EP}_{\mathrm{k}} \leq \overline{\mathrm{EP}_{\mathrm{k}}}$

Power Balance Equations at bus $i(i \in\{1,2, \ldots, N B\})$ :

$\mathrm{P}_{\mathrm{i}}(\mathrm{V}, \delta)=\mathrm{PG}_{\mathrm{i}}-\frac{\mathrm{EP}_{\mathrm{k} \in \mathrm{i}}}{1 \text { hour }}+\frac{\mathrm{EO}_{\mathrm{w} \in \mathrm{i}}}{1 \text { hour }}-\mathrm{PD}_{\mathrm{i}}$

Reactive Power Balance Equations at bus $i(i \in\{1,2, \ldots, N B\})$ :

$\mathrm{Q}_{\mathrm{i}}(\mathrm{V}, \delta)=\mathrm{QG}_{\mathrm{i}}-\mathrm{QD}_{\mathrm{i}}$

Power flow limits $l^{\text {th }}$ line / transformer: 
$-\overline{\mathrm{S}_{l}} \leq \mathrm{S}_{l}(\mathrm{~V}, \delta) \leq \overline{\mathrm{S}_{l}}$

Voltage constraints at each bus:

$\underline{\mathrm{V}_{\mathrm{i}}} \leq \mathrm{V}_{\mathrm{i}} \leq \overline{\mathrm{V}_{\mathrm{i}}}$

\subsubsection{Locational marginal prices for overproduction}

The lambda multiplier corresponding to the $\mathrm{i}^{\text {th }}$ bus in the equality (4.21) is $\lambda \mathrm{E}_{\mathrm{i}}^{\mathrm{OP}}$.

At the ith bus, the total payable money should be equal to the strike price less the option price.

$\lambda \mathrm{E}_{\mathrm{i}}^{\mathrm{OP}}=\mathrm{Kp}_{\mathrm{i}}-\mathrm{Pm}_{\mathrm{i}}$

Solving (4.4) and (4.25), one may determine $\mathrm{Kp}_{\mathrm{i}}$ and $\mathrm{Pm}_{\mathrm{i}}$.

For a solution benefitting both wind generators and reserve providers, the following must be true:

$(1-\gamma 0) . \lambda \mathrm{E}_{\mathrm{i}} \leq \lambda \mathrm{E}_{\mathrm{i}}^{\mathrm{OP}} \leq \lambda \mathrm{E}_{\mathrm{i}}$

\subsection{Algorithm}

Fig. 4.2 shows the algorithm of the proposed formulation. As mentioned in our formulation, transmission system data is essential to evaluate the feasibility of each transaction. In addition to grid data, all quoted prices and the ISO estimated prices and forecasted wind energies are collected at the beginning of the optimization process. 


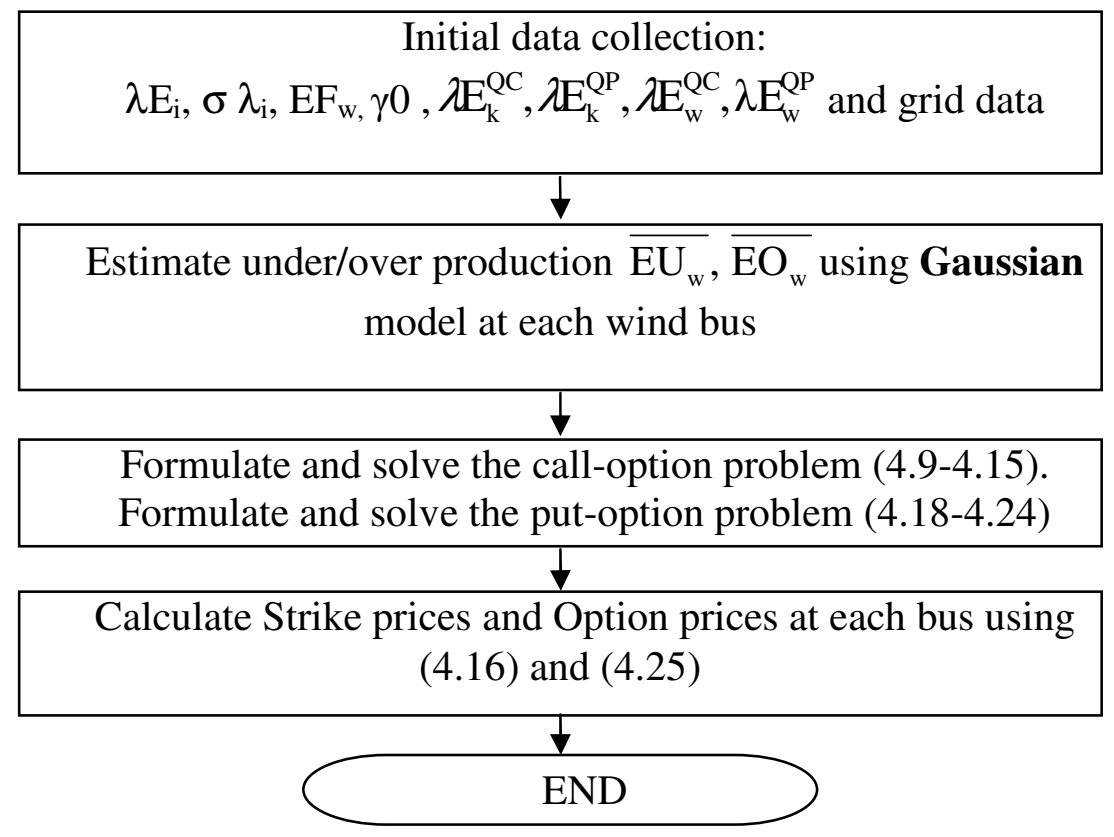

Fig. 4.2 Proposed model's algorithm 


\subsection{Results and Analysis}

\subsubsection{6-bus test system}

Fig. 4.3 shows the schematic diagram of the 6-Bus test system. It is assumed that two wind farms are connected to buses 4 and 5 (W1 and W2) and two reserve providers are connected to buses 2 and 3 (G1 and G2). All lines have the maximum capacity of 250 MVA and two $220+$ j20 MVA loads are connected to buses 5 and 6. Generators G1 and G2 are scheduled to supply $200 \mathrm{MWh}$ each by the ISO before entering into any option contract. It is assumed that the penalty/discount factor imposed by the ISO for under/over production is $\gamma 0=0.5$. The original ISO estimated market prices using day-ahead unit commitment and all quoted prices are given in Tables 4.1 and 4.2. The short-term 4 hours ahead forecasted wind energy at both wind farms is $200 \mathrm{MWh}$. At this hour, call and put option contracts for reserves are traded through this secondary intra-day market for use after 4 hours (the forecasted time). The maximum capacity of reserve providers (G1 and G2) is assumed to be $70 \mathrm{MWh}$ each. The market price volatility for all nodes is assumed to be $10 \%$ per hour. Table 4.3 shows the line data of such a system. Using the given data and adopting the 6-bus Test system as described above the optimal option prices and scheduled energy for each node are calculated. Fig. 4.4 shows the variation of locational marginal prices with respect to different wind energy forecast standard deviations in the case of underproduction. As mentioned in (4.16), each locational marginal price is equal to the summation of optimum call strike and premium prices. 


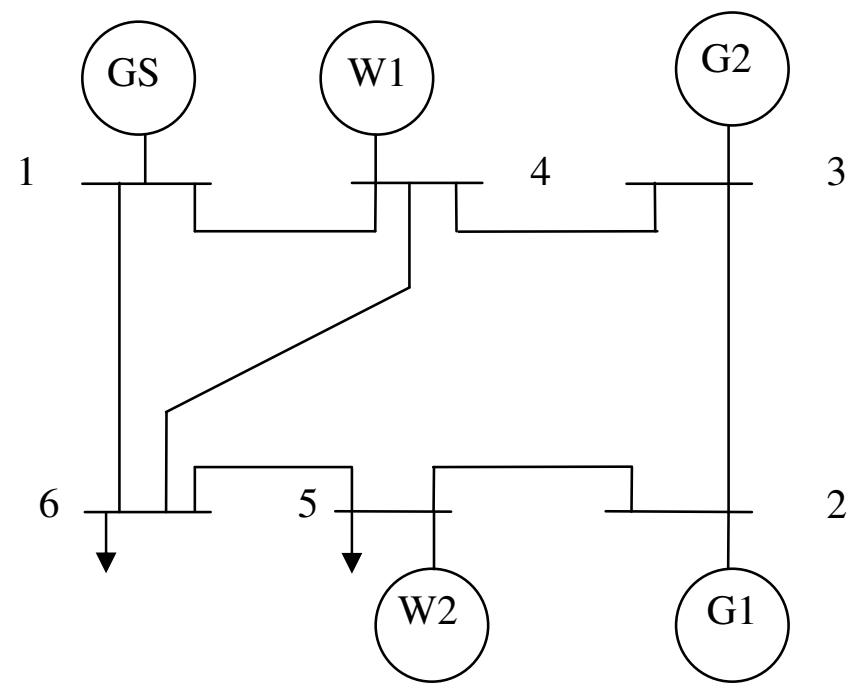

Fig. 4.3 The schematic diagram of the 6-Bus test system

Table 4.1 Nodal prices in the Example 1 estimated using day-ahead unit commitment (\$/MWh)

\begin{tabular}{|c|c|c|c|c|}
\hline $\begin{array}{c}\text { Bus } \\
\text { Number 1 } \\
\text { GS }\end{array}$ & $\begin{array}{c}\text { Bus } \\
\text { Number 2 } \\
\text { G1 }\end{array}$ & $\begin{array}{c}\text { Bus } \\
\text { Number 3 } \\
\text { G2 }\end{array}$ & $\begin{array}{c}\text { Bus } \\
\text { Number 4 } \\
\text { W1 }\end{array}$ & $\begin{array}{c}\text { Bus } \\
\text { Number 5 } \\
\text { W2 }\end{array}$ \\
\hline 28.45 & 31.79 & 29.46 & 27.23 & 33.80 \\
\hline
\end{tabular}

Table 4.2 Quoted prices in the Example 1 (\$/MWh)

\begin{tabular}{|c|c|c|c|c|c|}
\hline & Bus & Bus & Bus & Bus & Bus \\
& Number & Number & Number & Number & Number \\
& 1 & 2 & 3 & 4 & 5 \\
GS & G1 & G2 & W1 & W2 \\
\hline Underproduction & N/A & 34.96 & 35.35 & 38.12 & 43.94 \\
\hline Overproduction & N/A & 23.84 & 27.98 & 14.97 & 20.28 \\
\hline
\end{tabular}


Table 4.3 6-Bus test system line data

\begin{tabular}{|c|c|c|c|c|}
\hline & $\begin{array}{c}\text { From Bus } \\
\text { Number }\end{array}$ & $\begin{array}{c}\text { To Bus } \\
\text { Number }\end{array}$ & $\begin{array}{c}\text { Resistance } \\
\text { (p.u.) }\end{array}$ & $\begin{array}{c}\text { Inductance } \\
\text { (p.u.) }\end{array}$ \\
\hline Transformer & 1 & 6 & 0.123 & 0.218 \\
\hline Transformer & 1 & 4 & 0.080 & 0.270 \\
\hline Line & 4 & 6 & 0.097 & 0.207 \\
\hline Line & 5 & 2 & 0.102 & 0.240 \\
\hline Line & 2 & 3 & 0.123 & 1.250 \\
\hline Line & 5 & 6 & 0.100 & 0.240 \\
\hline Line & 4 & 3 & 0.100 & 0.240 \\
\hline
\end{tabular}

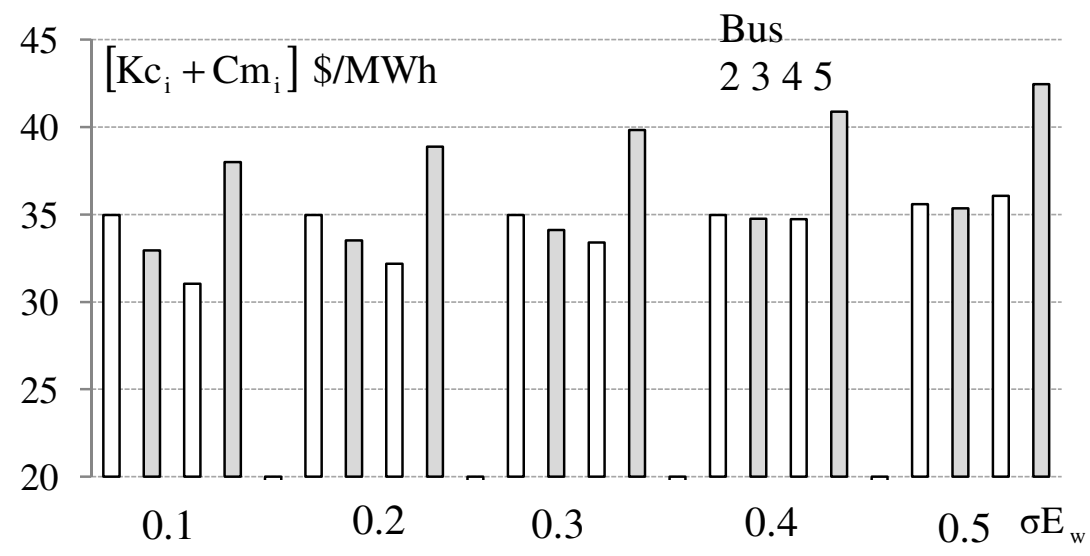

Fig. 4.4 Variation of locational marginal prices for underproduction with respect to Wind energy standard deviation (\$/MWh) 
Higher standard deviation means larger uncertainty and thus raises prices for the majority of the buses. Fig. 4.5 shows the variation of scheduled energy for wind underproduction and overproduction at buses 4 and 5. As expected, higher standard deviation means a higher uncertainty and higher reserve values are required by wind generators. Fig. 4.6 shows the amount of optimal reserve provided by reserve suppliers at buses 2 and 3 for the underproduction case. As it is shown in this graph, for wind energy standard deviations of 0.1 to 0.4 only G1 (Bus 2) supplies reserve but for standard deviation of 0.5 and higher, G2 (Bus 3) is also got scheduled. This is because G1 (Bus 2) has reached its maximum capacity of 70 MWh reserve at that point. Fig. 4.7 shows the negative reserve for overproduction in the put option and it is provided by G2 (Bus 2) only because it is more economical and it can readily lower its output from $200 \mathrm{MWh}$ downward. In order to examine the effect of line constraints in the example, assume that the maximum capacity of line connecting bus 2 to bus 5 is changed from 90 MVA to 50 MVA for a wind energy forecast standard deviation of 0.3. Fig. 4.8 shows that as the line limit between buses 2 and 5 decreases, W2 connected to bus 5 has less ability to purchase energy to compensate for its underproduction. However W1 connected to Bus 4 is not affected in this respect. Fig. 4.8 also shows variation of optimal scheduled reserve with respect to security constraint variation of line 2-5. Again the lower amount of allowable flow on this line will affect the scheduled reserve amounts. Variation of locational marginal prices for underproduction with respect to security constraint variation of line 2-5 is shown in Fig. 4.9. As mentioned before, each locational marginal price is equal to summation of optimum call strike and premium prices. The sensitivity of prices with respect to security constraint variation of line $2-5$ is observable in this graph. The price at buses 3,4 and 5 increases while the price at bus 2 is almost constant. 


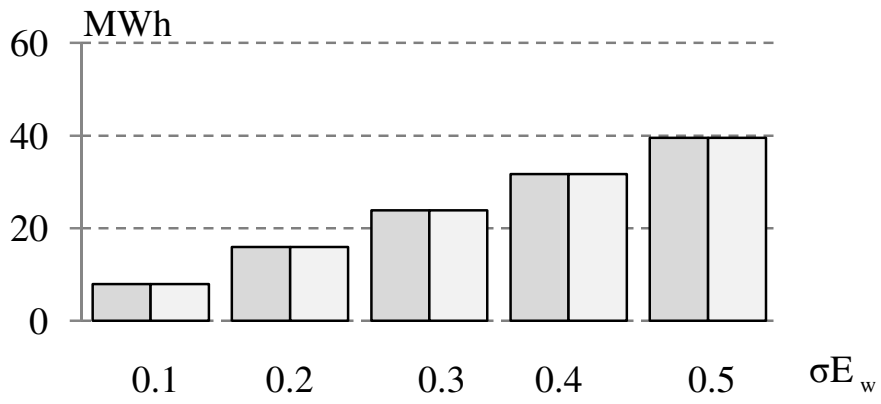

Fig. 4.5 Wind Energy under or over production

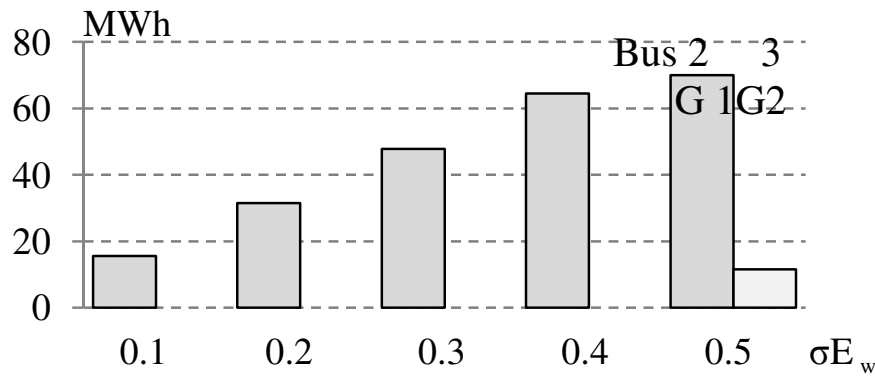

Fig. 4.6 Optimal amounts of positive reserve (call option) for wind underproduction

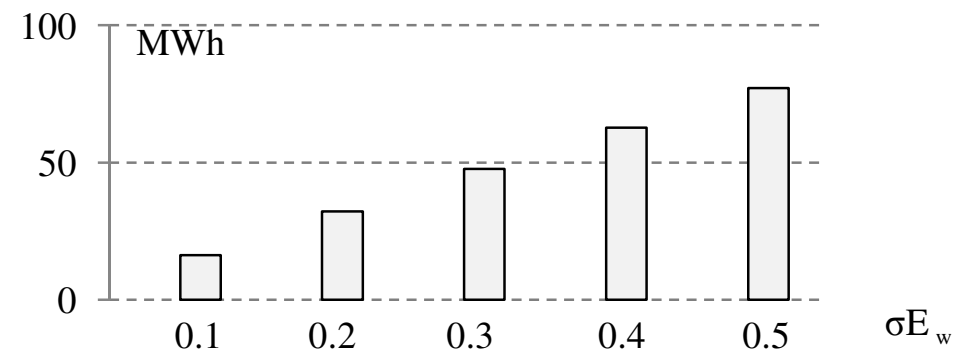

Fig. 4.7 Optimal amounts of negative reserve (put option) for wind overproduction at Bus 3 (G1 at Bus 2 is not scheduled) 


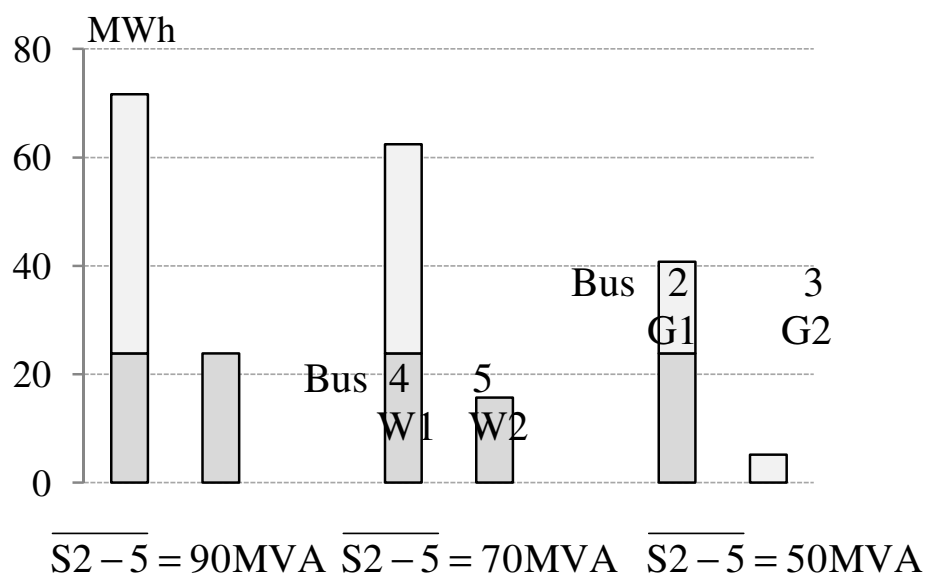

Fig. 4.8 Variation of purchased reserve by Wind Generators (W1 and W2 and optimal reserve sold by reserve providers G1 and G2 with respect to security constraint variation of line 2-5) for underproduction (call option)

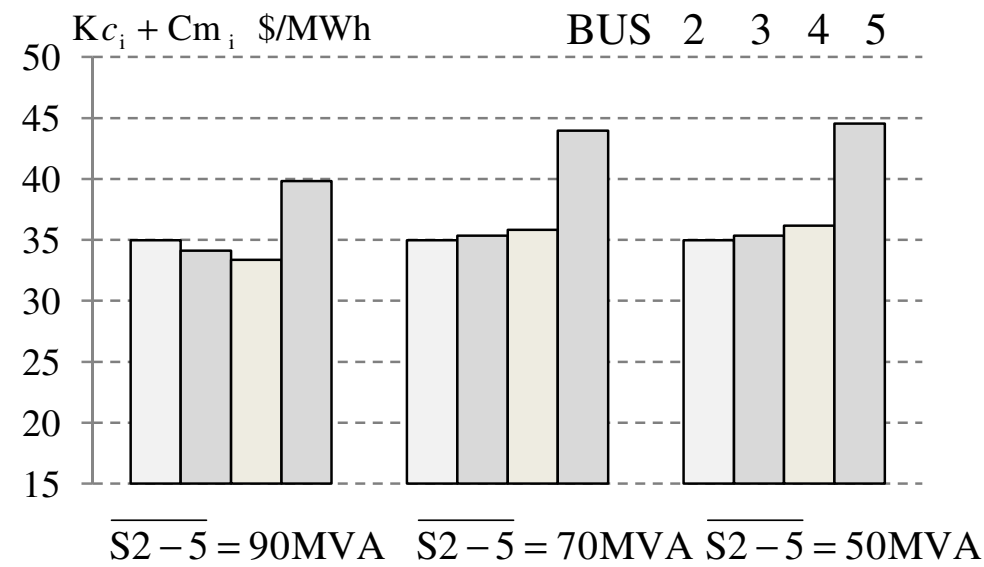

Fig. 4.9 Variation of locational marginal prices with respect to security constraint variation of line $2-5$ 
Assuming that the same reserve providers would have been called by ISO with the same market price here we define four new variables which give better insight of the proposed model:

1) The total avoidable loss due to underproduction for wind generators buying call options is equal to:

$$
\mathrm{TAWC}=\sum_{\mathrm{w}=1, \mathrm{i} \in \mathrm{w}}^{\mathrm{NW}} \mathrm{EU}_{\mathrm{w}} \cdot(1+\gamma 0) \cdot \lambda \mathrm{E}_{\mathrm{i}}-\sum_{\mathrm{w}=1, \mathrm{i} \in \mathrm{w}}^{\mathrm{NW}} \mathrm{EU}_{\mathrm{w}} \cdot\left(\mathrm{Kc}_{\mathrm{i}}+\mathrm{Cm}_{\mathrm{i}}\right)
$$

2) The total additional profit for reserve providers selling call option including capacity costs is equal to:

$$
\mathrm{TERC}=\sum_{\mathrm{k}=1, \mathrm{i} \in \mathrm{k}}^{\mathrm{NK}} \mathrm{EC}_{\mathrm{k}} \cdot\left(\mathrm{Kc}_{\mathrm{i}}+\mathrm{Cm}_{\mathrm{i}}-\lambda \mathrm{E}_{\mathrm{i}}\right)
$$

3) The total avoidable loss due to overproduction for wind generators buying put option is equal to:

$$
\mathrm{TAWP}=\sum_{\mathrm{w}=1, \mathrm{i} \in \mathrm{W}}^{\mathrm{NW}} \mathrm{EO}_{\mathrm{w}} \cdot\left(\mathrm{Kp}_{\mathrm{i}}-\mathrm{Pm}_{\mathrm{i}}\right)-\sum_{\mathrm{w}=1, \mathrm{i} \in \mathrm{w}}^{\mathrm{NW}} \mathrm{EO}_{\mathrm{w}} \cdot(1-\gamma 0) \cdot \lambda \mathrm{E}_{\mathrm{i}}
$$

4) The total additional profit for reserve providers selling put option including capacity costs is equal to:

$$
\mathrm{TERP}=\sum_{\mathrm{k}=1, \mathrm{i} \in \mathrm{k}}^{\mathrm{NK}} \mathrm{EP}_{\mathrm{k}} \cdot\left[\lambda \mathrm{E}_{\mathrm{i}}-\left(\mathrm{Kp}_{\mathrm{i}}-\mathrm{Pm}_{\mathrm{i}}\right)\right]
$$

Table 4.4 shows the variation of the above defined variables with respect to wind energy standard deviation. It is obvious that the objective function and avoided costs increase when standard deviation increases. This means that with a higher degree of forecast uncertainty, the parties can gain more by engaging in reserve trading through options contracts as proposed in this chapter. 
Table 4.4 Results of case study (\$)

\begin{tabular}{|c|c|c|c|c|c|}
\hline Wind & Avoided & Additional & Avoided & Additional & Net Profit \\
Energy & Costs for & Profits for & Costs for & Profits for & OBJ $_{\mathrm{C}}$ \\
Standard & Wind & Reserve & Wind & Reserve & + \\
Deviation & Generators & Providers & Generators & Providers & OBJ $_{\mathrm{P}}$ \\
& (Call) & (Call) & (Put) & (Put) & $\$$ \\
\hline$\sigma \mathrm{E}_{\mathrm{w}}$ & TAWC & TERC & TAWP & TERP & \\
\hline 0.10 & 177.79 & 48.82 & 208.62 & 24.07 & 286.48 \\
\hline 0.20 & 323.90 & 99.04 & 396.52 & 47.59 & 547.23 \\
\hline 0.30 & 434.48 & 150.75 & 564.17 & 70.57 & 782.82 \\
\hline 0.40 & 504.39 & 204.09 & 709.67 & 93.01 & 987.00 \\
\hline 0.50 & 514.19 & 333.77 & 830.49 & 114.87 & 1159.12 \\
\hline
\end{tabular}


Table 4.5 Load flow (MVA) of 6-bus test system (under production)

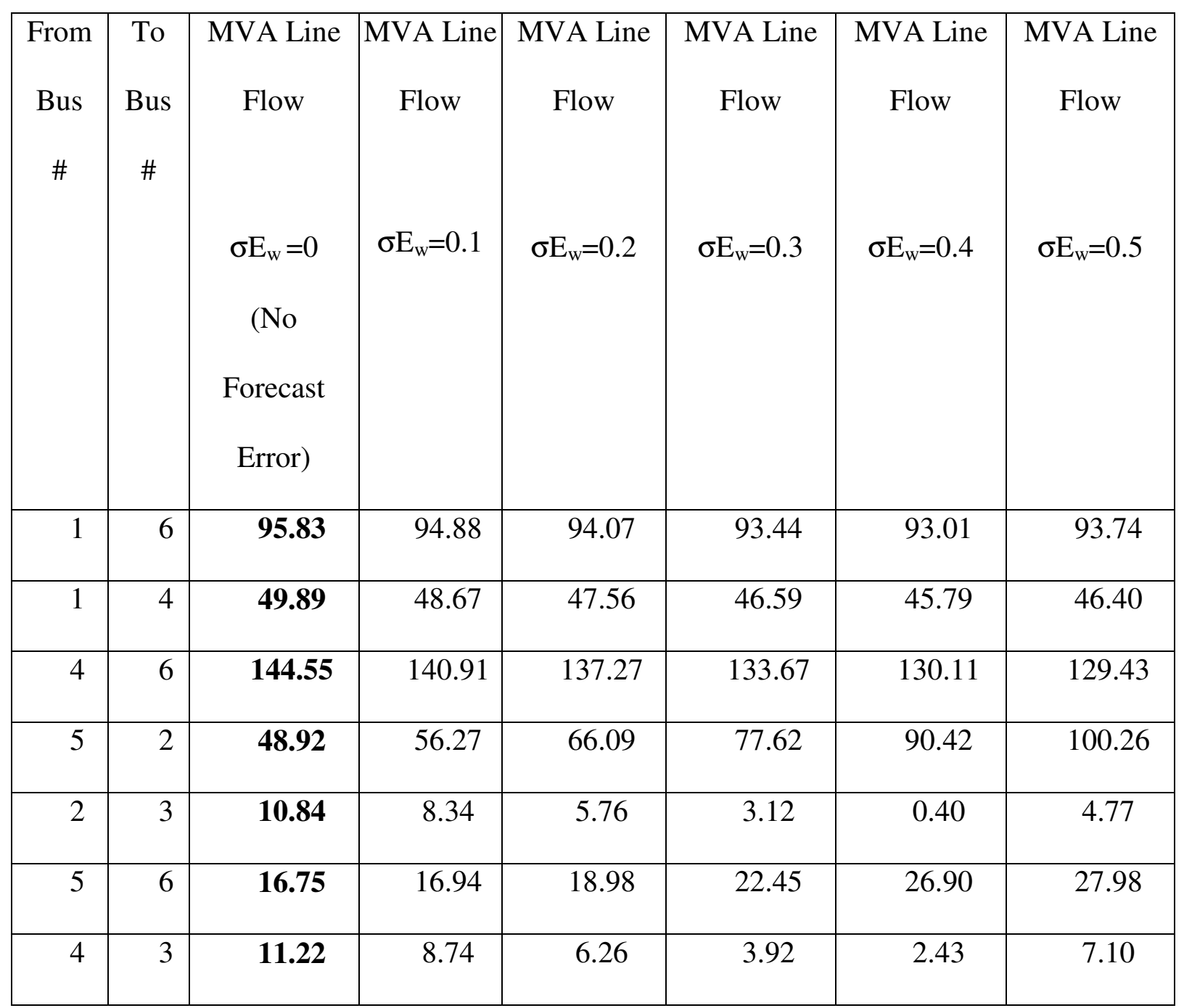


Table 4.5 shows the result of the load flow before and after optimization for different under production levels. In the first column it is assumed that there is no wind energy forecast error and wind generators will produce exactly the amount that they were committed to ISO. In the other columns the result of load flow for different standard deviations of wind energy forecast error is shown.

\subsubsection{8-bus test system}

This study considered four (4) real Ontario wind farm data that is superimposed on the IEEE 118 bus system. In this study we assume that four (4) wind farms are connected to buses 1, 4, 6 and 8 (W1 to W4) and four reserve providers are connected to buses 10, 66, 65 and 26 (G1 to G4). The recorded wind energy at Kingsbridge, Paroches, Port Alma and Port Alma2 wind farms in Ontario are used for this analysis $[11,58]$. In this study we assume that three separate contracts (call and put) are needed for three consecutive hours (1:00 pm to 3:00 pm) of March 1, 2012. All contracts are firmed up at 9:00 am to 11:00 am, 4 hours ahead of production hours (1:00 pm to 3:00 pm). The maximum capacity of reserve providers is $10 \mathrm{MWh}$ each and it is assumed that the penalty/discount factor imposed by the ISO is $\gamma 0=0.5$. The forecasted nodal prices for wind farms and reserve providers are shown in Tables 4.6. The prices quoted by wind farms and reserve providers are shown in Table 4.7. Fig. 4.10 shows the recorded wind energy production at these wind farms on March 1, 2012. The market volatility at each bus is assumed to be $10 \%$ per hour. In order to calculate the actual revenue of each wind generator, the energy available and the energy contracted for each hour must be compared with each other. 
Table 4.6 ISO estimated nodal prices using day-ahead unit commitment in Example 4.7.2 (\$/MWh)

\begin{tabular}{c|c|c|l}
\hline Participants & $1: 00 \mathrm{pm}$ & $2: 00 \mathrm{pm}$ & $3: 00 \mathrm{pm}$ \\
\hline Kingsbridge(W1) & 57.7 & 58.8 & 59.3 \\
\hline Paroches(W2) & 56.7 & 57.8 & 58.2 \\
\hline Port Alma(W3) & 56.7 & 57.8 & 58.3 \\
\hline Port Alma2(W4) & 57.0 & 58.0 & 58.4 \\
\hline G1 & 56.3 & 57.3 & 57.7 \\
\hline G2 & 58.6 & 59.2 & 59.4 \\
\hline G3 & 58.8 & 59.4 & 59.6 \\
\hline G4 & 56.2 & 57.0 & 57.3 \\
\hline
\end{tabular}

Table 4.7 Quoted market prices for underproduction (\$/MWh)

\begin{tabular}{c|r|r|r}
\hline Participants & \multicolumn{1}{|l|}{$1: 00 \mathrm{pm}$} & $2: 00 \mathrm{pm}$ & $3: 00 \mathrm{pm}$ \\
\hline Kingsbridge(W1) & 79.0 & 80.5 & 81.1 \\
\hline Paroches(W2) & 78.2 & 79.7 & 80.2 \\
\hline Port Alma(W3) & 78.2 & 79.7 & 80.4 \\
\hline Port Alma2(W4) & 80.9 & 82.4 & 82.9 \\
\hline G1 & 69.3 & 70.5 & 71.0 \\
\hline G2 & 66.8 & 67.5 & 67.7 \\
\hline G3 & 62.9 & 63.6 & 63.8 \\
\hline G4 & 60.7 & 61.5 & 61.9 \\
\hline
\end{tabular}


By defining $\lambda \mathrm{A}_{\mathrm{i}}$ as the actual energy price (assumed to be very close to projected prices by the ISO), $\mathrm{EA}_{\mathrm{w}}$ as the actual value of wind energy available at that time, we can have four possible cases as shown in Table 4.8.

Knowing actual generation values, one may ascertain if those 4 wind farms under produced or over produced. Various possible cases arising from it are listed in Table 4.8. On optimizing and comparing the results with actual data, Table 4.9 gives the related case numbers as defined in Table 4.8 that actually happened on March 12012 for the four wind farms. Table 4.10 compares the total amount of revenue of each wind farms with and without the option contracts. These results show that in the three-hour period of study, the wind generators save a total amount of $\$ 3053$ by entering into call and put option contracts with reserve providers using our proposed method. The results show that by transacting options contracts, both wind generators and their counterparties, their reserve service providers, will benefit. The market model is hence feasible while respecting network constraints.

It must be noted that if a wind company decides to go with both call and put contracts for each hour, an extra premium cost per hour must be deducted from its total revenue. 
Table 4.8 Actual Revenue of Wind Generators

\section{Underproduction Revenue $\left(\mathrm{EA}_{\mathrm{w}}<\mathrm{EF}_{\mathrm{w}}\right)$}

No contract

Revenue $=\lambda \mathrm{A}_{\mathrm{i}} \cdot \mathrm{EA}_{\mathrm{w}}-(1+\gamma \mathrm{o}) \cdot \lambda \mathrm{A}_{\mathrm{i}} \cdot\left(\mathrm{EF}_{\mathrm{w}}-\mathrm{EA}_{\mathrm{w}}\right)$

\section{With Contract}

Case 1: $\mathrm{EA}_{\mathrm{w}}+\mathrm{EC}_{\mathrm{k}}<\mathrm{EF}_{\mathrm{w}}$

Revenue $=\lambda \mathrm{A}_{\mathrm{i}} \cdot\left(\mathrm{EA}_{\mathrm{w}}+\mathrm{EC}_{\mathrm{k}}\right)-\left(\mathrm{Kc}_{\mathrm{i}}+\mathrm{Cm}_{\mathrm{i}}\right) \cdot \mathrm{EC}_{\mathrm{k}}-(1+\gamma \mathrm{o}) \cdot \lambda \mathrm{A}_{\mathrm{i}} \cdot\left(\mathrm{EF}_{\mathrm{w}}-\mathrm{EA}_{\mathrm{w}}-\mathrm{EC}_{\mathrm{k}}\right)$

Case 2: $\mathrm{EA}_{\mathrm{w}}+\mathrm{EC}_{\mathrm{k}}>\mathrm{EF}_{\mathrm{w}}$

Revenue $=\lambda \mathrm{A}_{\mathrm{i}} \cdot\left(\mathrm{EF}_{\mathrm{w}}\right)-\left(\mathrm{Kc}_{\mathrm{i}}+\mathrm{Cm}_{\mathrm{i}}\right) \cdot \mathrm{EC}_{\mathrm{k}}+\left(1-\gamma_{\mathrm{o}}\right) \cdot \lambda \mathrm{A}_{\mathrm{i}} \cdot\left(\mathrm{EA}_{\mathrm{w}}+\mathrm{EC}_{\mathrm{k}}-\mathrm{EF}_{\mathrm{w}}\right)$

\section{Overproduction Revenue $\left(\mathbf{E A}_{\mathrm{w}}>\mathbf{E F _ { \mathrm { w } }}\right)$}

\section{No Contract}

Revenue $=\lambda \mathrm{A}_{\mathrm{i}} \cdot \mathrm{EF}_{\mathrm{w}}+\left(1-\gamma_{\mathrm{o}}\right) \cdot \lambda \mathrm{A}_{\mathrm{i}} \cdot\left(\mathrm{EA}_{\mathrm{w}}-\mathrm{EF}_{\mathrm{w}}\right)$

\section{With Contract}

Case 3: $\mathrm{EA}_{\mathrm{w}}-\mathrm{EP}_{\mathrm{k}}>\mathrm{EF}_{\mathrm{w}}$

Revenue $=\lambda \mathrm{A}_{\mathrm{i}} \cdot \mathrm{EF}_{\mathrm{w}}+\left(\mathrm{Kp}_{\mathrm{i}}-\mathrm{Pm}_{\mathrm{i}}\right) \cdot \mathrm{EP}_{\mathrm{k}}+\left(1-\gamma_{\mathrm{o}}\right) \cdot \lambda \mathrm{A}_{\mathrm{i}} \cdot\left(\mathrm{EA}_{\mathrm{w}}-\mathrm{EF}_{\mathrm{w}}-\mathrm{EP}_{\mathrm{k}}\right)$

Case 4: $\mathrm{EA}_{\mathrm{w}}-\mathrm{EP}_{\mathrm{k}}<\mathrm{EF}_{\mathrm{w}}$

Revenue $=\lambda \mathrm{A}_{\mathrm{i}} \cdot\left(\mathrm{EA}_{\mathrm{w}}-\mathrm{EP}_{\mathrm{k}}\right)+\left(\mathrm{Kp}_{\mathrm{i}}-\mathrm{Pm}_{\mathrm{i}}\right) \cdot \mathrm{EP}_{\mathrm{k}}-(1+\gamma \mathrm{o}) \cdot \lambda \mathrm{A}_{\mathrm{i}} \cdot\left(\mathrm{EF}_{\mathrm{w}}-\mathrm{EA}_{\mathrm{w}}+\mathrm{EP}_{\mathrm{k}}\right)$

Table 4.9 Case number / Wind forecast data $(\mathrm{MWh}) / \sigma \mathrm{E}_{\mathrm{w}}($ refer to Table 4.7)

\begin{tabular}{c|c|c|c}
\hline Wind Farm & $1: 00 \mathrm{pm}$ & $2: 00 \mathrm{pm}$ & $3: 00 \mathrm{pm}$ \\
\hline Kingsbridge & $2 / 20 / 46 \%$ & $2 / 16 / 38 \%$ & $1 / 15 / 28 \%$ \\
\hline Paroches & $2 / 30 / 21 \%$ & $1 / 30 / 20 \%$ & $1 / 25 / 21 \%$ \\
\hline Port Alma & $2 / 70 / 44 \%$ & $2 / 60 / 45 \%$ & $2 / 45 / 28 \%$ \\
\hline Port Alma2 & $2 / 80 / 19 \%$ & $1 / 50 / 28 \%$ & $2 / 55 / 30 \%$ \\
\hline
\end{tabular}




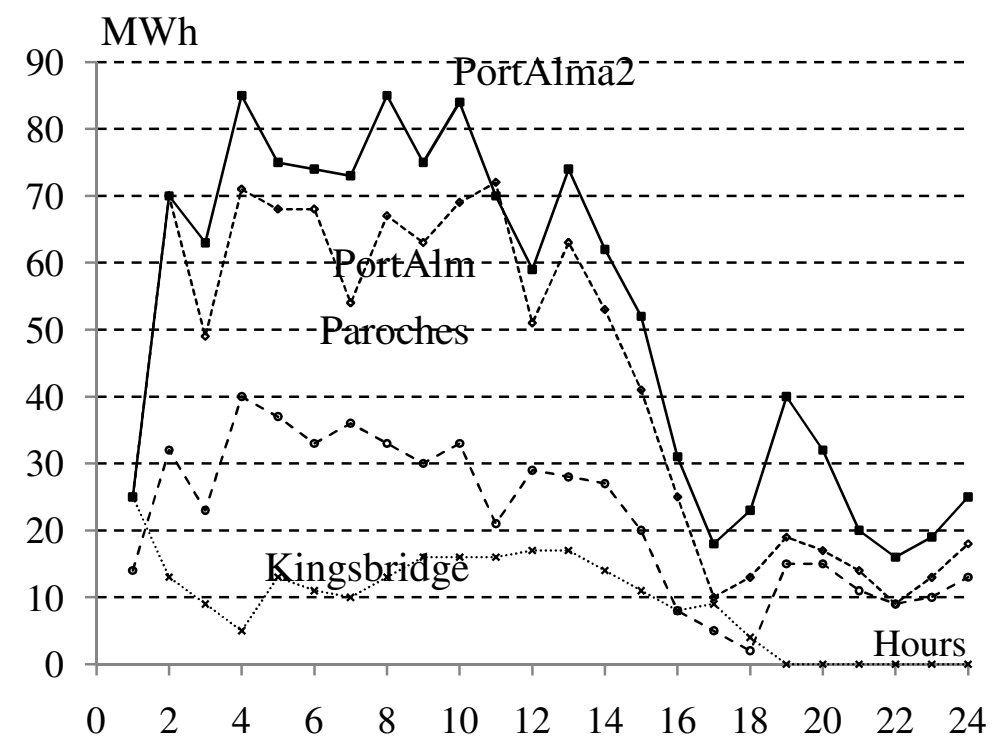

Fig. 4.10 Actual recorded wind energy production at different wind farms in March 1, 2012[57] 
Table 4.10 Total revenue of wind farms for 3 hours (\$)

\begin{tabular}{|c|c|c|c|}
\hline Wind Farm & A: No Contract & $\begin{array}{l}\text { B: With } \\
\text { Contract }\end{array}$ & $\begin{array}{c}(\mathrm{B}-\mathrm{A}) / \mathrm{B} \\
\%\end{array}$ \\
\hline Kingsbridge (1:00 pm) & 296 & 435 & 46.9 \\
\hline Kingsbridge $(2: 00 \mathrm{pm})$ & 647 & 790 & 22.1 \\
\hline Kingsbridge (3:00 pm) & 721 & 928 & 28.7 \\
\hline Paroches $(1: 00 \mathrm{pm})$ & 727 & 899 & 23.6 \\
\hline Paroches $(2: 00 \mathrm{pm})$ & 1300 & 1486 & 14.3 \\
\hline Paroches $(3: 00 \mathrm{pm})$ & 1418 & 1554 & 9.59 \\
\hline Port Alma (1:00 pm) & 2039 & 2330 & 14.2 \\
\hline Port Alma (2:00 pm) & 2456 & 2851 & 16.0 \\
\hline Port Alma (3:00 pm) & 2976 & 3299 & 10.8 \\
\hline Port Alma $2(1: 00 \mathrm{pm})$ & 2776 & 2919 & 5.1 \\
\hline Port Alma $2(2: 00 \mathrm{pm})$ & 1597 & 2043 & 27.9 \\
\hline Port Alma $2(3: 00 \mathrm{pm})$ & 3707 & 4179 & 12.7 \\
\hline Total & 20661 & 23715 & 14.7 \\
\hline
\end{tabular}




\subsection{Comparison of the results of Binomial and Gaussian Forecast Error}

As discussed before, the model introduced in Chapter 3 is for a large size power system and the model in this chapter is for a small geographical size power system. In this small geographical power system all of our wind farms either have underproduction or overproduction at the same time which results in both the prices and amounts of energy purchased or sold being led towards more extreme values. In order to compare the two models, we examined the model of this chapter on a 5-Bus test system similar to the one of Chapter 3. In Chapter 3 we use Cauchy coefficients while in Chapter 4 standard deviation of wind energy forecast is used. For a reasonable comparison, we thus need to adjust the standard deviation of the Gaussian model in this chapter in such a way that at each wind connected bus, the maximum of expected under/over production matches the corresponding values of example 3.8.1 in Chapter 3 independent of other buses.

Table 4.11 shows this comparison. It is quite noticeable that because in small size power system of Chapter 4, prices and scheduled energy values are at the two extremes for under/over production, and the amount of the transacted funds are significantly higher compared with the large size power system of Chapter 3, which can benefit from the smoothing effects of a large geographical system. 
Table 4.11 Comparison of the results of Chapter 3 (Cauchy) and Chapter 4 (Gaussian) for 5-Bus test system

\begin{tabular}{|c|c|c|c|c|c|}
\hline Standard & Cauchy & Avoided & Additional & Avoided & Additional \\
\hline Deviation & distribution & Costs for Wind & Profits for & Costs for Wind & Profits for \\
\hline of Wind & ratio & Generators & Reserve & Generators & Reserve \\
\hline Energy & $\gamma / \mathrm{EF}_{\mathrm{w}} \%$ & (Call and Put) & Providers & (Call and Put) & Providers \\
\hline$\sigma \mathrm{E}_{\mathrm{w}}$ & & & (Call and Put) & & (Call and Put) \\
\hline$(\mathrm{CH}-4)$ & $(\mathrm{CH}-3)$ & TAW (CH-3) & TER (CH-3) & TAW (CH-4) & TER (CH-4) \\
\hline & & $\$$ & $\$$ & $\$$ & $\$$ \\
\hline 0.046 & 2 & 103.15 & 18.60 & 206.8 & 37.33 \\
\hline 0.072 & 4 & 160.62 & 24.49 & 322.51 & 59.07 \\
\hline 0.095 & 6 & 203.87 & 41.88 & 418.39 & 77.61 \\
\hline 0.117 & 8 & 243.59 & 55.24 & 507.68 & 95.32 \\
\hline 0.1396 & 10 & 280.73 & 71.20 & 599.2 & 113.95 \\
\hline
\end{tabular}




\subsection{Chapter Summary}

This chapter proposes a new optimization model to trade in reserves to overcome uncertainty in wind energy production. The model is for reserve options traded through an intra-day secondary market. Reserve options, both put and call options, are modelled via the Black-Scholes model. The proposed formulation uses the Gaussian distribution function to model errors in a near term wind energy forecast. Furthermore, it models transmission system to ensure that these reserve contracts are network feasible.

Complete mathematical models for optimizing this proposed secondary market for reserve option trade are presented. Two systems, a 6-bus system and 118-bus system with Ontario wind generation data were studied. In these studies, via options trade for reserves, wind generators and reserve providers would benefit by getting better financial returns than the case of having no option trade for reserves and relying solely on the primary market as organized by the ISO. The amount of revenue they may gain depends on the reserve capacity, the network topology and the wind energy forecast accuracy. Two examples demonstrate the benefits of our proposed option trading model in detail. 


\section{Chapter 5: Wind Energy Forecast Error Estimation Using Black-Scholes Mathematical Model}

\subsection{Introduction}

In the previous chapter (Chapter 4) we estimated the wind energy forecast error based on a Gaussian curve provided by a centralized forecaster. In this chapter we introduce the concept of historic volatility of wind energy inspired by the Black-Scholes mathematical model. This approach provides us the ability to estimate wind energy forecast error by using the historic values of recorded energy for each wind farm comparing with forecasts. This method enables the wind energy market participants to conduct their individual error estimation independent of any centralized forecaster.

This chapter reports on a method for wind producers to buy reserve from reserve providers to mitigate the uncertainty using the Black-Scholes mathematical model not only for pricing the options but also for estimating the amount of possible errors in wind energy forecast for a future time span. In addition, this research integrates the network security constraints into the whole framework of reserve trades via our proposed option market.

\subsection{Proposed Secondary Market Model}

The proposed model intends to introduce a secondary market in which several Wind companies can buy reserve from several reserve providers with considering the security constraints. This secondary market uses Black and Scholes model both for Option pricing 
and wind energy forecast error. The proposed secondary intra-day reserve market model is shown in Fig. 2.1 and is used here for a small size power system.

\subsection{Options Model for Prices}

In the case of underproduction, all wind generators need to procure their energy shortfalls from other available reserve providers at the least cost. In the case of overproduction all wind generators need to sell their excess energy at the best possible prices. In the proposed model, it is assumed that wind generators with underproduction will face a penalty factor of $\gamma 0$ which marks up the market price for the energy it must buy from the market to compensate for its underproduction. Similarly it is also assumed that wind generators with overproduction will face a discount factor of $\gamma 0$ which marks down the market price for the over produced energy it sells to the market. The factor $\gamma 0$ represents the additional costs borne by the ISO to arrange for these reserves and transfers them to wind generators. The purpose of this research is to form an intra-day secondary market including renewable generators and reserve providers to reduce the effect of wind energy forecast errors and provide better economic options for market participants. Call option is considered in the case of underproduction and Put option is considered in the case of overproduction. Let us assume that $\lambda \mathrm{E}_{\mathrm{i}}$ are the marginal energy price determined by day-ahead unit commitment process at the $\mathrm{i}^{\text {th }}$ bus. At the $\mathrm{i}^{\text {th }}$ bus, let $\mathrm{Kc}_{\mathrm{i}}$ and $\mathrm{Kp}$ be call and put options strike prices. Using (1.9) to (1.11) and considering a zero interest rate for call option contract and assuming different market price volatilities for different nodes, we can write an equation to compute call option premiums: 
$\mathrm{Cm}_{\mathrm{i}}=\lambda \mathrm{E}_{\mathrm{i}} \cdot \mathrm{N}\left(\mathrm{d} 1 \lambda_{\mathrm{i}}\right)-\mathrm{Kc}_{\mathrm{i}} \cdot \mathrm{N}\left(\mathrm{d} 2 \lambda_{\mathrm{i}}\right)$

Where:

$\mathrm{d} 1 \lambda_{\mathrm{i}}=\frac{\ln \left(\lambda \mathrm{E}_{\mathrm{i}} / \mathrm{Kc}_{\mathrm{i}}\right)+\left(\sigma \lambda_{\mathrm{i}}^{2} / 2\right) \cdot \mathrm{t}}{\sigma \lambda_{\mathrm{i}} \sqrt{\mathrm{t}}}$

$\mathrm{d} 2 \lambda_{\mathrm{i}}=\mathrm{d} 1 \lambda_{\mathrm{i}}-\sigma \lambda_{\mathrm{i}} \sqrt{\mathrm{t}}$

And for put option contract using (1.13) we can write an expression for premium as below:

$\mathrm{Pm}_{\mathrm{i}}=\lambda \mathrm{E}_{\mathrm{i}} \cdot \mathrm{N}\left(\mathrm{d} 1 \lambda_{\mathrm{i}}\right)-\mathrm{Kp}_{\mathrm{i}} \cdot \mathrm{N}\left(\mathrm{d} 2 \lambda_{\mathrm{i}}\right)-\lambda \mathrm{E}_{\mathrm{i}}+\mathrm{K} \mathrm{p}_{\mathrm{i}}$

Where

$\mathrm{d} 1 \lambda_{\mathrm{i}}=\frac{\ln \left(\lambda \mathrm{E}_{\mathrm{i}} / \mathrm{Kp}_{\mathrm{i}}\right)+\left(\sigma \lambda_{\mathrm{i}}^{2} / 2\right) \cdot \mathrm{t}}{\sigma \lambda_{\mathrm{i}} \sqrt{\mathrm{t}}}$

$\mathrm{d} 2 \lambda_{\mathrm{i}}=\mathrm{d} 1 \lambda_{\mathrm{i}}-\sigma \lambda_{\mathrm{i}} \sqrt{\mathrm{t}}$

These parameters will be calculated using the optimization algorithm discussed in the next sections.

\subsection{Distribution Model for Error in Wind Energy Forecast}

In this section we discuss about the similar natures of forecasts of wind energy and stock price and the possibility of using the Black-Scholes mathematical model for wind energy forecast error calculation. They both fluctuate in time and we can assume that for the time step approaching zero the wind energy prediction errors become smaller and the limiting probabilistic distribution can be assumed to be a lognormal distribution. As an analogy to finance where the stock price at any time may be lower or higher than the strike price of an option associated with the stock, wind energy injected by a generator into the connected power system may also be under produced or over produced with respect to the forecasted wind energy value at a certain time in the near future. Now instead of stock and strike prices 
in $(5.1)$ we replace them by the amount of forecasted wind energy, $\mathrm{EF}_{\mathrm{w}}$ at $\mathrm{w}^{\text {th }}$ wind generator at a certain time, $\mathrm{t}$ in the near future. Knowing that there is no interest rate factor in this case, the expected energy over produced can be calculated as:

$\overline{\mathrm{EO}_{\mathrm{w}}(\mathrm{t})}=\mathrm{EF}_{\mathrm{w}} \cdot \mathrm{N}\left(\mathrm{d} 1 \mathrm{E}_{\mathrm{w}}\right)-\mathrm{EF}_{\mathrm{w}} \cdot \mathrm{N}\left(\mathrm{d} 2 \mathrm{E}_{\mathrm{w}}\right)$

With:

$\mathrm{d} 1 \mathrm{E}_{\mathrm{w}}=\frac{\left(\sigma E_{w}{ }^{2} / 2\right) \cdot \mathrm{t}}{\sigma \mathrm{E}_{\mathrm{w}} \sqrt{\mathrm{t}}}=\frac{1}{2} \sigma \mathrm{E}_{\mathrm{w}} \sqrt{\mathrm{t}}$

$\mathrm{d} 2 \mathrm{E}_{\mathrm{w}}=\mathrm{d} 1 \mathrm{E}_{\mathrm{w}}-\sigma \mathrm{E}_{\mathrm{w}} \sqrt{\mathrm{t}}$

At zero interest rate, the expected energy under-produced is analogous to a put option and therefore can be calculated using (1.13):

$\overline{\mathrm{EU}_{\mathrm{w}}}=\overline{\mathrm{EO}_{\mathrm{w}}}$ 


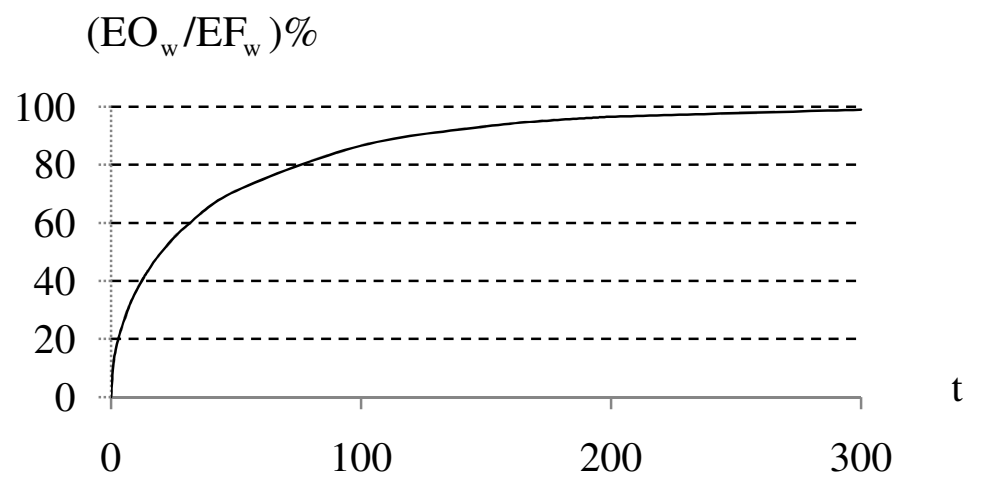

Fig. 5.1 Variation of forecast error percentage with respect to time for constant forecast of $100 \mathrm{MWh}$ and volatility $=0.15$

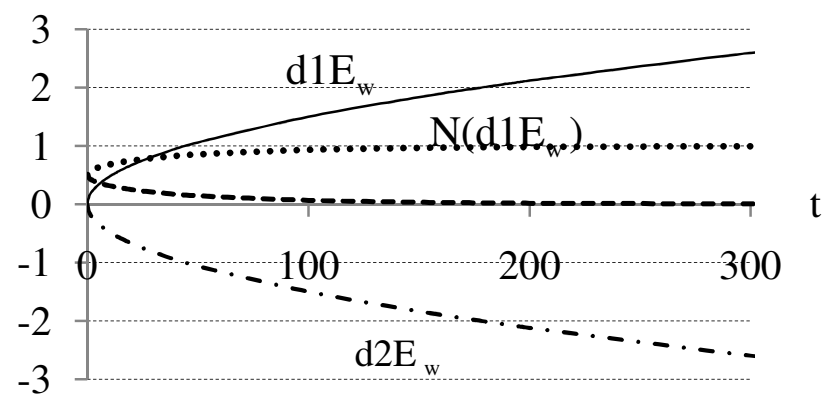

Fig. 5.2 Variation of $d 1 E_{w}, d 2 E_{w}, N\left(d 1 E_{w}\right)$ and $N\left(d 2 E_{w}\right)$ with respect to time for constant forecast of $100 \mathrm{MWh}$ and volatility $=0.15$ 
Similar to price volatility, the wind energy volatility $\left(\sigma \mathrm{E}_{\mathrm{w}}\right)$ can be computed from historic values of wind energy forecast. As the time approaches infinity, the expected energy under produced or over produced will reach the limit of $\mathrm{EF}_{\mathrm{w}}$ which means that the forecast error reaches $100 \%$ as shown in Fig. 5.1. Fig. 5.2 shows the variation of $\mathrm{d}_{\mathrm{E}} \mathrm{E}_{\mathrm{w}}$, $\mathrm{d} 2 \mathrm{E}_{\mathrm{w}}$, $\mathrm{N}\left(\mathrm{d} 1 \mathrm{E}_{\mathrm{w}}\right)$ and $\mathrm{N}\left(\mathrm{d} 2 \mathrm{E}_{\mathrm{w}}\right)$ with respect to time. At $\mathrm{t}=0, \mathrm{~N}\left(\mathrm{~d} 1 \mathrm{E}_{\mathrm{w}}\right), \mathrm{N}\left(\mathrm{d} 2 \mathrm{E}_{\mathrm{w}}\right)$ are both equal to 0.5 in standard normal distribution and as $\mathrm{t}$ approaches to infinity, $\mathrm{N}\left(\mathrm{d}_{1} \mathrm{E}_{\mathrm{w}}\right)$ approaches to one and $\mathrm{N}\left(\mathrm{d} 2 \mathrm{E}_{\mathrm{w}}\right)$ approaches to zero.

\subsection{Problem Formulation and Objectives}

The first step of this model is to calculate the expected under or over production of wind energy at the time of forecast, and to determine the optimal strike and option prices at each node (bus) of the system. In the case of underproduction, it is assumed that all of wind generators participating in an option market have underproduction at the maturity time. These wind generators can use the amount of reserve they purchased in the option market to avoid penalties imposed by the ISO. They have already paid call option prices (premiums) to one or more reserve providers located at different buses to enjoy this privilege. In the case of overproduction, it is assumed that all of wind generators participating in an option market have overproduction at the maturity time. These wind generators can use the amount of negative reserve they purchased in the option market to avoid discounted prices imposed by the ISO. By assuming all having underproduction or all having overproduction at the same time the model brings out the maximum option prices.

In this section, the overall formulation of the proposed model is discussed. 


\subsubsection{Underproduction objective and constraints}

The objective function is to maximize the benefit of the call option market participants at market equilibrium using quoted offers to determine $\mathrm{EU}_{\mathrm{w}}$ and $\mathrm{EC}_{\mathrm{k}}$ :

$\mathrm{OBJ}_{\mathrm{C}}=\sum_{\mathrm{w}=1}^{\mathrm{NW}} \mathrm{EU}_{\mathrm{w}} \cdot \lambda \mathrm{E}_{\mathrm{w}}^{\mathrm{QC}}-\sum_{\mathrm{k}=1}^{\mathrm{NK}} \mathrm{EC}_{\mathrm{k}} \cdot \lambda \mathrm{E}_{\mathrm{k}}^{\mathrm{QC}}$

Subject to:

Limitations of Energy purchased by wind entities and sold by reserve providers:

$0 \leq \mathrm{EU}_{\mathrm{w}} \leq \overline{\mathrm{EU}_{\mathrm{w}}}$

$0 \leq \mathrm{EC}_{\mathrm{k}} \leq \overline{\mathrm{EC}_{\mathrm{k}}}$

The following constraints ensure the network feasibility which includes active and reactive power balance at each bus and also transmission lines' limits:

$\mathrm{P}_{\mathrm{i}}(\mathrm{V}, \delta)=\mathrm{PG}_{\mathrm{i}}+\frac{\mathrm{EC}_{\mathrm{kei}}}{1 \text { hour }}-\frac{\mathrm{EU}_{\mathrm{wei}}}{1 \text { hour }}-\mathrm{PD}_{\mathrm{i}}$

$\mathrm{Q}_{\mathrm{i}}(\mathrm{V}, \delta)=\mathrm{QG}_{\mathrm{i}}-\mathrm{QD}_{\mathrm{i}}$

Limits on power flow in transmission elements:

$-\overline{\mathrm{S}_{l}} \leq \mathrm{S}_{l}(\mathrm{~V}, \delta) \leq \overline{\mathrm{S}_{l}}$

Voltage magnitude constraints at each $\mathrm{i}^{\text {th }}$ bus:

$\underline{\mathrm{V}_{\mathrm{i}}} \leq \mathrm{V}_{\mathrm{i}} \leq \overline{\mathrm{V}_{\mathrm{i}}}$

\subsubsection{Locational marginal prices for underproduction}

The lambda multiplier corresponding to the $\mathrm{i}^{\text {th }}$ bus in the equality (5.14) is $\lambda \mathrm{E}_{\mathrm{i}}^{\mathrm{OC}}$. The value of the Lagrangian multiplier associated with the real power balance equation (5.14) at each bus must be equal to the total amount of money payable at that bus. 
$\lambda \mathrm{E}_{\mathrm{i}}^{\mathrm{OC}}=\mathrm{Kc}_{\mathrm{i}}+\mathrm{Cm}_{\mathrm{i}}$

After determining $\lambda \mathrm{E}_{1}^{\mathrm{OC}}$ by optimizing (5.11)-(5.17), solving (5.1) and (5.18) simultaneously, one can determine $\mathrm{Kc}_{\mathrm{i}}$ and $\mathrm{Cm}_{\mathrm{i}}$.

If the solution benefits both reserve service providers and wind generators, the following must be true:

$\lambda \mathrm{E}_{\mathrm{i}} \leq \lambda \mathrm{E}_{\mathrm{i}}^{\mathrm{OC}} \leq(1+\gamma 0) \cdot \lambda \mathrm{E}_{\mathrm{i}}$

\subsubsection{Overproduction objective and constraints}

The objective function is to maximize the benefit of the put option market participants at market equilibrium using quoted offers to determine $\mathrm{EP}_{\mathrm{k}}$ and $\mathrm{EO}_{\mathrm{w}}$ :

$\mathrm{OBJ}_{\mathrm{P}}=\sum_{\mathrm{k}=1}^{\mathrm{NK}} \mathrm{EP}_{\mathrm{k}} \cdot \lambda \mathrm{E}_{\mathrm{k}}^{\mathrm{QP}}-\sum_{\mathrm{w}=1}^{\mathrm{NW}} \mathrm{EO}_{\mathrm{w}} \cdot \lambda \mathrm{E}_{\mathrm{w}}^{\mathrm{QP}}$

Subject to:

Limitations of Energy purchased by wind entities and sold by reserve providers:

$0 \leq \mathrm{EO}_{\mathrm{w}} \leq \overline{\mathrm{EO}_{\mathrm{w}}}$

$0 \leq \mathrm{EP}_{\mathrm{k}} \leq \overline{\mathrm{EP}_{\mathrm{k}}}$

Power Balance Equations at bus $i(i \in\{1,2, \ldots, N B\})$ :

$\mathrm{P}_{\mathrm{i}}(\mathrm{V}, \delta)=\mathrm{PG}_{\mathrm{i}}-\frac{\mathrm{EP}_{\mathrm{k} \in \mathrm{i}}}{1 \text { hour }}+\frac{\mathrm{EO}_{\mathrm{w} \in \mathrm{i}}}{1 \text { hour }}-\mathrm{PD}_{\mathrm{i}}$

Reactive Power Balance Equations at bus $i(i \in\{1,2, \ldots, N B\})$ :

$\mathrm{Q}_{\mathrm{i}}(\mathrm{V}, \delta)=\mathrm{QG}_{\mathrm{i}}-\mathrm{QD}_{\mathrm{i}}$

Security limit of each line:

$-\overline{\mathrm{S}_{l}} \leq \mathrm{S}_{l}(\mathrm{~V}, \delta) \leq \overline{\mathrm{S}_{l}}$ 
Voltage magnitude constraints at each $\mathrm{i}^{\text {th }}$ bus:

$\underline{\mathrm{V}_{\mathrm{i}}} \leq \mathrm{V}_{\mathrm{i}} \leq \overline{\mathrm{V}_{\mathrm{i}}}$

\subsubsection{Locational marginal prices for overproduction}

The lambda multiplier corresponding to the $\mathrm{i}^{\text {th }}$ bus in the equality (5.23) is $\lambda \mathrm{E}_{\mathrm{i}}^{\mathrm{OP}}$. At the $\mathrm{i}^{\text {th }}$ bus, the total payable money should be equal to strike price less the option price.

$\lambda \mathrm{E}_{\mathrm{i}}^{\mathrm{OP}}=\mathrm{Kp}_{\mathrm{i}}-\mathrm{Pm}_{\mathrm{i}}$

After determining $\lambda \mathrm{E}_{\mathrm{i}}^{\mathrm{OP}}$ by optimizing (5.20)-(5.26), solving (5.27) and (5.4) simultaneously, we can obtain the value of $\mathrm{Kp}_{\mathrm{i}}$ and $\mathrm{Pm}_{\mathrm{i}}$.

For a solution benefitting both wind generators and reserve providers, the following must be true:

$(1-\gamma 0) \cdot \lambda \mathrm{E}_{\mathrm{i}} \leq \lambda \mathrm{E}_{\mathrm{i}}^{\mathrm{OP}} \leq \lambda \mathrm{E}_{\mathrm{i}}$

\subsection{Algorithm}

Fig. 5.3 shows the model's algorithm. As mentioned in our formulation, transmission system data is essential to evaluate the feasibility of each transaction. In addition to grid data, all quoted prices and ISO estimated prices and forecasted wind energies are collected at the beginning of the optimization process. 


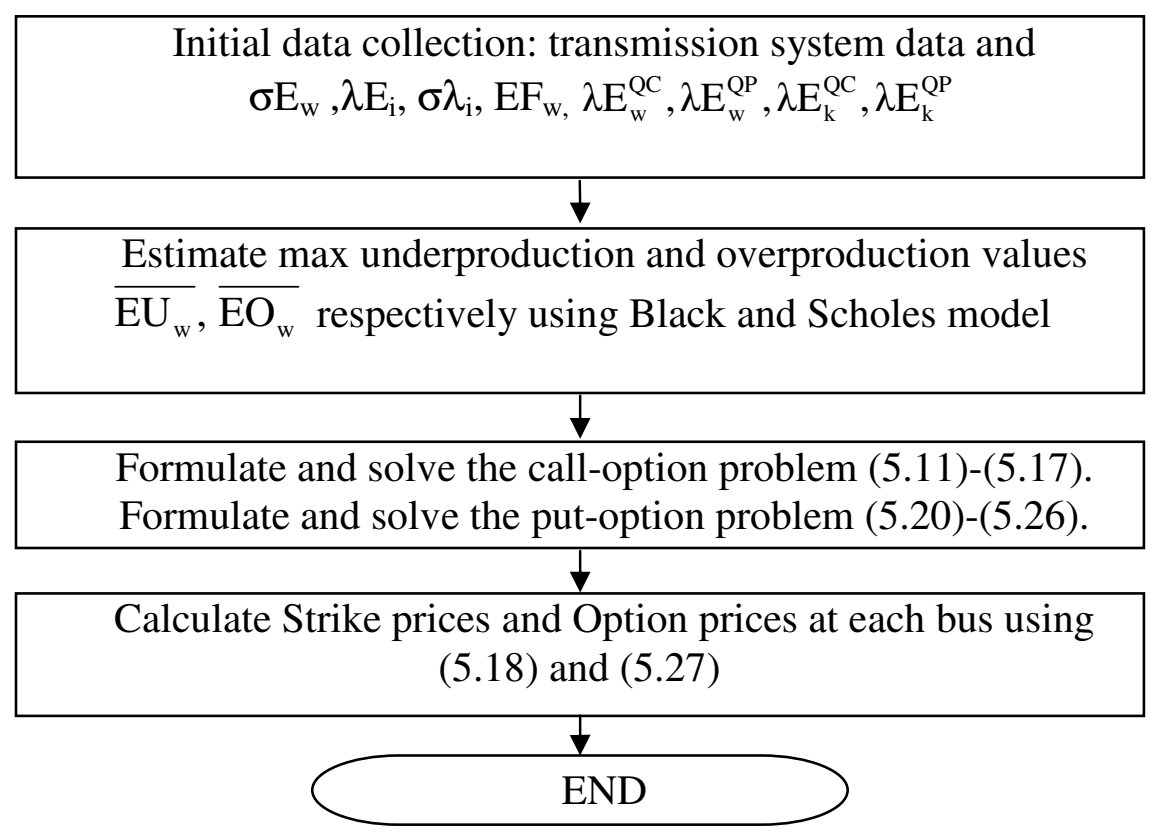

Fig. 5.3 Proposed model's algorithm 


\subsection{Results and Analysis}

The proposed method of this chapter is tested and demonstrated in a 6-bus test system. Using IEEE 6-bus test system, we assume that there are two wind farms connected to buses 4 and 5 (W1 and W2) and there are two reserve providers connected to buses 2 and 3 (G1 and G2). The single-line diagram is shown in Fig. 5.4. Each transmission line has the maximum capacity of 250 MVA and two $220+$ j20 MVA loads are connected to buses 5 and 6. G1 and G2 are scheduled to supply 200 MWh each before participating in any option contract. Also the penalty/discount factor imposed by the ISO for under/over production is $\gamma 0=0.5$. The original ISO estimated market prices are given in Table 5.1. Also quoted prices are shown in Table 5.2. The forecasted wind energy at each wind farms is assumed to be $200 \mathrm{MWh}$. Option contracts are taking place 4-hour ahead of option exercise time. Each reserve provider is ready to provide maximum amount of $70 \mathrm{MWh}$ reserve. The market price volatility for all nodes is assumed to be $10 \%$ per hour. The IEEE 6-Bus test system line data can be found in Table 5.3. Fig. 5.5 shows how strike and premium call options change with increasing of wind energy forecast volatility. It is obvious that higher volatility increases the uncertainty at the time of contract and thus the prices for majority of the buses also increase.

Scheduled energy for wind under/over production at buses 4 and 5 (wind connected buses) can be found in Fig. 5.6. It is obvious that higher wind energy volatility increases the uncertainty at the time of contract and thus higher value of required reserve for wind generators is required. The amounts of optimal reserve provided by reserve suppliers at buses 2 and 3(G1 and G2) for the underproduction case are shown in Fig. 5.7. The negative reserve for overproduction is shown in Fig. 5.8 and it is provided by G2 only resulting from its lower quoted price compared against G1's quote. 
Now let's observe the effect of constraints on transmission lines in this test system. Let us assume that the maximum capacity of line between buses 2 and 5 is changed from 90 MVA to 50 MVA for a wind volatility value of 0.15 . As it is shown in Fig 5.9, the tighter security constraint of the line means that W2 connected to bus 5 can only purchase limited amount of energy to compensate for the underproduction. In contrast, W1 connected to bus 4 is not limited in purchasing its required reserve energy. Variation of optimal scheduled reserve with respect to security constraint variation of line $2-5$ is shown in Fig. 5.10. It is obvious that the lower amount of allowable flow on this line will affect the scheduled reserve amounts. Variation of optimal call strike prices with respect to security constraint variation of line 2-5 is shown in Fig. 5.10. The sensitivity of prices to the security constraint of line 2-5 is obvious in this graph. Prices at a majority of buses increase as a result of the tighter security constraint.

Assuming that the same reserve providers would have been called by ISO with the same market price the following four parameters (5.29)-(5.32) can help us to measure the economic benefits of the model to both wind generators and their counterpart reserve providers contracted under call and put options; their numerical values are shown in Table 5.4. It is worth emphasizing that these parameters must not be confused with objective functions.

1) The total avoidable loss due to underproduction for wind generators buying call options is equal to:

$$
\mathrm{TAWC}=\sum_{\substack{\mathrm{w}=1 \\ \mathrm{i} \in \mathrm{w}}}^{\mathrm{NW}} \mathrm{EU}_{\mathrm{w}} \cdot(1+\gamma 0) \cdot \lambda \mathrm{E}_{\mathrm{i}}-\sum_{\substack{\mathrm{w}=1 \\ \mathrm{i} \in \mathrm{W}}}^{\mathrm{NW}} \mathrm{EU}_{\mathrm{w}} \cdot\left(\mathrm{Kc}_{\mathrm{i}}+\mathrm{Cm}_{\mathrm{i}}\right)
$$


2) The total additional profit for reserve providers including capacity costs selling call option is equal to:

$$
\mathrm{TERC}=\sum_{\substack{\mathrm{k}=1 \\ i \in \mathrm{k}}}^{\mathrm{NK}} \mathrm{EC}_{\mathrm{k}} \cdot\left(\mathrm{Kc}_{\mathrm{i}}+\mathrm{Cm}_{\mathrm{i}}-\lambda \mathrm{E}_{\mathrm{i}}\right)
$$

3) The total avoidable loss due to overproduction for wind generators buying put option is equal to:

$\mathrm{TAWP}=\sum_{\substack{\mathrm{w}=1 \\ \mathrm{i} \in \mathrm{w}}}^{\mathrm{NW}} \mathrm{EO}_{\mathrm{w}} \cdot\left(\mathrm{Kp}_{\mathrm{i}}-\mathrm{Pm}_{\mathrm{i}}\right)-\sum_{\substack{\mathrm{w}=1 \\ \mathrm{i} \in \mathrm{w}}}^{\mathrm{NW}} \mathrm{EO}_{\mathrm{w}} \cdot(1-\gamma 0) \cdot \lambda \mathrm{E}_{\mathrm{i}}$

4) The total additional profit for reserve providers including capacity costs selling put option is equal to:

$$
\mathrm{TERP}=\sum_{\substack{\mathrm{k}=1 \\ \mathrm{i} \in \mathrm{k}}}^{\mathrm{NK}} \mathrm{EP}_{\mathrm{k}} \cdot\left[\lambda \mathrm{E}_{\mathrm{i}}-\left(\mathrm{Kp}_{\mathrm{i}}-\mathrm{Pm}_{\mathrm{i}}\right)\right]
$$




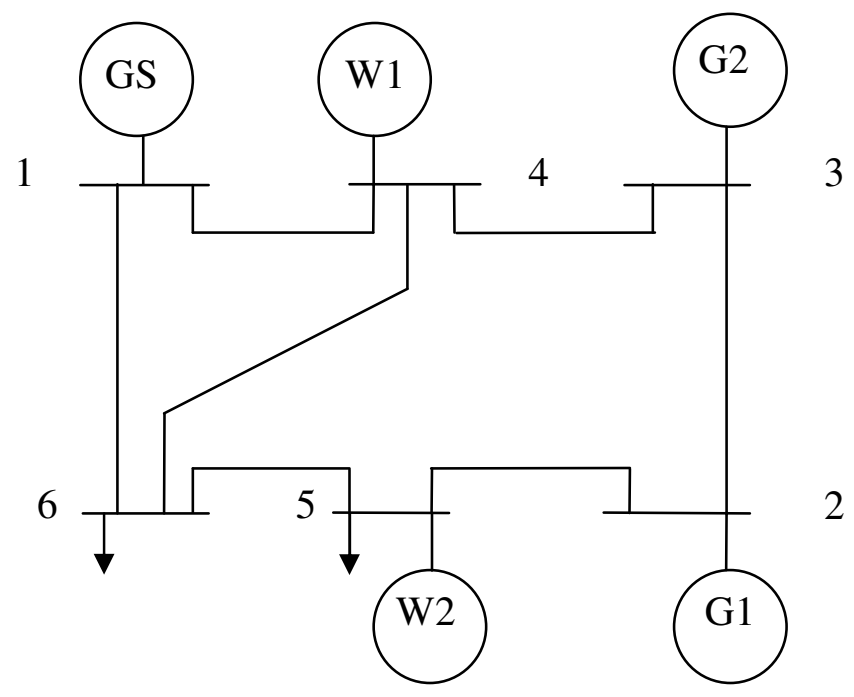

Fig. 5.4 Single-Line diagram of the 6-Bus test system.

Table 5.1 ISO estimated nodal prices in the Example (\$/MWh)

\begin{tabular}{|c|c|c|c|c|}
\hline $\begin{array}{c}\text { Bus } \\
\text { Number 1 } \\
\text { GS }\end{array}$ & $\begin{array}{c}\text { Bus } \\
\text { Number 2 } \\
\text { G1 }\end{array}$ & $\begin{array}{c}\text { Bus } \\
\text { Number 3 } \\
\text { G2 }\end{array}$ & $\begin{array}{c}\text { Bus } \\
\text { Number 4 } \\
\text { W1 }\end{array}$ & $\begin{array}{c}\text { Bus } \\
\text { Number 5 } \\
\text { W2 }\end{array}$ \\
\hline 28.45 & 31.79 & 29.46 & 27.23 & 33.80 \\
\hline
\end{tabular}


Table 5.2 Quoted prices in the Example (\$/MWh)

\begin{tabular}{|l|c|c|c|c|c|}
\hline & Bus & Bus & Bus & Bus & Bus \\
& Number & Number & Number & Number & Number \\
& 1 & 2 & 3 & 4 & 5 \\
Gs & G1 & G2 & W1 & W2 \\
\hline Underproduction & N/A & 34.96 & 35.35 & 38.12 & 43.94 \\
\hline Overproduction & N/A & 23.84 & 27.98 & 14.97 & 20.28 \\
\hline
\end{tabular}

Table 5.3 6-Bus test system line data

\begin{tabular}{|c|c|c|c|c|c|}
\hline & $\begin{array}{c}\text { From Bus } \\
\text { Number }\end{array}$ & $\begin{array}{c}\text { To Bus } \\
\text { Number }\end{array}$ & $\begin{array}{c}\text { Resistance } \\
\text { (p.u.) }\end{array}$ & $\begin{array}{c}\text { Inductance } \\
\text { (p.u.) }\end{array}$ & $\begin{array}{c}\text { Half line } \\
\text { Admittance } \\
\text { (p.u.) }\end{array}$ \\
\hline Transformer 1 & 1 & 6 & 0.123 & 0.218 & - \\
\hline Transformer 2 & 1 & 4 & 0.080 & 0.270 & - \\
\hline Line 1 & 4 & 6 & 0.097 & 0.207 & 0 \\
\hline Line 2 & 5 & 2 & 0.102 & 0.240 & 0 \\
\hline Line 3 & 2 & 3 & 0.123 & 1.250 & 0 \\
\hline Line 4 & 5 & 6 & 0.100 & 0.240 & 0 \\
\hline Line 5 & 4 & 3 & 0.100 & 0.240 & 0 \\
\hline
\end{tabular}

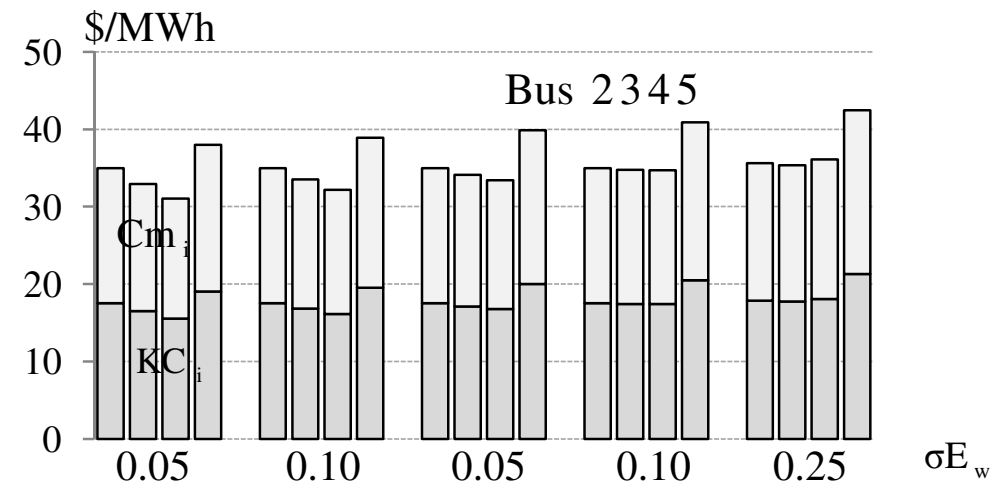

Fig. 5.5 Call option strike prices and premiums at all buses for underproduction with respect to wind energy volatility $(\$ / M W h)$ 


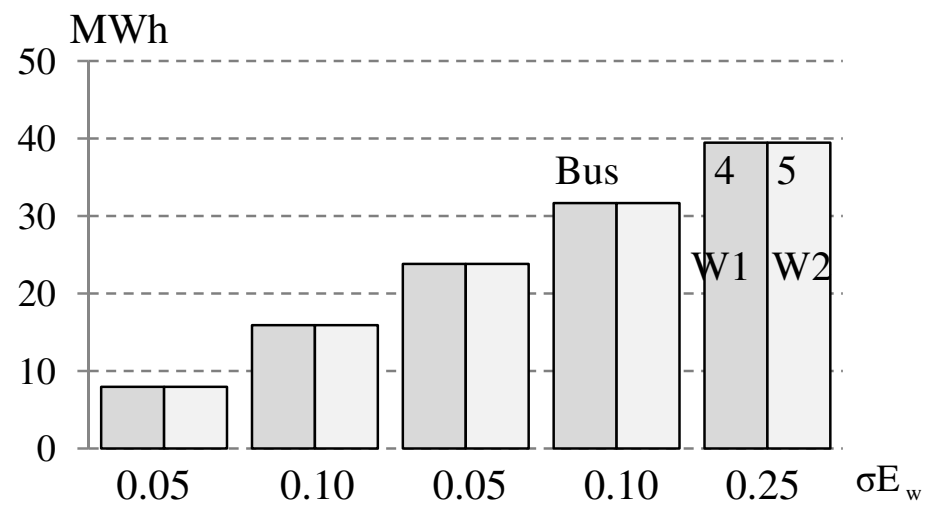

Fig. 5.6 Wind Energy under or over production

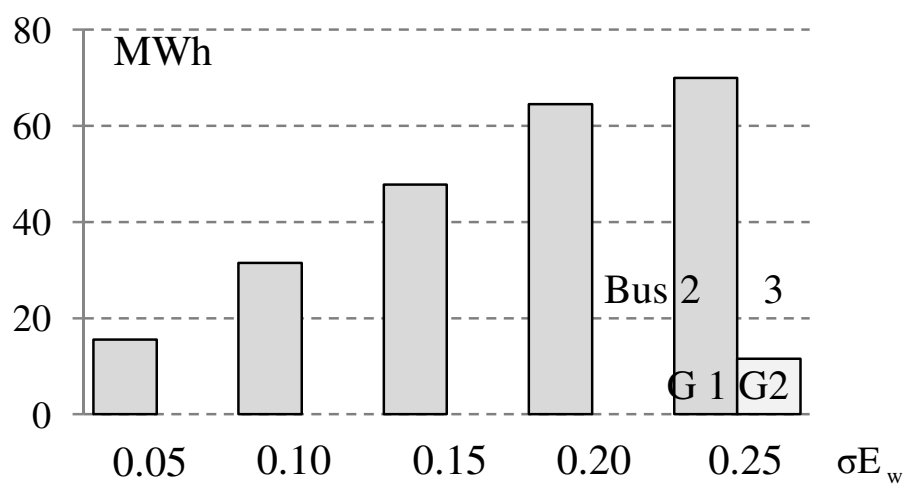

Fig. 5.7 Optimal amounts of positive reserve (call option) for wind underproduction

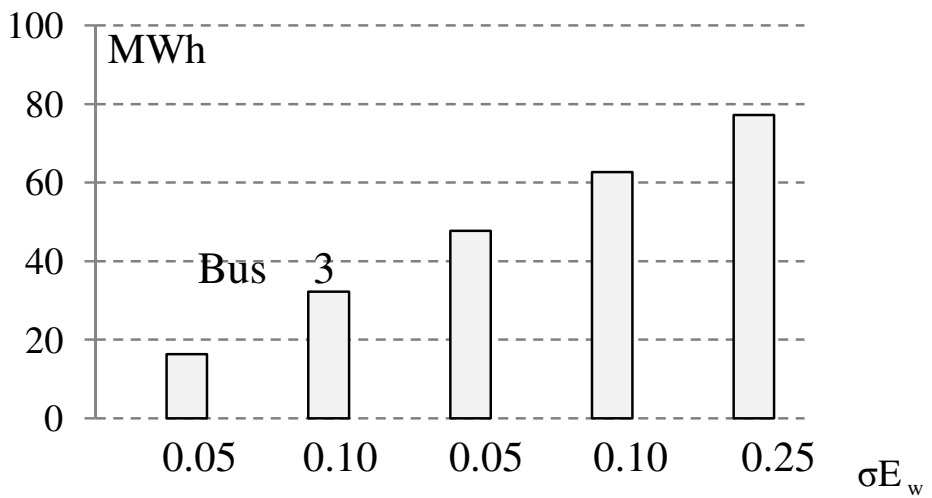

Fig. 5.8 Optimal amounts of negative reserve (put option) for wind overproduction 


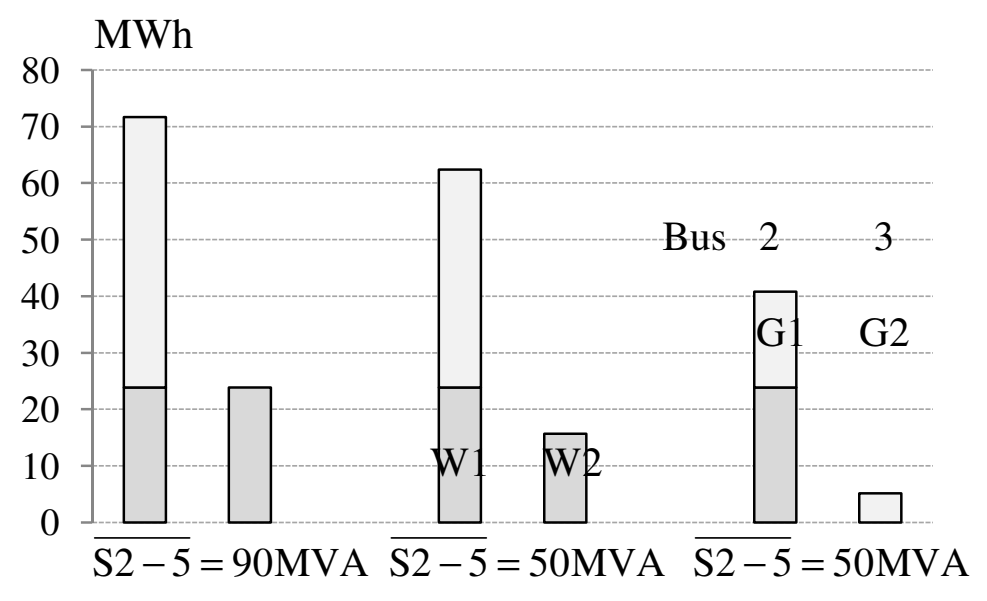

Fig. 5.9 Purchased reserve by Wind Generators (W1 and W2) and optimal reserve purchased from reserve providers (G1 and G2) with respect to security constraint of line 2-5 for underproduction (call option)

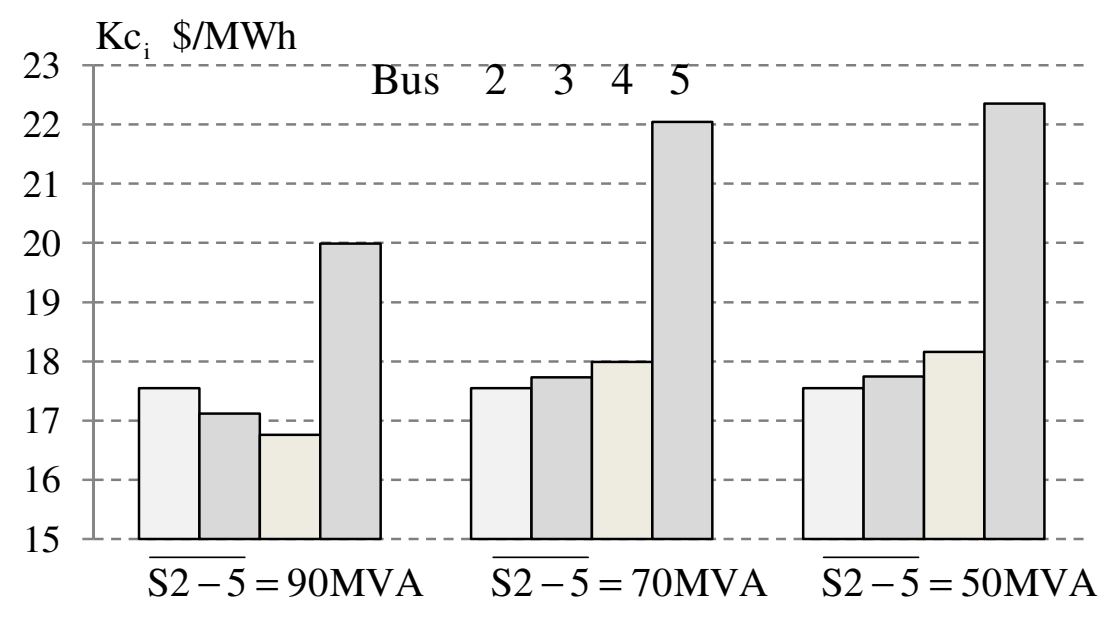

Fig. 5.10 Optimal call strike prices with respect to security constraint of line 2-5 
Table 5.4 Results of case study

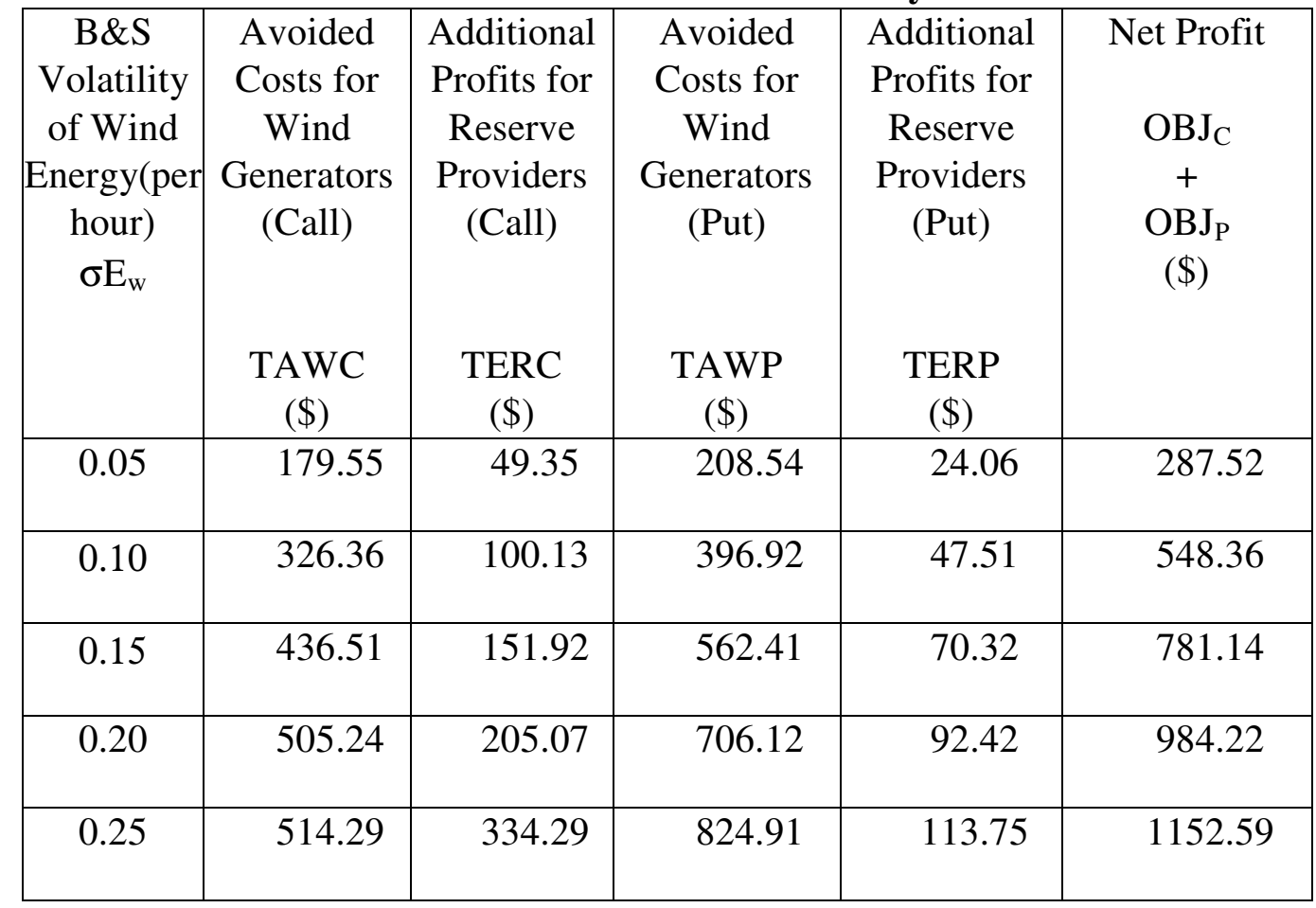




\subsection{Comparison of the Results of Gaussian and Black \& Scholes Forecast Error}

In both Chapters 4 and 5 we examined out small size power system model on the same IEEE 6-Bus test systems. Both chapters use the Black-Scholes option pricing method. Chapter 4 used the Gaussian model for wind energy forecast error estimation while Chapter 5 uses the Black-Scholes mathematical model for that purpose. Table 5.5 shows this comparison. It must be noted that in the Black-Scholes model volatility is defined per hour but in the Gaussian model the standard deviation of our example is given for four hours. We thus expanded the Black-Scholes model's volatility for four hours so that the results of both models would be comparable. The comparison in Table 5.5 shows very close relationship between the results. 
Table 5.5 Comparison of the results of Chapter 4 (Gaussian) and Chapter 5 (Black \& Scholes) for IEEE 6-Bus test system

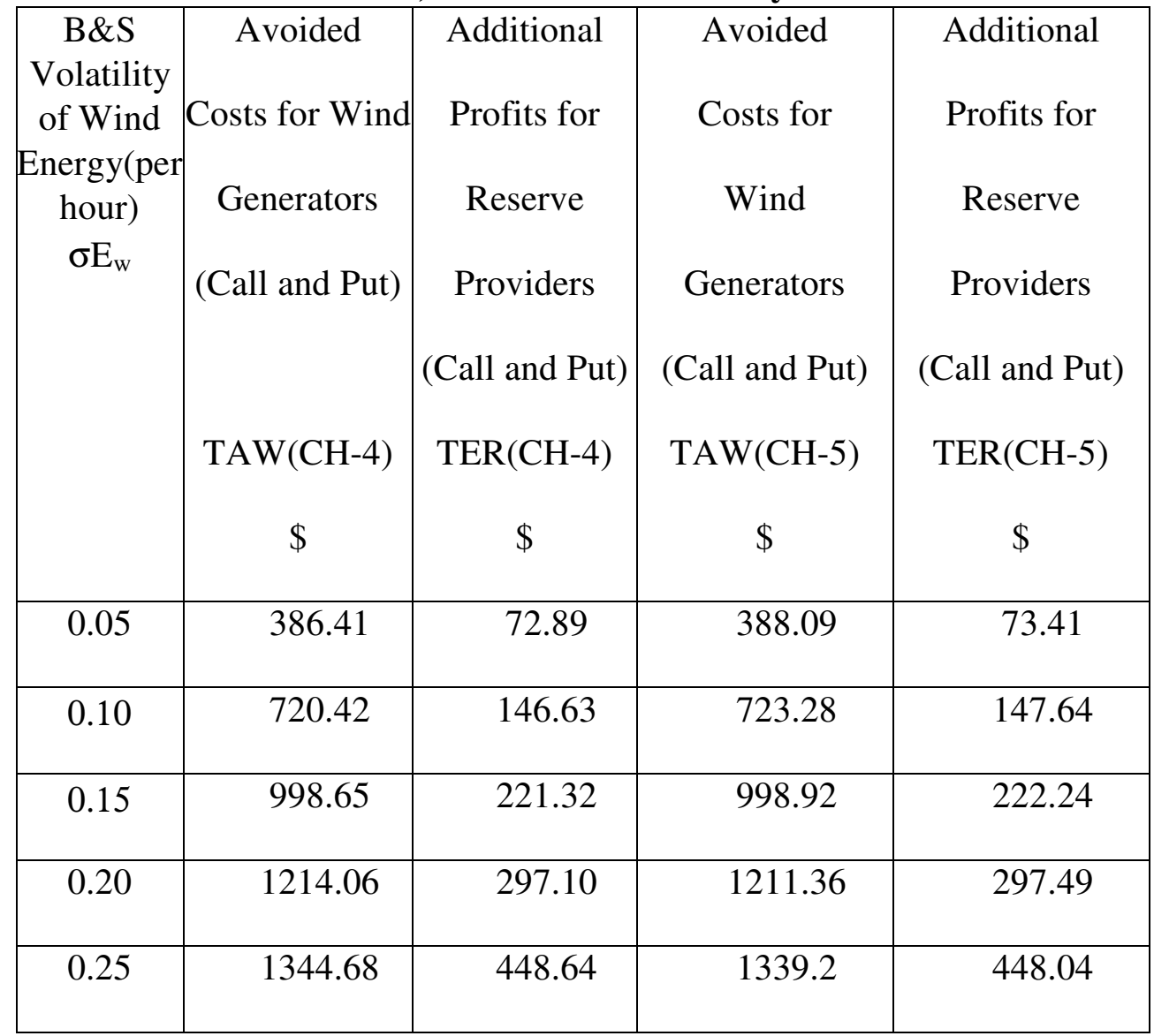




\subsection{Chapter Summary}

This chapter proposes and investigates the usage of the Black-Scholes mathematical model not only for pricing options but also for estimating the amount of possible errors in wind energy forecast in a future time span. This method borrows the concept of historic volatility in finance and applies it to historic volatility of wind energy forecast which can be utilized for wind energy forecast error estimation. In both cases of call and put options, wind generators and reserve providers would benefit by getting better financial returns than the default case of having no option trading. The amount of revenue they may gain depends on the reserve capacity, network topology and the wind energy volatility level.

The method is demonstrated on IEEE 6-bus test system and compared with method proposed in previous chapters. 


\section{Chapter 6: Conclusion and Future Work}

General conclusions and the key contributions of this dissertation work are summarized in this chapter. Recommended future research studies related to this dissertation are also discussed.

\subsection{Conclusion}

This research proposes a completely new secondary reserve market for intra-day reserve trade between wind generators and reserve providers where wind generators purchase reserve from reserve providers to overcome forecast errors that lead to deficits or excess of wind energy. The secondary market design is based upon Option Contract Theory and complements the electricity market operated by independent system operator (ISO). In such a market subsidies are not offered to wind power producers and they must compete with other conventional generator in the power system. An intra-day secondary reserve market is proposed in addition to the main electricity market run by the ISO, to operate in parallel. In the secondary market, wind generators and reserve providers can enter into options contracts to trade in reserve, required to overcome wind energy uncertainty, to reach market equilibrium based upon state of the electricity market.

The intra-day secondary market model considers two aspects. The options contract model and wind generator uncertainty model. In this work, two widely used Option pricing methods namely the Binomial model and the Black-Scholes model are used. Uncertainty of wind generator output forecast error is modeled using Gaussian, Cauchy, Binomial Tree, etc. This allows several variants of the secondary market model, considering one type of options 
contract and one model of wind generator uncertainty. In addition, transmission system limitation can be considered to ensure that the model is feasible.

Several of those variants of the secondary market model were developed and tested with simple systems and the IEEE 118-bus system with Ontario wind farm data.

In each case, when the wind generators participate in the electricity market and procure reserves from the proposed secondary market, their profits increase. These results are consistent for the test systems and Ontario cases. In conclusion, the results demonstrate benefits of the secondary reserve market. Chapter-wise summary is presented below.

\subsection{Chapter-wise Summary}

In the first objective of this research (Chapter 2), the goal was to develop an intra-day secondary reserve trade model considering one wind company and one reserve provider using the Binomial tree model for both trade and wind energy forecast error modeling. This step does not consider network constraints or transmission system. From participation in the secondary market, the wind generators benefit by procuring reserve options. It allows them to avoid penalties of deviating from production schedules.

In the second objective of this research (Chapter 3), the goal was to develop an intraday secondary reserve trade model considering several wind companies and several reserve providers including security constraints to ensure that these models are physically feasible. This step uses the Binomial tree model for trade and the Cauchy model for wind energy forecast error modeling. In this chapter, it is evident that transmission system limits set locational prices for reserve contract premiums and strike prices. The wind generators benefit from participation in the secondary reserve market. 
In the third objective of this research (Chapter 4), the goal was to develop an intra-day secondary reserve trade model considering several Wind Companies and several Reserve providers including security constraints. This step uses the Black-Scholes model for trade and the Gaussian model for wind energy forecast error modeling in a small size power system in which we can assume that all wind turbines have either underproduction or overproduction at the same time.

In the fourth objective of this research (Chapter 5), the goal was to develop an intra-day secondary reserve trade model considering several Wind Companies and several Reserve providers including security constraints to ensure that these models are physically feasible. This step uses the Black-Scholes model both for trade and wind energy forecast error modeling in a small size power system in which we can assume that all wind turbines have either underproduction or overproduction at the same time.

In both Chapters 4 and 5, the wind generators benefit from the Black and Scholes model of options contract for reserves offered by reserve providers. The various models of wind forecast uncertainties influence results but are compliant with the overall secondary market structure.

Table 6.1 shows the summary of the models adopted in this dissertation. From the simulation results of all the above option models reported in this thesis, wind generators and reserve providers would benefit by getting better financial returns via option trading than the default case of having no option trading. The amount of revenue they may gain depends on the reserve capacity, the wind energy volatility level and also network topology. 


\subsection{Summary of Major Contributions}

The contribution of this dissertation could be summarized as follows:

- It introduces a secondary market not governed by ISO, but to complement and operate in parallel with the primary electricity market governed by ISO.

- It utilizes the financial concept of options contract for reserve trade.

- It considers several models of wind generator forecast uncertainty.

- It considers the physical characteristics and transmission system of the power system.

- Several variants of the secondary market were developed. In each instance, the secondary reserve market performed well and provided benefit to wind generators, enabling them to participate the ISO operated electricity market.

Table 6.1 Summary of Option Models Adopted in this Research

\begin{tabular}{|l|l|l|l|l|l|}
\hline & $\begin{array}{l}\text { Option } \\
\text { Model }\end{array}$ & $\begin{array}{l}\text { Energy } \\
\text { Forecast } \\
\text { error }\end{array}$ & $\begin{array}{l}\text { Network } \\
\text { Constraint } \\
\text { being } \\
\text { considered }\end{array}$ & $\begin{array}{l}\text { Number of Wind } \\
\text { generators (WG) } \\
\text { and Reserve } \\
\text { Providers (RP) in } \\
\text { the market }\end{array}$ & $\begin{array}{l}\text { Geographical } \\
\text { size of the } \\
\text { power } \\
\text { system }\end{array}$ \\
\hline Chapter 2 & $\begin{array}{l}\text { Binomial } \\
\text { Tree }\end{array}$ & $\begin{array}{l}\text { Binomial } \\
\text { Tree }\end{array}$ & No & $\begin{array}{l}\text { WG =1 } \\
\text { RP =1 }\end{array}$ & $\begin{array}{l}\text { Generic; no } \\
\text { restriction }\end{array}$ \\
\hline Chapter 3 & $\begin{array}{l}\text { Binomial } \\
\text { Tree }\end{array}$ & $\begin{array}{l}\text { Cauchy- } \\
\text { Lorentz }\end{array}$ & Yes & No Limit & $\begin{array}{l}\text { Generic; no } \\
\text { restriction }\end{array}$ \\
\hline Chapter 4 & $\begin{array}{l}\text { Black- } \\
\text { Scholes }\end{array}$ & Gaussian & Yes & No Limit & Small Sized \\
\hline Chapter 5 & $\begin{array}{l}\text { Black- } \\
\text { Scholes }\end{array}$ & $\begin{array}{l}\text { Black- } \\
\text { Scholes }\end{array}$ & Yes & No Limit & Small Sized \\
\hline
\end{tabular}




\subsection{Recommendations for Future Work}

A number of future directions for related research activities could be explored:

1) Financial options can be used in Demand Response programs.

2) Other source of renewable energy such as Solar can use financial options to purchase reserve to mitigate their forecast uncertainty. The behaviour of their forecast error probability distribution function must be explored.

3) Purchasing reserve from pump storage devices instead of thermal power plants can be considered as well.

4) A secondary market frame can be used for all sources of renewable energy (Wind, Solar, etc.) with different forecast error probability distribution function characteristics. 


\section{REFERENCE LIST}

[1] E. Lantz, R. Wiser and M. Hand, "The Past and Future Cost of Wind Energy," National Renewable Energy Laboratory, Golden, CO, Tech. Rep. NREL/TP-6A2053510, May 2012.

[2] World Energy Outlook 2010, International Energy Agency, 75739 Paris Cedex 15, France, [Online]. Available: http://www.worldenergyoutlook.org/publications/weo2010/

[3] A. J. Conejo, M. Carrion and J. M. Morales, "Decision making under uncertainty in electricity markets," 2010 International series in operations research and management science.

[4] W.W. Hogan, "A Competitive Electricity Market," Harvard publications vol. 1993, 1993.

[5] [Online]. Available: http://www.ieso.ca/imoweb/pubs/ircp/NPCC/A-06.pdf

[6] Y. Wu, "Operating Reserve Model in the Power Market," IEEE Transactions on Power Systems, vol.20, no.1, pp. 223-229, February 2005.

[7] “Spinning Reserve and Non-Spinning Reserve," California ISO, January 2006.

[8] "WSCC Operating Reserve White Paper," Western Systems Coordinating Council, July 1998.

[9] E. Hirst, "The Value of Reliability in Power Systems," MIT Energy Laboratory, June 1999.

[10] E. Hirst, "Price-Responsive Demand as Reliability Resources." IET Renewable Power Generation, vol.4, no.2, pp. 165-175. 
[11] [Online]. Available: http://www.ieso.ca/imoweb/marketdata/marketData.asp

[12] [Online]. Available: http://www.iso-ne.com/regulatory/tariff/index.html

[13] G. Juand and Z. Li-zi, "The Design of Reserve Market Basing on Reserve Responsibilities Bilateral Contracts," Power and Energy Engineering Conference, APPEEC 2009, Asia-Pacific, 2009.

[14] T. Zheng and E. Litvinov, "Contingency-Based Zonal Reserve Modeling and Pricing in a Co-Optimized Energy and Reserve Market" IEEE Transactions on Power Systems, vol.23, no. 2, pp. 1-1, 2008.

[15] J. Wang, X. Wang, Y. Song and X. Zhang, "Study on reserve problem in power market," International Conference on Power System Technology, 2002.

[16] F. Wen and A. K. David, "Strategic Bidding in Reserve Market," Proceedings of the 5th International Conference on Advances in Power System Control, Operation and Management, APSCOM 2000, Hong Kong, October 2000.

[17] L. Jiaqi, S. Grijalva and R.G. Harley, "Increased Wind Revenue and System Security by Trading Wind Power in Energy and Regulation Reserve Markets," IEEE Transactions on Sustainable Energy, vol.2, no. 3, pp. 340-347, July 2011.

[18] C. Zeng, B. Zhang, G. Tu, S. Wang and P. Xie, "Optimal allocation of available generation capacity between open access energy market and reserve market based on risk management," 39th International Universities Power Engineering Conference, 2004. UPEC 2004.

[19] I. Umbrasko, R. Varfolomejeva and A. Mahnitko, "Modeling of the Generating Company Behavior in Energy and Reserve Market," 11th International Conference on Environment and Electrical Engineering (EEEIC), Venice. 2012. 
[20] D. He, J. Guo and W. Lin, "The Impact of Trading Wind Power in Both Energy and Regulation Reserve Market on System Operation," North American Power Symposium (NAPS), Champaign, IL, 2012.

[21] H. Zhao, K. Bhattacharya and J. Zhong, "A Spinning Reserve Market Considering Security and Biddable Reserve,” Power India IEEE Conference, New Delhi, 2006.

[22] G. Ju and Z. Li-zi, "Pareto Optimality Model of Reserve Market Including Interruptible Load,” Power India IEEE Conference, New Delhi, 2008.

[23] G. Hinuber and H.-J. Haubrich, "Optimal Intraday Operation Strategy of Power Plants at Wholesale and Reserve Markets," IEEE Power Tech, Lausanne, 2007.

[24] K. Pal, M. Pandit and L. Srivastava, "Spot Pricing of Energy and Reserve under Market Power," Joint International Conference on Power Electronics, Drives and Energy Systems (PEDES) \& Power India, New Delhi, 2010.

[25] S. Porkar, M. Fotuhi-Firuzabad, A.A.-T. Farad and B. Porkar, "An Approach to Determine Spinning Reserve Requirements in a Deregulated Electricity Market," Power Systems Conference and Exposition, Atlanta, GA, 2006. pp. 1341 - 1344.

[26] D. Gan and E. Litvinov, "Energy and Reserve Market Designs With Explicit Consideration to Lost Opportunity Costs," IEEE Transactions on Power Systems, vol. 18, no.1, pp. 53-59, February 2003.

[27] J. Wang, X. Wang and Y. Wu, "Operating Reserve Model in the Power Market," IEEE Transactions on Power Systems, vol. 20, no. 1, pp. 223-229, February 2005.

[28] J. Chen, J.S. Thorp, R.J. Thomas and T.D. Mount, "Locational Pricing and Scheduling for an Integrated Energy-Reserve Market," Proceedings of the 36th Annual Hawaii International Conference on System Sciences, Hawaii, 2003. 
[29] V. M. Pandurangan, H. Zareipour and O. Malik, "Frequency Regulation Services: A Comparative Study of Select North American and European Reserve Markets,” North American Power Symposium (NAPS), Champaign, IL , 2012. pp. 1-8 .

[30] D. Waniek, M. Bolczek, C. Rehtanz and E. Handschin, "Modeling of the Operating Reserve Market Based on the Theory of Industrial Organization,” 6th International Conference on the European Energy Market. Leuven, 2009.

[31] M. Madrigal and V.H. Quintana, "A Security-Constrained Energy and Spinning Reserve Markets Clearing System Using an Interior-Point Method," IEEE Transactions on Power systems, vol. 15, no. 4, pp. 1410-1416, November 2000.

[32] L.M. Xia and H.B. Gooi, "A Reserve Market with Reliability Incentives," International Conference on Power System Technology, PowerCon 2004.

[33] F. Li and T.M. Lindquist, "Genetic Algorithm Based Optimal Contracting Strategy in a Typical Standing Reserve Market," IEEE Bologna PowerTech Conference, June 23-26, Bologna, Italy, 2003.

[34] V. Ionescu and A. Cernat, "Romanian Proposal for the Establishment of a Power Reserve Market,” IEEE Bologna PowerTech Conference, June 23-26, Bologna, Italy, 2003.

[35] S.J. Kazempour, M. Hosseinpour and M.P. Moghaddam, "Self-Scheduling of a Joint Hydro and Pumped-Storage Plants in Energy, Spinning Reserve and Regulation Markets," IEEE Power \& Energy Society General Meeting, Calgary, AB., 2009.

[36] A. Ahmadi-Khatir and R. Cherkaoui, "A Probabilistic Joint Energy and Spinning Reserve Market Model," IEEE Power \& Energy Society General Meeting, Minneapolis, MN., 2010. 
[37] J. Zhong and K. Bhattacharya, "Design of Competitive Markets for Spinning Reserve Services,” IEEE Power \& Energy Society General Meeting, Chicago, IL., 2002.

[38] Y. He, W. Yang, Q. He, J. Wei and W. Wang, "Study of the compensation mechanism of reserve service in the primary power market," International Conference on Power System Technology, Chongqing. 2006.

[39] P. Wang, Y. Liu, L. Goel, Q. Wu, Y. Ding and W. Qin, “A Reliability-Based Reserve Criterion for Market Settlement with Interruptible Loads," IEEE Power \& Energy Society General Meeting, Calgary, AB., 2009.

[40] R. Entriken and M.S. DePillis, "Preliminary Evaluation of an Energy and Reserve Co-Optimization Market Design for the ISO New England,” IEEE Power \& Energy Society General Meeting, Calgary, AB ., 2009.

[41] V. Siriariyaporn and M. Robinson, "Co-Optimization of Energy and Operating Reserve in Real-Time Electricity Markets," Third International Conference on Electric Utility Deregulation and Restructuring and Power Technologies, Nanjuing, 2008.

[42] S. Matthews and I. Kockar, "New Short-Term-Operation-Reserve Services in the UK Electricity Market," IEEE Power \& Energy Society General Meeting, Tampa, FL., 2007.

[43] M. Rubinstein, "implied binomial trees" Journal of Finance, Presidential Address to the American Finance Association. Jul. 1994.

[44] G. C. Pflug and N. Broussev, "Electricity swing options: Behavioural models and pricing," European Journal of Operational Research, vol. 197, 2009, pp. 1041-1050. 
[45] E. Hjalmarsson, "Does the Black-Scholes formula work for electricity markets? A nonparametric approach," Working Papers in Economics no 101, July 2003.

[46] M. Rashidinejad, Y.H. Song and M.H. Javidi, "Option Pricing of Spinning Reserve in a Deregulated Electricity Market," 2000 Symposium on Nuclear Power Systems, 18-19 October, Lyon, France.

[47] J. Cox, S. Ross and M. Rubinstein, "Option pricing: A simplified approach," Journal of Financial Economics, vol. 7, Sep. 1979, pp. 229-263.

[48] R. J. Rendleman and B. J. Bratter, "Two-State Option Pricing" Journal of Finance24, 1979, pp. 1093-1110.

[49] S. Liu, "Trinomial tree option pricing via threshold-Garch model" International Journal of Research and Reviews in Applied Sciences, May, 2011.

[50] F. Black and M. Scholes, The Pricing of Options and Corporate Liabilities, Political Economy, vol. 81, issue 3 May. 1973, pp. 637-654.

[51] J. Wang, M. Shahidehpour and Z. Li, "Security-constrained unit commitment with volatile wind power generation," IEEE Transaction on Power Systems, 23(3), 13191327, 2008.

[52] M. Ortega-Vazquez and D. Kirschen, "Estimating Spinning Reserve Requirements in Systems With Significant Wind Power Generation Penetration," IEEE Transactions on Power Systems, vol. 24, no. 1, pp. 114-124, 2009.

[53] R. Doherty and M. O'Malley, “A New Approach to Quantify Reserve Demand in Systems with Significant Installed Wind Capacity," IEEE Transactions on Power Systems, vol. 20, no. 2, pp. 587-595, 2005. 
[54] B.-M. Hodge and M. Milligan, "Wind Power Forecasting Error Distributions over Multiple Timescales," IEEE Power \& Energy Society General Meeting, San Diego, CA. 2011.

[55] K. Coughlin and J. H. Eto., "Analysis of Wind Power and Load Data at Multiple Time Scales,” Environmental Energy Technologies Division, December 2010.

[56] B.M. Hodge, A. Florita, K. Orwig, D. Lew and M. Milligan, "A Comparison of Wind Power and Load Forecasting Error Distributions," 2012 World Renewable Energy Forum Denver, Colorado, 2011.

[57] [Online]. Available: http://www.ieso.ca

[58] [Online]. Available: windturbineins.com/_literature_64405/Wind_Power_Industry

[59] [Online]. Available: http://www.ieso.ca/map/index.html 